\title{
Individual saturated fatty acids and cardiovascular risk markers : studies in healthy women and men
}

Citation for published version (APA):

Temme, E. H. (1997). Individual saturated fatty acids and cardiovascular risk markers : studies in healthy women and men. [Doctoral Thesis, Maastricht University]. Universiteit Maastricht. https://doi.org/10.26481/dis.19971219et

Document status and date:

Published: 01/01/1997

DOI:

10.26481/dis.19971219et

Document Version:

Publisher's PDF, also known as Version of record

\section{Please check the document version of this publication:}

- A submitted manuscript is the version of the article upon submission and before peer-review. There can be important differences between the submitted version and the official published version of record.

People interested in the research are advised to contact the author for the final version of the publication, or visit the DOI to the publisher's website.

- The final author version and the galley proof are versions of the publication after peer review.

- The final published version features the final layout of the paper including the volume, issue and page numbers.

Link to publication

\footnotetext{
General rights rights.

- You may freely distribute the URL identifying the publication in the public portal. please follow below link for the End User Agreement:

www.umlib.nl/taverne-license

Take down policy

If you believe that this document breaches copyright please contact us at:

repository@maastrichtuniversity.nl

providing details and we will investigate your claim.
}

Copyright and moral rights for the publications made accessible in the public portal are retained by the authors and/or other copyright owners and it is a condition of accessing publications that users recognise and abide by the legal requirements associated with these

- Users may download and print one copy of any publication from the public portal for the purpose of private study or research.

- You may not further distribute the material or use it for any profit-making activity or commercial gain

If the publication is distributed under the terms of Article $25 \mathrm{fa}$ of the Dutch Copyright Act, indicated by the "Taverne" license above, 


\title{
Individual saturated fatty acids and cardiovascular risk markers
}

studies in healthy women and men

\author{
Elisabeth Helena Maria Temme
}


Temme, Elisabeth H.M. Temme

Individual saturated fatty acids and cardiovascular risk markers:

studies in healthy women and men/Elisabeth Helena Maria Temme

Thesis Maastricht University, Maastricht, The Netherlands - with summary in Dutch. ISBN 90-9011116-6

C 1997 Temme, Maastricht, The Netherlands 


\title{
Individual saturated fatty acids and cardiovascular risk markers
}

studies in healthy women and men

\author{
PROEFSCHRIFT \\ ter verkrijging van de graad van doctor \\ aan de Universiteit Maastricht \\ op gezag van de Rector Magnificus, prof. mr. M.J. Cohen. \\ volgens het besluit van het College van Decanen \\ in het openbaar te verdedigen \\ op vrijdag 19 december 1997 om 12.00 uur
}

door

Elisabeth Helena Maria Temme geboren te Heemskerk op 10 november 1966 
Promotor:

Prof. dr. G. Hornstra

Co-promotor:

Dr. ir, R.P. Mensink

Beoordelingscommissie:

Prof. dr. W.H.M. Saris (voorzitter)

Prof. dr. ir. P.A. van den Brandt

Dr. K. Hamulyak

Prof. dr. M.B. Katan (Landbouwuniversiteit, Wageningen)

Dr. G.J. Miller (MRC Epidemiology and Medical Care Unit, London)

Financial support by the Dutch Dairy Foundation on Nutrition and Health for the publication of this thesis is gratefully acknowledged. 
Voor Chris an Riet 


\title{
Abstract
}

\section{Individual saturated fatty acids and cardiovascular risk markers: studies in healthy women and men}

\author{
PhD thesis by Elisabeth HM Temme, Department of Human Biology, Maastricht \\ University, Maastricht, The Netherlands, December 19, 1997.
}

A high intake of saturated fatty acid is associated with increased risk for cardiovascular diseases (CVD). Although it has been postulated that individual saturated fatty acids may have dissimilar effects on lipid and lipoprotein concentrations, those of some (MCFA and lauric acid) have hardly been studied, whereas results of others (myristic or palmitic acids) are conflicting. The effects of the individual saturated fatty acids on hemostatic factors have not been examined in detail, while mainly young and lean male subjects were studied. In two studies we, therefore, compared the effects of individual saturated fatty acids (MCFA, lauric acid, myristic acid and palmitic acid) with those of a monounsaturated fatty acid (oleic acid).

Eighteen women and fourteen men participated in the first study with a cross-over design, and consumed three 6 wk experimental diets enriched in lauric, palmitic or oleic acids. Thirty-seven women and twenty three men participated in the second study with a parallel design and consumed a 3 wk run-in diet enriched in oleic acid and 6 wk experimental diets enriched in either MCFA, or myristic acid or oleic acid. The calculated nutrient composition was the same in each diet except for $8.5 \mathrm{En} \%$ (study 1) and $10 \mathrm{En} \%$ (study 2) which was provided by lauric, palmitic or oleic acids (study 1) or MCFA, myristic or oleic acids (study 2).

Compared with a diet rich in oleic acid, diets rich in myristic acid raised LDL cholesterol concentrations most pronounced followed by lauric and then palmitic acid rich diets. Lauric and myristic acid enriched diets, in addition, increased HDL cholesterol concentrations whereas diets enriched in palmitic acid or MCFA had similar effects compared with oleic acid. Serum lipoprotein(a) concentrations were lower with the myristic acid diet compared with the oleic acid diets, but did not change with the MCFA, lauric or palmitic acid diets. The individual saturated fatty acids did not affect in vitro whole blood aggregation velocity compared with oleic acid. Lauric, myristic and palmitic acid significantly increased factor VIlam activity. This effect was much more pronounced in women than in men. The lauric acid diet tended to decrease antithrombin activity. The TFPI activity, which was not measured in the first study was decreased on the myristic acid diet. The palmitic acid diet increased PAI activity.

The increase of CVD-risk is most pronounced when elevated levels of LDL cholesterol go together with increased coagulant capacity. These studies, therefore, suggest that it will be advisable to decrease the intake of fats rich in lauric, myristic and palmitic acids in favor of a higher intake of unsaturated fatty acids for example from oils rich in monounsaturated fatty acids (oleic acids) such as olive oil, high oleic sunflower or rapeseed oill. 


\section{Contents}

1. General introduction.

2. Comparison of the effects of diets enriched in lauric, palmitic or oleic acids on serum lipids and lipoproteins in healthy women and men.

3. Effects of medium chain fatty acids (MCFA), myristic acid and oleic acid on serum lipoproteins in healthy subjects.

4. Dietary induced changes in lipoproteins and mood.

5. Individual saturated fatty acids and effects on whole blood aggregation in vitro.

6. Effects of diets enriched in lauric, palmitic or oleic acids on blood coagulation and fibrinolysis.

7. Effects of diets rich in medium chain fatty acids (MCFA), myristic acid or oleic acid on coagulation and fibrinolysis.

8. Dietary fatty acid composition and feelings of appetite.

9. General discussion.

Samenvatting.

Met dank aan...

Curriculum vitae.

Publications. 
1

General introduction 
It is well established that diets rich in saturated fatty acids increase the risk for the development of cardiovascular diseases (CVD) $(1,2)$. Factors involved in blood processes of importance for the cardiovascular risk profile, such as factors involved in lipid metabolism are affected by changes in the saturated fatty acid content of diets (35). In addition, other processes that determine the thrombotic capacity of the blood (i.a. platelet aggregation, coagulation and fibrinolytic factors) are affected by dietary fatty acid composition $(6,7)$. Saturates with different chain length may, however, differ in their cholesterol-raising effects. For example, fats rich in stearic acid (C18:0) decrease serum total, low density lipoprotein (LDL) and high density lipoprotein (HDL) cholesterol concentrations compared with fats rich in lauric $(\mathrm{C} 12: 0)$ plus myristic acids $(\mathrm{C} 14: 0)(8)$. The effects of saturates on hemostatic factors might also depend on the particular effects of individual saturated fatty acids (8).

In this chapter the saturated fatty acids of different chain lengths are introduced. Then, epidemiological and clinical evidence for the role of lipid and hemostatic factors in the development of CVD is discussed. For the hemostatic factors the way of measurement will be focused on. Then, the present knowledge on the effects of (individual) saturates on lipid and hemostatic factors is discussed. Finally at the end of this chapter, the outline of the thesis will be given.

\section{SATURATED FATTY ACIDS}

Fats and oils always consist of a mixture of fatty acids, although one or two fatty acids are usually predominant. Table 1 shows the fatty acid composition of some edible fats rich in saturated fatty acids. An "average" Dutch person consumes 37 percent of energy from fat, or on average 92 grams. Saturated fatty acids contribute 14 percent of energy or about 35 grams a day (9). In the Western diet half of the saturated fatty acids consists of palmitic acid (C16:0) (10), thereby the major saturated fatty acid. Fats rich in palmitic acid are palm oil, dairy fat and meat fat. A smaller proportion of saturated fat intake is provided by stearic acid (C18:0), followed by myristic acid $(C 14: 0)$, lauric acid $(C 12: 0)$ and short and medium chain fatty acids (MCFA; $\leq$ C10:0). Stearic acid is a major fatty acid in cocoa fat lauric and myristic acids are both found in coconut and palm kernel fat, and in dairy fat. Natural sources of medium and short chain fatty acids are coconut fat and dairy fat, but intakes via these sources will usually be very low. Higher doses of MCFA are ingested with structured lipids (caprenin), special (par)enteral or infant nutrition or certain sports drinks containing MCFA. 


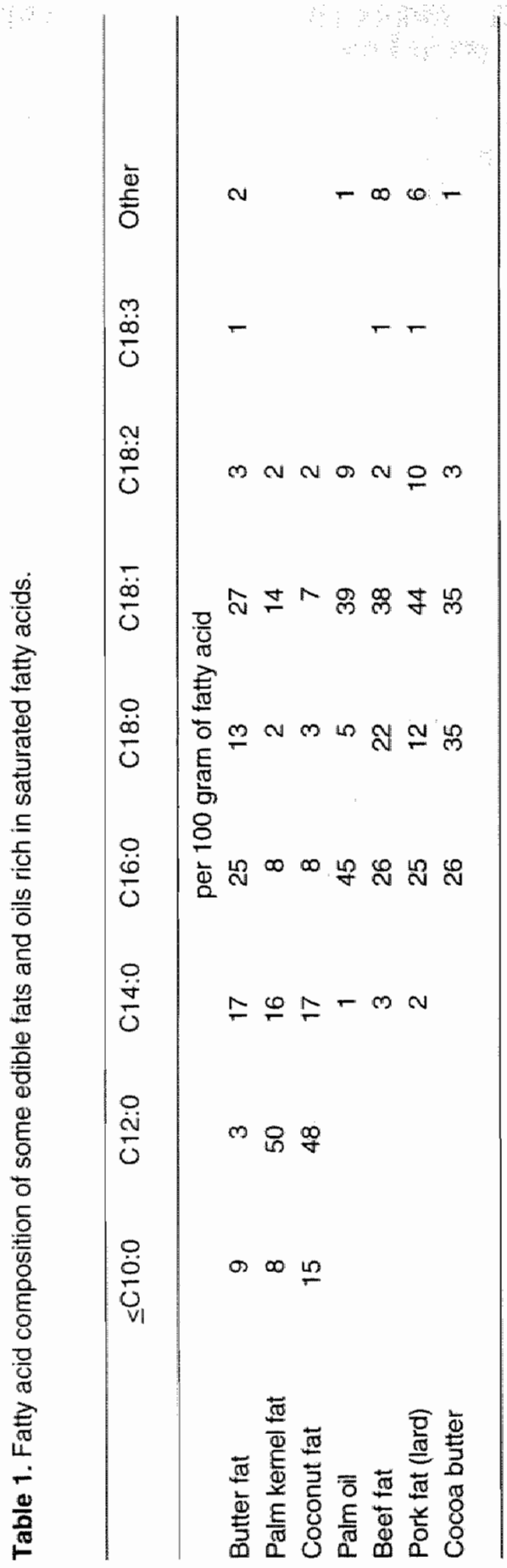




\section{EPIDEMIOLOGICAL EVIDENCE FOR EFFECTS OF LIPID AND HEMOSTATIC FACTORS ON CVD RISK MARKERS}

CVD is a major cause of morbidity and mortality in the prosperous Western countries, in women as well as in men, and responsible for $30-50 \%$ of all deaths (11). The main clinical conditions of CVD are ischemic heart diseases $(40 \%)$ and cerebrovascular diseases (24\%) (12). Many factors, such as smoking, hypertension, age, gender, body mass index, genetic, hormonal, lipid and hemostatic factors may affect risk for CVD. Of these, diet amendable factors such as lipid and hemostatic factors, are discussed below.

\section{Lipid factors}

Well known risk markers for the development of CVD are high circulating levels of plasma total cholesterol, low density lipoprotein (LDL) or low levels of high density lipoprotein (HDL) cholesterol (13) (see table 2). Epidemiological studies $(14,15)$ suggest that for every increase of $1 \%$ (corresponding to approximately $0.05 \mathrm{mmol} / \mathrm{L}$ ) in total cholesterol concentrations (14) or for every $0.03 \mathrm{mmol} / \mathrm{L}$ fall in $\mathrm{HDL}$ cholesterol concentrations (15), the risk for coronary heart diseases rises by $2-3 \%$. Raised triacylglycerol concentrations may also imply a higher CVD risk, although controversies exist on the independence of this relationship (see (16), for review). In addition, ratios such as the total cholesterol to $\mathrm{HDL}$ cholesterol ratio $(17,18)$, or concentrations of the apolipoproteins associated with LDL or HDL -apolipoprotein B100 (apoB) and apolipoprotein A-I (apoA-1), respectively- and their ratio (19) have been reported as potent predictors of CVD-risk.

Recently, associations between high lipoprotein(a) (Lp(a)) concentrations and CVD have been demonstrated in cross-sectional studies $(20,21)$. This relationship was not confounded by levels of LDL or HDL cholesterol (21). Whether $L p(a)$ is indeed an independent risk factor for CVD needs to be confirmed in further prospective studies. Because of the homology of the apolipoprotein(a) part of $\operatorname{Lp}(a)$ with plasminogen, $L p(a)$ may well cause its action via impaired fibrinolytic function $(22,23)$.

Most studies were carried out in men, but the few that were carried out in both men and women found that the associations between lipids and lipoproteins with CVD risk were essentially similar in both sexes $(13,15)$.

\section{Hemostatic factors}

A delicately balanced system of interactions keeps the blood circulating as a fluid through the blood vessels. In case of imbalance, for example when a vessel is damaged, the blood starts to clot and a stable thrombus will be formed. This, of course, is necessary to stop a wound from bleeding. However, if a stable thrombus is formed in a small coronary artery, the artery can become occluded, blood and oxygen supply is then hampered, and a heart attack can be the result.

The hemostatic system involves interacting processes for the formation of a stable thrombus -platelet activation and blood clotting-, but also a mechanism to dissolve the 
thrombus, fibrinolysis (figure 1). In vivo, these processes are associated and the interplay defines the thrombotic capacity of the blood.

Table 2. Relationship between increasing levels or activities of fasting lipid or hemostatic factors with cardiovascular risk: evidence from epidemiological studies.

\section{CVD risk Remarks}

\section{Lipid factors}

LDL cholesterol

HDL cholesterol

Triacylglycerol

Lipoprotein(a)

+ ?

$+$

Apolipoprotein B

Apolipoprotein A-I

Total:HDL cholesteroll

ApoA-1:ApoB

\section{Hemostatic factors}

$\begin{array}{lll}\begin{array}{l}\text { Platelet aggregation } \\ \text { Coagulation }\end{array} & +? & \begin{array}{l}\text { (ADP-induced whole blood } \\ \text { ADP-induced platelet-rich plasma) }\end{array} \\ \begin{array}{l}\text { Factor Vilc activity } \\ \text { Women }\end{array} & + & \text { (fatal events) } \\ \text { Men } & + & \text { (fatal events) } \\ \text { Fibrinogen } & + & \\ \text { Antithrombin activity } & =\text { or }+? & \text { (U-shaped risk profile) } \\ \text { Fibrinolysis } & & \\ \text { PAl activity } & +?\end{array}$

The presence of stable thrombi in advanced atherosclerotic plaques suggests an important contribution of thrombogenesis in CVD (24). In addition, hypercoagulability and impaired fibrinolytic function, forming occlusive thrombi, after an atherosclerotic plaque has been fissured, has been proposed to play a role in the pathogenesis of CVD (25).

Clinical trials indeed revealed that the treatment of CVD-patients with anticoagulants or fibrinolytic therapy reduces the incidence of recurrent infarction and decrease the progression of new lesion formation (25). However, the evidence for the role of hemostatic factors in CVD from prospective studies, which link these factors 
with CVD, are scarce, In addition, the few prospective studies on platelet aggregation $(26,27)$, coagulation $(28,29)$ and fibrinolytic factors $(30,31)$ (see below for further discussion) have only been carried out in males. Whether the associations for females are similar awaits confirmation.

Hemostatic factors are difficult to measure. Due to the venipuncture and subsequent blood sampling and plasma preparation, platelets and coagulation factors may become activated which makes it very difficult to obtain a true reflection of the in vivo situation. In addition, many different methods are used, which makes comparisons between studies difficult.

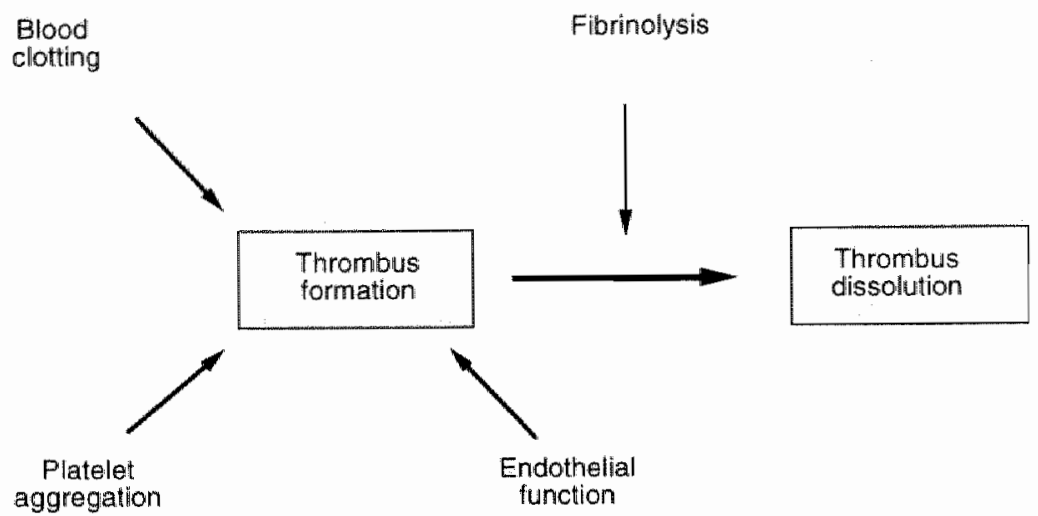

Figure 1. Processes involved in thrombus formation as discussed in this thesis. The hemostatic system involves interacting processes for the formation of a stable thrombus -platelet aggregation, blood clotting and endothelial function-, but also a mechanism to dissolve the thrombus, fibrinolysis.

\section{Platelet aggregation}

Blood platelets have a central role in thrombus formation. Circulating platelets display on their surfaces pessive and activation dependent receptors, which can interact with many agonists, including small molecules, plasma proteins and proteins from the extracellular matrix. Receptor mediated reactions then initiate complex series of intercellular activation events which lead to excretion of substances important for the overall hemostatic response. Receptor mediated reactions lead to platelet adhesion and aggregation of platelets to the injured blood vessel to form a hemostatic plug (32). Platelets excrete substances like calcium, stimulate the 
formation of thrombin, carry a fibrinogen receptor, and provide the phospholipid surface that is important for blood coagulation.

\section{Measurement of platelet aggregation}

A broad scalla of methods is available to measure platelet aggregation in vitro. First of all, the blood sample needs to be anticoagulated to avoid clotting of the blood in the test tube or in the aggregometer. Different anticoagulants are used like citrate, which depletes the sample from calcium, heparin, which bind to antithrombin as a result of which the conversion of prothrombin to thrombin is subsequently inhibited. and hirudin, which is a specific thrombin inhibitor. Platelet aggregation in vitro can be measured in whole blood, in platelet rich plasma, or to remove the influence of possible interfering constituents from the plasma- in washed platelet suspensions. Also, the aggregation reaction in the test tube can be triggered with many different compounds, like collagen, ADP, arachidonic acid, and thrombin.

\section{Platelet aggregation and CVD}

Although platelets and platelet activity undoubtedly play an important role in thrombogenesis and tests of platelet function have been helpful clinically for detecting platelet hemostatic defects, limited evidence for the association between increased in vitro platelet aggregation and CVD is available from prospective studies. in one study, subjects with increased ADP-induced platelet rich plasma aggregation had a higher risk to develop fatal cardiovascular events (26). Collagen- or adrenalime-induced aggregation, however, was not related with CVD mortality (26). Another study, in addition, demonstrated higher CVD prevalence subjects with high ADP-induced compared with those having low ADP-induced wholle blood aggregation (27). Results were, however, not adjusted for other risk indicators associated with increased CVD risk.

\section{Coagulation factors}

Several pathways for blood coagulation exist. Most important in vivo is the tissue factor pathway of blood coagulation, previously known as the extrinsic pathway of blood coagulation (33). The factors involved in the tissue factor pathway of blood coagulation are depicted in a simplified scheme in figure 2. The coagulation factors are present in the plasma in inactivated form. Of factor $V I I$, however, $1 \%$ is present in the activated state (factor VIla) (34). Figure 2 shows, mainly the activated coagulation factors.

Blood coagulation in vivo is initiated when factor VII or factor Vlla contacts a tissue factor, for example after vessel injury or inflammation. A tissue factor, an integral membrane glycoprotein, that is expressed by the subendothelial components of the vessel wall, acts as a procoagulant. Once bound, factor VII is rapidly activated into factor VIla. The complex of factor Vlla with tissue factor then initiates a cascade of reactions, which ultimately results in the conversion of factor $X$ into factor $X a$ and the generation of thrombin from prothrombin. Thrombin cleaves fibrinogen and finally an insoluble fibrin clot is formed, that stabilizes a thrombus. Thrombin is one of the key 
factors in blood coagulation. Besides many other actions such as stimulation of platelet aggregation and back-activation of coagulation factors, thrombin also activates the anticoagulant pathways.

\section{Factor VII}

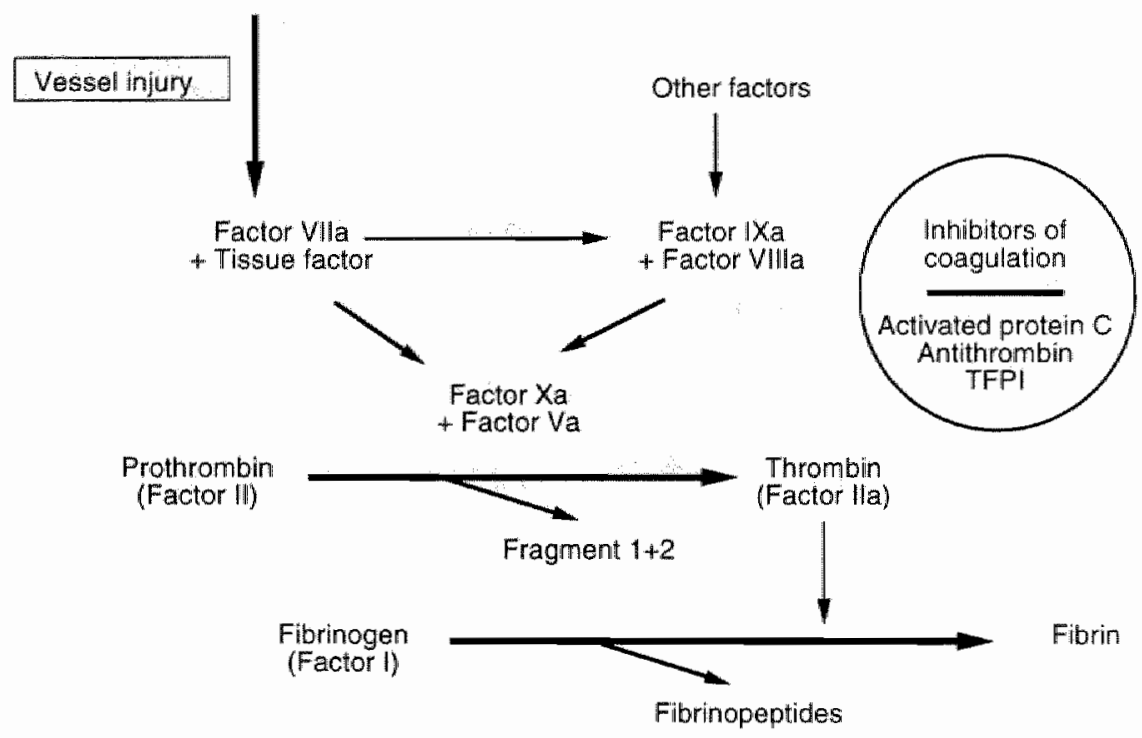

Figure 2. Schematic representation of the coagulation cascade (simplified). When factor VII contacts tissue factor, expressed for example after vessel injury or inflammation, factor VII is rapidly activated into factor VIla. The complex of factor VIla with tissue factor initiates a cascade of reactions, which ultimately results - after cleavage of fragment $1+2$ - in the conversion of prothrombin into thrombin. Thrombin cleaves fibrinogen into fibrin, that stabilizes a thrombus. Antithrombin and tissue factor pathway inhibitor (TFPI) inhibit the coagulation cascade via complex formation with activated coagulation factors. Activated protein $C$ in complex with protein $S$ inactivates factor Va and factor VIIla.

Important inhibitors of coagulation are antithrombin and tissue pathway inhibitor (TFPI). Antithrombin inhibits most of the activated coagulation factors. The main targets of antithrombin are probably thrombin and factor Xa (32). TFPI binds to factor $X a$ and induces feedback inhibition of coagulation by complex formation with the tissue factor/factor Vlla complex. This prevents further activation of the coagulation 
cascade (33). Another anticoagulant pathway is via protein $C$. Protein $C$ is activated when thrombin interacts with thrombomodulin. A complex of activated protein $C$ with protein $S$ then inactivates factors $\mathrm{Va}$ and VIlla.

\section{Measurement of coagulation}

Most assays measure the total amount (e.g. factor VII antigen or fibrinogen concentrations) or the activity (e.g. factor VIl-coagulant activity) of circulating coagulation factors. However, these factors are normally present in large excess in the blood, and only a small percentage is converted into active enzymes under in vivo situations. Nowadays, other assays are also available, which reflect actual in wivo coagulation. The plasma fragment $1+2$ concentration reflects the amount of prothrombin conversion into thrombin, while fibrinopeptides $A$ and $B$ concentrations reflect the conversion of fibrinogen into fibrin. However, in healthy subjects, concentrations of these markers are very low and just above detection limits, which makes it sometimes difficult to implement their measurements in dietary studies.

Many methods are available to measure factor VII. In most studies, factor VII is measured with a coagulant assay (factor VIIC). Factor VII amidolytic (factor VIlam) activity can be measured with a two step chromogenic assay, which depends on the rate of generation of factor $\mathrm{Xa}$ from factor $\mathrm{X}$ by activated factor VII (factor VIla). Both the factor VIIC and the factor VIlam activity assay do not differentiate between factor VIIla and factor VII antigen (factor VIllag) concentrations (34).

Fibrinogen concentrations are usually measured with the method of Clauss (35) or a functional assay modified after Clauss. A fixed surplus of thrombin is added to diluted platelet poor plasma samples, the clotting time recorded, and the fibrinogen concentration read from a calibration curve.

\section{Coagulation and CVD}

Several long-term prospective epidemiological studies have reported that in healthy males factor VIIc activity and fibrinogen concentrations were higher in subjects who developed cardiovascular diseases at a later stage of the study $(28,29)$. Factor VIIc activity was in particular associated with an increased risk of dying of cardiovascular disease $(28,29)$. It was also noted that low fibrinogen levels were associated with low CVD risk even when LDL cholesterol concentrations were raised (28). Other factors of the coagulation system that might be related to CVD risk is high factor VIII activity (36) and high factor VIlag (37).

Data from the Northwick Park Heart Study (NPHS) showed that low and, unexpectedly, also high concentrations of antithrombin were associated with increased deaths from CVD (38). In view of results of several cross-sectional studies (39-41) the relation of high antithrombin concentrations and high CVD risk was unexpected. In a clinical study, high activity of TFPI has been demonstrated in patients with CVD (42), but this might be related to raised levels of lipoprotein-bound TFPI, which probably has lesser anticoagulant capacity than free TFPI (43), 


\section{Fibrinolytic factors}

The process involved in thrombus dissolution, and thus the conversion of fibrin in fibrin degradation products, is called fibrinolysis. A simplified scheme of fibrinolysis is given in figure 3 . The central reaction in the fibrinolytic process is the conversion of plasminogen into plasmin, which is regulated by the action of tissue plasminogen activator ( $t-P A)$. The fibrinolytic capacity of blood is regulated by inhibiting t-PA activity by the action of Plasminogen Activator Inhibitor type-1 (PAl), while plasmin is inhibited mainly by $\alpha_{2}$-antiplasmin (44).

\section{Measurement of fibrinolysis}

The fibrinolytic capacity of plasma can be measured by global tests or more specific assays. The global tests include the dilute clot lysis time, euglobulin, clot lysis time and the fibrin plate assay. The dilute and euglobulin clot lysis time measure total fibrinolytic capacity. The total blood sample, or the insoluble protein fraction (euglobulin fraction) is diluted with a buffer, clotted, and then the lysis time of the clot is recorded. In the fibrin plate assay, a standard volume of the euglobulin fraction of plasma is added to standardized plasminogen-rich fibrin plates and the amount of lysis is recorded. In more specific assays total plasma antigen concentration of t-PA and PAll can be determined with enzyme-linked immunosorbent assay methods. Plasma t-PA and PAl activities can be assessed with chromogenic assays.

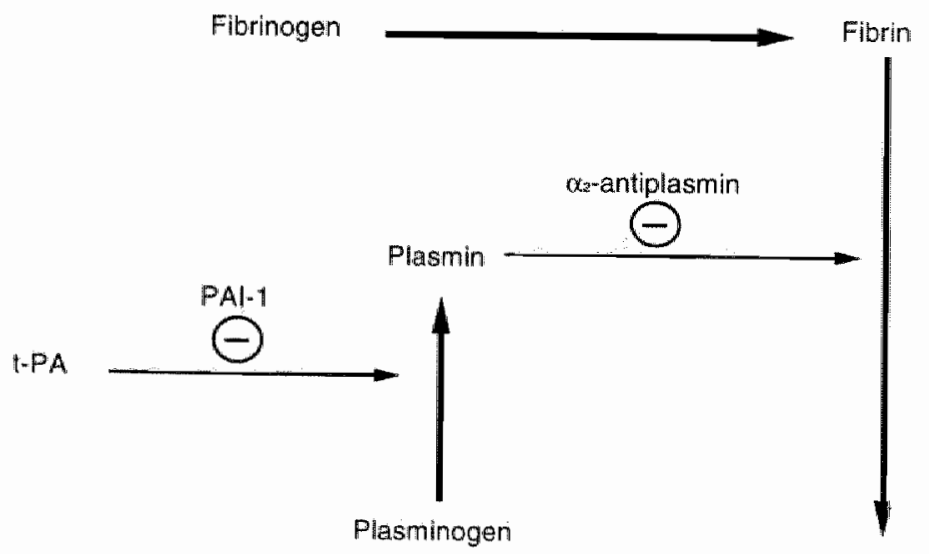

Fibrin degradation products.

Figure 3. Schematic representation of the fibrinolytic pathway (simplified). Fibrin is degraded by plasmin. The conversion of plasmin from plasminogen is regulated by the action of tissue plasminogen activator (t-PA). t-PA activity is suppressed by plasminogen activator inhibitor type-1 (PAl), while plasmin is inhibited by ac-antiplasmin. 


\section{Fibrinolysis and CVD}

The Northwick Park Heart Study demonstrated that low fibrinolytic capacity of plasma, measured as clot lysis time was significantly associated with increased CVD risk in middlemaged men (30). Prospective studies in healthy subjects, including determinations of the individual components of the fibrinolytic system, t-PA and PAl, however, are lacking. Hamsten et al (31) reported that higher PAl concentrations were associated with increased risk of reoccurrence of coronary events. The evidence for a role of t-PA in CVD is conflicting. In general, t-PA activity is inversely related to $\mathrm{PAl}$ activity, the association of $t-P A$ with $C V D$ risk therefore is generally opposite to that for PAI. Hamstem et al (45), in agreement, found lower I-PA activities in patients with myocardial infarction compared with control subjects. Other studies, however, showed the opposite and demonstrated that patients with atherosclerotic disease have higher concentrations of t-PA suggesting increased fibrinolytic capacity of plasma $(46,47)$. In addition, a prospective follow-up of the Physicians. Health Study showed significantly higher t-PA concentrations in subjects with future stroke compared with those who remained free of cardiovascular disease (48).

\section{SATURATED FATTY ACIDS AND CVD RISK MARKERS}

More than 40 years ago, the Seven Countries Study already demonstrated that countries with a higher average intake of total fat, and in particular of saturated fatty acids, experienced a higher mortality from CVD after 15 years of follow up (1). The strong correlation between saturated fat intake and CVD mortality rates extended through the $25 \mathrm{yr}$. follow up (49). Of the individual saturated fatty acids, lauric, myristic. palmitic and stearic acids intakes correlated strongly with CVD risk ( $r=0.84$ for lauric acid, $r=0.86$ for myristic acid, $r=0.81$ for palmitic acid, $r=0.84$ for stearic acid) (49).

The results from the Seven Countries Study (1) strongly suggested that the saturated fatty acid content of the diet affected processes involved in the development of cardiovascular diseases. Of these processes increased cholesterol concentrations in those men dying of CVD were demonstrated, and serum total cholesterol levels were strongly correlated with saturated fat intake (1). More recent data indicate that this correlation is slightly stronger for lauric and myristic acids than for palimitic and stearilc acids (49). Several clinical trials, in addition, confirmed that lowering cholesterol levels reduces the risk for CVD and can retard the progression of atherosclerosis (50).

Recent data (2) highlighted that the correlation between saturated fatty acids and CVD risk persists even after adjustment for other CVD factors such as cholesterol concentrations. Saturated fatty acids may thus also exert their effects on CVD risk via other processes than those involved in cholesterol metabolism. Among them, factors involved in hemostasis might be important, as evidence exists for an effect of dietary fatty acid composition on factors involved in platelet aggregation $(51,52)$ coagulation $(6,7)$ and fibrinolysis $(6,7)$. The effects of saturated fatty acids and certainly those of 
individual saturated fatty acids on hemostatic components, however, have been studied less extensively than those on lipid and lipoprotein concentrations.

\section{INDIVIDUAL SATURATED FATTY ACIDS AND CVD RISK MARKERS}

\section{Lipid factors}

Controlled dietary trials have demonstrated that serum lipid and lipoprotein levels are affected by the total saturated fat content and the type of saturated fatty acid in the diet. Keys and co-workers (4) already observed that cocoa butter did not raise total cholesterol concentrations compared with palm oil. Later studies indicated that stearic acid, the main saturated fatty acid of cocoa butter decreases serum total cholesterol concentrations compared with palmitic acid from palm oll (53). This different serum cholesterol-raising potency of two fats high in saturated fatty acids showed that not all saturated fatty acids have equal cholesterolemic effects.

The effects of MCFA have been thought to be neutral compared with carbohydrates (54). Like carbohydrates, MCFA have been demonstrated to increase fasting triacylglycerol concentrations $(55,56)$. However, studies on the effects of MCFA were carried out with limited number of subjects, with short dietary periods, or with experimental diets in which MCFA were not the only variable among the diets. Thus, precise effects of MCFA are not known.

Also the effects of lauric acid are not yet conclusive, because only a small number of studies have been carried out indicating either lowering (57), increasing (58) or similar effects $(59,60)$ compared with palmitic acid. Of the saturates, myristic acid might have the strongest potency to increase serum total (3) and LDL cholesterol concentrations. Hegsted et al (3) estimated that the cholesterol raising effect of myristic acid is about 4.8 times that of lauric acid and 1.3 times that palmitic acid. However, as mentioned by the authors, this estimate varied with the regression bquation used. Fats rich in lauric acid naturally contain allso large amounts of myristic acid. Therefore, it is difficult to study lauric acid separately. If lauric acid, for example, was not included in the equation, myristic acid was about 3.8 times as cholesterol raising as palmitic acid. Other authors also combined the results of several experiments by using multiple regression analysis, but concluded that myristic acid was about equally hypercholesterolemic as palmitic acid $(55,61)$.

The cholesterol raising properties of palmitic acid, the major dietary saturated fatty acid have been studied extensively. However, results on the effects of palmitic acid are not yet conclusive. Many studies $(53,57,62,63)$ have indicated that palmitic acid raises serum total and LDL cholesterol, but only slightly increases HDL cholesterol relative to carbohydrates. Other studies $(64,65)$ indicated that palmitic acid not raises ciral and LDL cholesterol concentrations as compared with oleic acid under special circumstances that not down-regulate the LDL receptor activity. These circumstances include adequate dietary linoleic acid and low cholesterol content of the diet in
normocholesterolemic, nonobese subjects. 
Adverse effects of lowering cholesterol concentrations on mortality of non-illiness related causes (violence, suicides and accidents) have also been reported from epidemiological studies. The hypothesized mechanism associates declining serum cholesterol concentrations with a more negative mood state (66). The latter might be related to the low plasma serotonin (67) or low trypophan concentrations (68), found in subjects with low cholesterol concentrations as compared with a reference group.

\section{Hemostatic factors}

Limited studies have investigated the effects on hemostatic factors of individual saturated fatty acids in healthy human subjects. The interest for the effects for individual saturated fatty acids on platelet aggregation, coagulation and fibrinolytic factors has increased lately. Separate effects of MCFA and lauric acid, however, have never been studied. In addition, studies in other subjects than young and lean men are scarce. The effects of diets rich in lauric plus myristic acids (8), myristic acid (69), palmitic acid $(8,69)$ and stearic acid $(8)$ on coagulation and fibrinolytic factors have been investigated. These studies $(8,69)$ suggested that particular saturated fatty acids alter factor VIlc activity in a different way. Fats rich in lauric plus myristic acid or palmitic acid raise factor VIlc activity compared with fats rich in stearic acid (8). In addition, fats rich in myristic acid increase factor VII activity slightly stronger than fats rich in palmitic acid (69).

\section{Food intake}

Maintaining a healthy weight is another factor that is important to prevent CVD. Food intake therefore needs to be balanced with the energy need. In the etiology of the development of obesity, factors that affect feelings of appetite might play a role. Results of Rolls et al $(70)$ suggest that differences in satiety mechanisms exist between different fatty acids as preloads of medium chain triglycerides reduced food intake shortly after the preload had been given, compared with preloads of corn oil. No other data "however, are available on the effects of fatty acid composition on feelings of appetite. 


\section{OUTLINE OF THE THESIS}

This thesis describes two studies on the effects of individual saturated fatty acids on risk markers for cardiovascular diseases in healthy women and men. In the first study effects of lauric and palmitic acids were investigated and the second study focused on the effects of MCFA and myristic acid. In both studies the reference fatty acid was oleic acid.

\section{Lipid factors}

In Chapter 2 we have compared the effects of lauric acid and palmitic acid with the effects of oleic acid on lipid and lipoprotein concentrations. The effects of these fatty acids were studied under circumstances that were expected not to downregulate the LDL receptor activity: diets contained sufficient linoleic acid and low cholesterol levels, while subjects were normocholesterolemic and non-obese. Chapter 3 addresses the effects of MCFA and myristic acid. Because natural fats only rich in MCFA or myristic acid do not exist, synthetic fats were used in this second study. To know to what extent the triglyceride structure of these fats differs from natural fats, the triglyceride structure of the experimental fats was also determined. Chapter 4 focuses on dietary induced changes in lipoproteins and effects on mood.

\section{Hemostatic factors}

Chapter 5 discusses the effects of MCFA, lauric acid, myristic acid and palmitic acid on whole blood aggregation. The effects on coagulation and fibrinolytic parameters are discussed in Chapter 6 for lauric and palmitic acid and in Chapter 7 for MCFA and myristic acid.

III. Appetite and proposed regulators of food intake.

Chapter 8 focuses on the effects of dietary fatty acid composition (MCFA, myristic or oleic acid rich diets) on feelings of appetite. In addition, concentrations of some proposed regulators of food intake -apolipoprotein A-IV and leptin-are studied.

Finally, in Chapter 9 the main results of both studies will be summarized and its implications will be discussed. 


\section{REFERENCES}

1. Keys A, Menoti A Karvonen MJ, Aravanis C, Blackburn H, Buzina $\mathbb{A}$, Djordjevic BS, Dontas AS. Fidanza F. Keys MH. The diet and 15-year death rate in the seven countries study. Am $J$ Epidemiol 1986; 124:903-915.

2. Esrey KL, Joseph L, Grover SA. Relationship between dietary intake and coronary heart disease mortality: lipid research clinics prevallence follow-up study. J Clim Epidemiol 1996;49:211-216.

3. Hegsted DM, McGandy RB, Myers ML. Stare FJ. Quantitative effects of dietary fat on serum cholesterol in man. Am J Clin Nutr 1965:17:281-295.

4. Keys A, Anderson JT, Grande F. Serum cholesterol response to changes in the diet. IV. Particulliar saturated fatty acids in the diet. Metabolism 1965;14:776-786.

5. Kris-Etherton PM, Krummel D, Russel ME, Dreon D, Mackey S, Borchers J, Wood PD. The effect of diet on plasma lipids, lipoproteins, and coronary heart disease. I Am Diet Assoc 1988;88:13731400.

6. Mitropoulos KA, Miller GJ, Martin JC, Reeves BEA, Cooper J. Dietary fat induces changes in factor VIll coagulant activity through effects on plasma free stearic acid concentration. Arterioscler Thromb 1994;14:214-222.

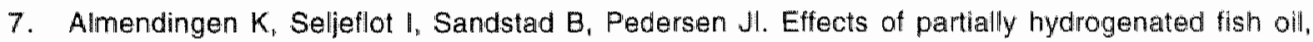
partially hydrogenated soybean oil, and butter on hemostatic variables in men. Arterioscter Thromb Vasc Biol 1996:16:375-380.

8. Tholstrup $T$, Marckmann $P$, Jespersen $J$, Sandström B. Fat high in stearic acid favorably affects blood lipids and factor VII coagulant activity in comparison with fats high in palimitic acid or high in myristic and lauric acids. Am J Ctin Nutr 1994;59:371-377.

9. Ministeries van Welzijn, Volksgezondheid en Cultuur en van Landbouw, Natuurbeheer en Visserij. Zo eet Nederland, 1992. Voorlichtingsbureau voor de voeding, 1993.

10. Schwab US, Maliranta HM, Sarkkinen ES, Savolainen MJ, Kesäniemi YA, Uusitupa MIJ. Different effects of palmitic and stearic acid-enriched diets on serum lipids and lipoproteins and plasma cholesteryl ester transfer protein activity in healthy young women. Metabolism 1996;45:143-149.

11. Henderson A. Coronary heart disease: overview. Lancet 1996;348:s1-s4.

12. Reitsema J. Hart-en vaatziekten in Nederiand. Cijfers over ziekte en sterfte. Den Haag, Nederland: Nederlandse Hartstichting, 1996: 1-62.

13. Gordon T, Kannel WB, Castelli WB, Dawher TR. Lipoproteins, cardiovascular diseases and death: The Framingham Study. Arch Intern Med 1981:141:1128-1131.

14. National Cholesterol Education Program. Report of the expert panel on population strategles for blood cholesteroll reduction. Circulation 1991;83:2154.

15. Gordon DJ, Probstteld JL, Garrison RJ, Neaton JD, Castell WP, Knoke JD, Jacobs jr DF, Bangdiwala S, Tyroter HA. High-density lipoprotein cholesterol and cardiovascular disease. Four prospective American studies. Circulation 1989:79:8-15.

16. Austin MA. Plasma triglyceride and coronary heart disease. Arterioscler Thromb 1991:11:2-14.

17. Castelli WP. Anderson K. Wilson PWF. Levy D. Lipids and risk of cononary heart disease: The Framingham Study. Ann Epidemiol 1992;2:23-28.

18. Gardner CD, Fortmann SP, Krauss RM. Association of small low-density lipoprolein particles with the incidence of coronary artery disease in men and women. JAMA 1996;276:875-881.

19. Kwiterowich Jr PO, Coresh J Smith HH, Bachorik PS, Derby CA, Pearson TA. Comparison of the plasma levels of apolipoprotein $B$ and $A-\|$, and other risk factors in men and women with premature coronary artery disease. Am J Cardiol 1992;69:1015-1021. 
20. Seed M. Hoppichler D, Reaveley D. MCCratty S. Thompson GR, Boerwinkle $E$, Utermann $G$. Relationship of serum lipoprotein(a) and apolipoprotein(a) phenotype to coronary heart disease in patients with familial hypercholesterolemia. N Engl I Med 1990;332:1494-1499.

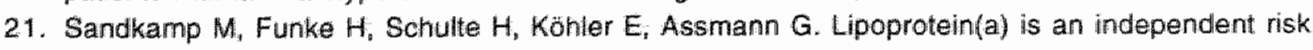
factor for myocardial infarction at a young age. Clin Chem 1990;36:20-23.

22. Loscalzo $\mathrm{J}$. Weinfeld $M$, Fless $G M$, Scamu AM. Lipoprotein(a) fibrin binding, and plasminogen activation. Anteriosclerosis 1990;10:240-245.

23. Hajar KA, Gavish D, Breslow JL, Nachman RL. Lipoprotein(a) modulation of endothelial cell surface fibrinolysis and its potential role in atherosclerosis. Nature 1989;339:303-305.

24. Davies Mu, Thomas A. Thrombosis and acute coronary artery lesions in sudden ischemic death. $N$ Engl J Med 1984,310:1137-1140.

25. Fuster $\mathrm{V}$, Badimon $\mathrm{L}$, Badimon JJ, Chesbro $\mathrm{JH}_{\mathrm{H}}$ The pathogenesis of coronary artery disease and the acute coronary syndromes. N Engl I Med 1992;326:242-250.

26. Thaulow E, Erikssen J, Sandvik L, Stormorken H, Cohn PF. Blood platelef count and function are related to total and cardiovascular death in apparently healthy men. Circulation 1991;:84:613-617.

27. Elwood PC, Beswick AD, Sharp DS, Yarnell JWG, Riogers $S$, Renaud S. Whole blood impedance platelet aggregometry and ischemic heart disease. Arteriosclerosis 1990;10:1032-1036.

28. Heinrich $\mathrm{d}$, Balleisen $L$. Schulte $H$, Assmann $G$, van de Loo J. Fibrinogen and factor $V / l$ in the prediction of conomary risk. Arterioscler Thromb 1994;14:54-59.

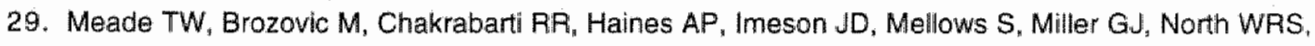
Stirling $Y$, Thompson SG. Haemostatic function and ischaemic heart disease: principal results of the Northwick Park Heart Study. Lancet 1986;2:533-537.

30. Meade TW, Ruddock V, Stirling Y, Chakrabarti R, Miller G.J. Fibrinolytic activity, clotting factors, and long-term incidence of ischaemic heart disease in the Northwick Park Heart Study. Lancet 1993;342:1076-1079.

31. Hamsten $A$, Walldius $G$, Szamosi A, Blombäck $M$, Faire Ud, Dahlén $G$, Landou $C$, Wiman $B$. Plasminogen activator inhibitor in plasma: risk factor for recurrent myocardial infarction. Lancet $1987 ; 2: 3-8$.

32. Mann KG. Thrombosis: theoretical considerations. Am J Clin Nutr 1997;65:1657s-1664s.

33. McVey JH. Tissue factor pathway. In: Meade. TW, ed: Thrombophilia. London: Bailliere Tindall, 1994: 469-484.

34. Morrissey JH, Macik BG, Neuenschwander PF, Comp PC. Quantification of activated facior VIII levels in plasma using a tissue factor mutant selectively deficient in promoting factor VIl activation. Blood $1993 ; 81: 7344-744$.

35. Clauss A. Gerinnungsphysiologische schnellmethode zur bestimmung des fibrinogens. Acta Haematol 1957:17:237-246.

36. Cortellero M, Boschetti $C$, Confrancesco E. Zanussi $C$, Catalano M, de Gaetano $G_{\text {" Gabrielli L. }}$ Lombardi B. Specchia G. Tavazzi L. The PLAT study: hemostatic function in relation to atherothrombotic ischemic events in vascullar disease patients. Arterioscter Thromb 1992;12:10631070 .

37. Miller GJ, Bauer KA, Barzegar S, Cooper JA, Rosenberg RD. Increased activation of the haemostatic system in men at high risk of fatal coronary disease. Thromb Haemost 1996;75:767-771.

38. Meade TW, Cooper J, Miller GJ, Howarth DJ, Stirling Y. Antithrombin III and arterial disease. Lancet $1991 ; 337: 850-851$.

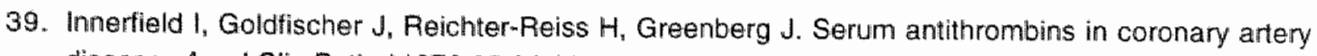
disease. Am J Clim Pathor 1976;65:64-68. 
40. Banerjee $R$, Sahni $A$, Kumar $V_{\text {, Arya }} M$ : Antithrombin deficiency in maturity onset diabetes mellitus: and atherosclerosis. Thromb Diath Haemorthag 1974;31:339-345.

41. O'Bien $J$, Etherington $M$, Jamieson $S$, Lawford $P$. Lincoin $S$, Alkjaersig ZN. Blood ohanges in atherosclerosis and long after myocardial infarction and venous thrombosis. Thromb Diath Haemorrhag 1975;34:483-497.

42. Sandset PM, Sirnes PA, Abildgaard U. Factor VII and extrinsic pathway inhibitor in acute coronary disease. Br J Haematol 1989;72:391-396.

43. Hansen J-B, Raanaas Huseby K, Hulseby N-E, Sandset P, Hanssen T-A, Nordoy A. Effects of cholesterol lowering on intravascular pools of TFPI and its anticoagulant potential in type II hyperlipoproteinemia. Arterioscler Thromb Vasc Biol 1995; 15:879-885.

44. Booth NA, Bennet B. Fibrinolysis and thrombosis. In: Meade TW, ed. Thrombophilia. London: Bailliere Tindall, 1994: 559-572.

45. Hamsten $A$, Wiman $B$, de Faire U, Blombäck M. Increased plasma levels of a rapid inhibitor of tissue plasminogen activator in young survivors of myocardial infarction. N Engl J Med 1985:313:1557* 1563.

46. Jansson $\mathrm{JH}$, Nilsson TK, Olofsson BO. Tissue plasminogen activator and other risk factors as predictors of cardiovascular events in patients with severe angina pectoris. Eur Heart $J$ $1991 ; 12: 157-161$.

47. Jansson $\mathrm{JH}$, Olofsson $\mathrm{BO}$, Nilsson TK. Predictive value of tissue activalor mass concentration on long-term mortality in patients with coronary artery disease: a seven-year follow up. Circulation 1993;88:2030-2034.

48. Ridker PM, Hennekens CH, Stampfer MJ, Manson JE, Vaughan DE. Prospective study of endogenous tissue plasminagen activatior and risk of stroke. Lancet 1994;343:940-943.

49. Kromhout D, Menotti A, Bloemberg B, Aravanis C, Blackburn H, Buzina R, Dontas AS, Fidanza $F$. Giampaoli $S$, Jansen A. Dietary saturated and trans fatty acids and cholesterol and 25-year mortality from coronary heart disease: the Seven Countries Study. Prev Med 1995;24:308-315.

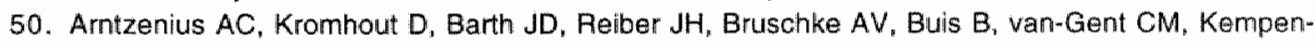
Voogd N, Strikwerda S, van-der-Velde EA. Diet, lipoproteins, and the progression of coronary atherosclerosis. N Engl J Med 1985:312:805-811.

51. Renaud S, Marazain R, Godsey F, Dumont $E$, Thevenon $C_{n}$ Martin JL, Mendy F. Nutrients, platelet function and composition in nine groups of French and British farmers. A.therosclerosis 1986;60:3748.

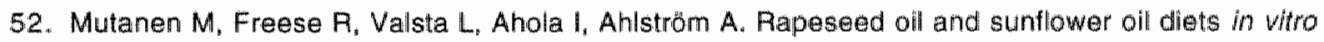
aggregation and thromboxane production in healthy men when compared with milk lat ar habitual diets. Thromb Haemost 1992;67:352-356.

53. Bonanome A, Grundy SM. Effect of dietary stearic acid on plasma cholesterol and lipoprotein levels. N Engl J Med 1988;318:1244-1248.

54. Grundy SM, Denke MA. Dietary influences on serum lipids and lipoproteins. I Lipid Res 1990;31:1149-1172.

55. McGandy RB, Hegsted DM. Myers ML. Use of semisynthetic fats in determining effects of specilic dietary fatty acids on serum lipids in man. Am J Clin Nutr 1970;23:1288-1298.

56. Swift LL, Hill JO, Peters JC, Greene HL. Medium chain fatty acids: evidence for incorporation into chylomicron triglycerides in humans. Am J Clin Nutr 1990;52:834-836.

57. Derike MA, Grundy SM. Comparison of effects of lauric acid and palmitic acid on plasma lipids and lipoproteins. Am J Clin Nutr 1992;56:895-898.

58. Vergroesen AJ. Dietary fat and cardiovascular disease: possible modes of action of linoleic acid. Proc Nutr Soc 1972;31:323-329. 
59. Dougherty RM, lacono JM. Dietary lauric acid has similar ettects on blood cholesterol as patmitic acid in natural diets in man (abstract). FASEB I 1992;6:A1680.

60. Schwab US, Niskanen LK, Maliranta HM, Savolainen MJ, Kesãniemi YA, Uusitupa MIJ. Lauric and Palmitic acid-enriched diets have minimal impact on serum lipid and lipoprotein concentrations and glucose metabolism in healthy young women: J Nutr 1995;125:466-473.

61. Derr J, Kris-Etherton $P_{1}$ Pearson TA seligson FH. The role of fatty acid saturation on plasma lipids, lipoproteins and apoproteins: 11. The plasma total and low-density lipoprotein cholesterol response of individual fatty acids: Metabolism 1993;42:130-134.

62. Nestel $P$, Noakes $M$; Belling $B$; McArthur $R$, Clitton $P$, Janus $E$, Abbey M. Plasma lipoprotein lipid and Lp[a] changes with substitution of elaidic acid for oleic acid in the diet. J Lipid Res 1992:33:10291036.

63. Zock PL, de Vries JHM, Katan MB. Impact of myristic acid versus palmitic acid on serum lipid and lipoprotein levels in healthy women and men. Arteriosicler Thromb 1994;14:567-575.

64. Choudhury N, Tan L, Truswell AS. Comparison of palmolein and olive oil: effects on plasma lipids and vitamin $E$ in young adults. Am J Clin Nutr 1995:61:1043-1051.

65. Ng TKW, Hayes KC, DeWitt GF, Jegathesan M, Satgunasingam N, Ong ASH, Tan D. Dietary palmitic and aleic acids exert similar effects on serum cholesterol and lipoprotein protiles in normocholesterolemic men and women. J Am Coll Nutr 1992;11:383-390.

66. Engelberg $\mathrm{H}$. Low serum cholesteroll and suicide. Lancet 1992;339:727-728.

67. Steegmans PHA, Fekkes D, Hoes AW, Bak AAA, van der Does E, Grobbee DE. Low serum cholesterol concentration and serotonin metabolism in men. BMJ1996;221.

68. Steegmans PHA. Laag serumcholesterol, depressies en geweldadige dood; Serotonine als mogelijke schakel. Voeding 1996;6:20-21.

69. Tholstrup T, Marckmann P, Jespersen J: Vessby B, Jart A, Sandström B. Effect on blood lipids, coagulation, and fibrinolysis of a fat high in myristic acid and a fat high in palmitic acid. Am J Clim Nutr $1994 ; 60: 919: 925$.

70. Rolls BJ, Gnizak N, Summerfelt A, Jacobs Laster L. Food intake in dieters and non-dieters after a liquid meal containing medium-chain triglycerides. Am J Clin Nutr 1988;48:66-71. 


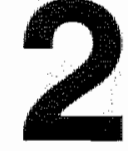

\title{
Comparison of the effects of diets enriched in lauric, palmitic or oleic acids on serum lipids and lipoproteins in healthy women and men
}

\author{
Elisabeth HM Temme, Ronald P Mensink, Gerard Hornstra \\ Based on: American Journal of Clinical Nutrition 1996;63:897-903.
}

\section{ABSTRACT}

The degree to which different saturated fatty acids exert their cholesterol-raising effects is still unknown. We, therefore, studied the effect on serum lipid and lipoproteins of diets rich in lauric, pallmitic or oleic acids. Eighteen women and fourteen men consumed in random order three experimental diets, each for six weeks. The diets consisted of solid foods, and contained 40 energy percent (En\%) fat of which $28 \mathrm{En} \%$ was supplied by the experimental fats. The fat high in lauric acid was a mixture of palm kernel $(75 \%)$ and a high oleic acid sunflower oil $(25 \%)$, the fat high in palmitic acid consisted of dairy fat $(55 \%)$, palmstearin $(36 \%)$ and sunflower oil $(9 \%)$ and the fat high in oleic acid of dairy fat $(37 \%)$ and the sunflower oil $(63 \%)$. The calculated nutrient composition was the same in each diet except for about $8.5 \mathrm{En} \%$ which was provided by either lauric, palmitic or oleic acids. On the lauric acid diet the subjects" serum total cholesterol concentration increased by $0.22 \mathrm{mmol} / \mathrm{L}(\mathrm{P}=0.0121$; $95 \%$ confidence interval $(\mathrm{Cl}), 0.02$ to $0.41 \mathrm{mmol} / \mathrm{L}$ ) as compared with the palmitic acid diet and by $0.48 \mathrm{mmol} / \mathrm{L}(\mathrm{P}<0.0001 ; 95 \% \mathrm{Cl}, 0.29$ to $0.67 \mathrm{mmol} / \mathrm{L}$ ) versus the oleic acid diet. Total cholesterol concentrations on the palmitic acid diet were $0.26 \mathrm{mmol} / \mathrm{L}$ $(\mathrm{P}=0.0012 ; 95 \% \mathrm{Cl}, 0.07$ to $0.46 \mathrm{mmol} / \mathrm{L}$ ) higher than on the oleic acid diet. Highdensity lipoprotein (HDL) cholesterol concentrations increased by $0.12 \mathrm{mmol} / \mathrm{L}$ $(P=0.006 ; 95 \% \mathrm{Cl}, 0.04$ to $0.20 \mathrm{mmol} / \mathrm{L})$ on the lauric acid versus the palmitic acid diet and by $0.14 \mathrm{mmol} / \mathrm{L}(\mathrm{P}<0.001 ; 95 \% \mathrm{Cl}, 0.07$ to $0.22 \mathrm{mmol} / \mathrm{L})$ versus the oleic acid diet. HDL cholesterol concentrations on the palmitic acid and the oleic acid diet were the same. No effects were seen on serum triacylglycerol and lipoprotein(a) concentrations. We conclude that both lauric and palmitic acids are hypercholesterolemic as compared with oleic acid. Lauric acid raises total cholesterol concentrations more than palmitic acid, which is partly due to a stronger rise in HDL cholesterol. 


\section{INTRODUCTION}

The serum cholesterol-raising effect of the saturated fatty acids in the diet appears to be limited to lauric acid $(\mathrm{C} 12: 0)$, myristic acid $(\mathrm{C14:0)}$ and palmitic acid $(\mathrm{C} 16: 0)(1$, 2). Several studies suggest that the degree to which these saturated fatty acids increase serum cholesterol concentrations is different. Coconut and palm kernel oils, rich in lauric acid, have been shown to raise serum total, low density lipoprotein (LDL) and high density lipoprotein (HDL) cholesterol concentrations compared with palm oll, high in palmitic acid $(3,4)$. These effects are not necessarily due to increased intakes of lauric acid, as these fats also contain relatively high concentrations of myristic acid. Which is probably a very potent serum cholesterol-raising fatty acid $(2$, 5). Recent studies have investigated the specific effects of lauric acid relative to those of other fatty acids, using either mixtures of natural fats (6, abstr) or synthetic fats (7). Results, however, are still inconclusive. In one study lauric acid was found to lower (7) serum cholesterol concentrations relative to palmitic acid, but in the other study no differences between these two fatty acids were found (6, abstr). A possible explanation for this discrepancy is that effects of synthetic fats, rich in lauric acid, differ from thase of natural fats.

Many previous studies have shown that palmitic acid raises serum total and LDL cholesterol concentrations compared with oleic acid (7-10). Recently, however, it has been suggested that palmitic acid may be neutral in normocholesterolemic subjects, if the diet contains little cholesterol and the linoleic acid intake is adequate (11). Indeed it has been reported that under these conditions palmitic and oleic acids exert similar effects on serum total, LDL and HDL cholesterol concentrations $(12,13)$. We, therefore, decided to examine, at adequate intakes of linoleic acid, the effects on serum lipids and lipoproteins of lauric, pallmitic and oleic acids in healthy volunteers. The experimental fats, which were incorporated into solid foods, were natural and contained little or no myristic acid and relatively small amounts of cholesterol.

\section{SUBJECTS AND METHODS}

\section{Subjects}

Volunteers were recruited via advertisements in local newspapers and posters in public buildings. After they had been thoroughly informed about the purpose and protocol of the study, 62 subjects from Maastricht and surroundings entered the selection procedure. Forty-three people were selected for participation since they met all our eligibility criteria: aged between 20 and 60 years, not on a prescribed or a slimming diet, no anemia, no hypertension and serum total cholesterol concentrations below $6.5 \mathrm{mmol} / \mathrm{L}$. The protocol of the study had been approved by the local ethics committee and was explained to the volunteers. All subjects had given their written informed consent.

Forty volunteers completed the first dietary period, 35 the first and the second period and 32 subjects completed all three dietary periads. Subjects withdrew 
because of reasons specifically related to the strict study protocol (6 subjects), job or study commitments (2 subjects), family circumstances ( 2 subjects) and ilness (one subject).

Thus, 18 women and 14 men, aged between 20 and 60 years (mean, 41 years old) completed the trial. The women weighed 51 to $96 \mathrm{~kg}$ (mean, $69 \mathrm{~kg}$ ), were between 156 and $183 \mathrm{~cm}$ (mean $166 \mathrm{~cm}$ ) while their body mass indexes varied from 19 to $30 \mathrm{~kg} / \mathrm{m}^{2}$ (mean $25 \mathrm{~kg} / \mathrm{m}^{2}$ ). The men weighed 71 to $101 \mathrm{~kg}$ (mean, $81 \mathrm{~kg}$ ), were between 175 and $188 \mathrm{~cm}$ (mean $179 \mathrm{~cm}$ ), while their body mass indexes varied from 22 to $31 \mathrm{~kg} / \mathrm{m}^{2}$ (mean $25 \mathrm{~kg} / \mathrm{m}^{2}$ ). Four women and 5 men were smokers. None of the selected volunteers received medications known to affect serum lipids. Two women used oral contraceptives and 6 women were postmenopausal. Fasting concentrations of serum lipids ranged from 3.41 to $6.48 \mathrm{mmol} / \mathrm{L}$ (mean, $5.13 \mathrm{mmol} / \mathrm{L}$ or $198 \mathrm{mg} / \mathrm{dL}$ ) for total cholesterol, 0.86 to $2.48 \mathrm{mmol} / \mathrm{L}$ (mean, $1.51 \mathrm{mmol} / \mathrm{L}$ or $58 \mathrm{mg} / \mathrm{dL}$ ) for HDL cholesteral, and 0.26 to $2.53 \mathrm{mmol} / \mathrm{L}$ (mean, $0.93 \mathrm{mmol} / \mathrm{L}$. or $82 \mathrm{mg} / \mathrm{dL}$ ) for serum triacylglycerols. These characteristics did not differ between the people who withdrew and the people who completed the trial.

\section{Design and statistical analyses}

Each participant consumed each of the three different diets during three periods of six weeks. One diet was high in lauric acid, another high in palmitic acid and a third high in oleic acid. Before the study started, subjects were categiorized according to sex and then randomly divided into six groups. Each group received the diets in one of the six possible treatment orders. The three dietary periods were interrupted by wash-out periods of two and three weeks, respectively. During these periods the participants consumed their habitual diets.

Data were analyzed with diet, period, and diet and sex interaction as independent variables. When the analyses indicated a significant effect $(P<0,05)$ of the diet, the Tukey method was used to compare the diets pairwise (14). The data were analyzed using the General Linear Models (GLM) procedure of the Statistical Analyses System (15). Only data of the thirty two subjects, who completed three dietary periods were included in the analyses. Because lipoprotein-(a) (Lp(a)) concentrations were not normally distributed, the untransformed individual changes of Lp(a) were analyzed with the non-parametric Friedman test (16).

\section{Diets}

Before the start of the study, subjects recorded their habitual food intake for two working days and one weekend day, in order to enable us to estimate each subjects" actual energy intake. The food records were coded and the composition of the diets was calcullated using the Dutch food composition table (17). As this method underestimates actual energy intake by on average $10 \%(18)$, the calculated amount of energy was multiplied by 1.1. Diets used in the study consisted of products in which the normal fat was replaced by the experimental fats which were mixtures of natural oils and fats. The fat high in lauric acid was a mixture of palm kernel (75\%) (Wesco; Karlshamns, Zaandijk. The Netherlands) and a high oleic acid sunflower oill (Trisun; 
SVO enterprises, Wickliffe, USA) (25\%), the fat high in palmitic acid consisted of dairy fat $(55 \%)$ (FDF, Leeuwarden, The Netherlands), palmstearin (36\%) (Aarhus oil, Aarhus, Denmark) and sunflower oil $(9 \%)$ and the fat high in oleic acid of dairy fat $(37 \%)$ and sunflower oil $(63 \%)$. Cholesterol was added to the fats high in lauric and oleic acids, so that all fats contained $145 \mathrm{mg}$ of cholesterol per $100 \mathrm{~g}$ of fat. The composition of the experimental fats is given in table 1. In addition, we supplied a high linoleic margarine for preparing dinner meals. In this way we increased the subjects linoleic acid intake to between four and five energy percent. Subjects did not get any payment for the study, except that the products were free. These products included margarines, dairy products (cheese and custards) and bakery products (bread, cake, biscuits and pie).

The calculated fatty acid composition was converted into a list of the available products. Lists were formulated at fifteen levels of energy ranging from 5 to $22 \mathrm{MJ}$ per day. Diets consisted of 40 energy percent of fat $(E n \%)$. The experimental fats provided about 70 percent of total fat energy, which equals $28 \mathrm{En} \%$.

The subjects had to eat a certain amount of the experimental products corresponding with their energy intake. The remaining thirty percent of total fat intake was free and provided by the "free choice" fat containing products. These products were listed and given points according to their fat contents.

Table 1. Fatty acid composition of the experimental fats ( $g / 100 \mathrm{~g}$ fatty acids).

\begin{tabular}{lccc}
\hline & $\begin{array}{c}\text { Lauric Acid } \\
\text { Fat }\end{array}$ & $\begin{array}{c}\text { Palmitic Acid } \\
\text { Fat }\end{array}$ & $\begin{array}{c}\text { Oleic Acid } \\
\text { Fat }\end{array}$ \\
\hline C10:0 & 3.7 & 5.3 & 3.4 \\
C12:0 & 43.8 & 1.9 & 1.2 \\
C14:0 & 15.4 & 6.1 & 3.6 \\
C16:0 & 6.8 & 45.1 & 12.1 \\
C18:0 & 2.4 & 8.7 & 6.5 \\
C18:1 & & & 61.9 \\
C18:2 & 24.4 & 25.2 & 7.1 \\
Others & 3.1 & 1.8 & 4.1 \\
& 0.3 & 5.9 & \\
\hline
\end{tabular}

One point was equal to 1 gram of fat. Each subject was required to eat daily a number of points, again corresponding with his or her energy intake. The free choice items were listed by the subject in a diary. Detailed diet instructions, menu suggestions, suggestions for free choice items and recipes were provided during personal interviews by a registered dietitian and in a three-weekly newspaper. 
The planned fatty acid composition of the three diets was the same except for 8.5 En\% which was provided by either lauric acid, palmitic acid or oleic acid. However, the lauric acid diet contained also 2.2 En\% more myristic acid than the other two diets.

The volunteers came at least once a week to a special room at the department to receive a new supply of products. All products, coded with a blue, red or yellow label to blind the subject, were handed out to the volunteers on an individual basis. The subjects were asked to maintain their usual pattern of activity and not to change their smoking habits or use of contraceptives. They recorded in diaries any signs of illnesses, medication used, alcoholic consumption, menstrual phase, the free choice items selected and any deviations from the study protocol.

Body weight was recorded every week and individual allowances were adjusted to minimize weight changes. In each period subjects recorded their food intake for two working days and two weekend days and records were checked by a dietitian. For computing the fatty acid composition of the diets, the various individual saturated fatty acids were added to the Dutch food compasition table (17) manually.

\section{Blood sampling and analyses}

Blood was sampled after an overnight fast and after abstinence from drinking alcohol the preceding day and smoking on the morning before blood sampling. Blood was sampled twice at the end of a dietary period (week 5 and week 6) with minimum stasis and using a $1.2 \mathrm{~mm}$ needle (StrauB Kanule, Luer) with the volunteer in a recumbent position. About $15 \mathrm{~mL}$ blood was taken for additional measurements (to be reported elsewhere) and finally, $10 \mathrm{~mL}$ blood was drawn in a $10 \mathrm{~mL}$ clotting-tube to obtain serum. All vemipunctures were performed by the same person, at the same location, and for each subject generally at the same time of the same day of the week.

Serum was obtained by low-speed centrifugation one hour after venipuncture and stored at $-80^{\circ} \mathrm{C}$. Total cholesterol (CHOD-PAP method; Monotest cholesteroll, Boehringer Mannheim, Mannheim, Germany). HDL cholesterol (precipitation method; Monotest cholesterol, Boehringer Mannheim. Mannheim, Germany) and triacylglycerols (GPO-Trinder; Sigma Diagnostics, St Louis, USA) were analyzed enzymatically. The coefficient of variation within runs was $1.1 \%$ for total cholesterol, $0.4 \%$ for HDL cholesterol and $1.2 \%$ for triacylglycerols. LDL cholesterol was calcullated using the Friedewald equation (19).

Apolipoprotein A-1 (apoA-1) and apolipoprotein B (apoB) were measured in serum, using an immunoturbidimetric reaction (UNI-KIT apoA-I and UNI-KIT apoB, Roche, Basel, Switzerland) and antiserum raised in sheep and rabbits, respectively. The coefficients of variation within runs were $1.9 \%$ for apoA-I and $2.9 \%$ for apoB.

Plasma lipoprotein(a) concentrations were analyzed by Enzyme Linked Immuno Sorbent Assay (ELISA) using a commercial kit (Apo-TEK, Organon Teknika, Maryland, USA). The samples were incubated in microelisa wells coated with a monoclonal antibody that specifically recognizes apolipoprotein(a). Unbound antigen is washed away and the immune complex is further incubated with a horseradish peroxidase coupled to a polyclonal antibody that recognizes apoB. The coefficient of 
variation was $3.9 \%$ within runs. All samples from one subject were analyzed within one run.

The lipid and lipoprotein values obtained for the two sampling days at the end of each dietary period were averaged for data analyses. Samples for apolipoprotein and lipoproten(a) analyses from these two sampling days, however, were pooled and analyzed as such.

\section{RESULTS}

\section{Diets and dietary adherence}

The mean daily energy intake and the composition of the three different diets, as determined by the food records, agreed well with the calculated diet composition (table 2). The intake of oleic acid decreased from 19.0 to $10.3 \mathrm{En} \%$ on the lauric acid diet and to $10.6 \mathrm{En} \%$ on the palmitic acid diet. It was exchanged for extra lauric acid or for palmitic acid. The lauric acid diet, however, also provided some more myristic acid (mean $2.2 \mathrm{En} \%$ ) than the palmitic and oleic acid diets.

The mean amount of fat consumed via "free choice" fat items, as listed daily in the subjects' diary, agreed with the calculated amount and was about $30 \%$ of total fat energy.

The effectiveness of blinding was measured using a questionnaire. Four subjects made a correct guess and recognized all three diets while four other subjects recognized the oleic acid diet only. The taste of experimental products on the three diets, as revealed by the same questionnaire, was almost identical. The palmitic acid margarine and palmitic acid cheese, however, were appreciated less than the margarines and cheeses of the lauric acid and oleic acid diets. Body weights did not differ between the three diets and were $74 \pm 12 \mathrm{~kg}($ mean $\pm S D)$ on the lauric, $75 \pm 12 \mathrm{~kg}$ on the palmitic and $74 \pm 11 \mathrm{~kg}$ on the oleic acid diet.

\section{Serum lipid and lipoproteins}

Table 3 gives the serum lipid and lipoprotein concentrations at the end of each dietary period. Compared with the oleic acid diet, serum total cholesterol concentrations increased by $0.48 \mathrm{mmol} / \mathrm{L}$ or $19 \mathrm{mg} / \mathrm{dL}(\mathrm{P}<0.0001 ; 95 \%$ confidence interval $(\mathrm{Cl}), 0.29$ to $0.67 \mathrm{mmol} / \mathrm{L}$ ) on the lauric acid diet and by $0.26 \mathrm{mmol} / \mathrm{L}$ or 10 $\mathrm{mg} / \mathrm{dL}(\mathrm{P}=0.0012 ; 95 \% \mathrm{Cl}, 0.07$ to $0.46 \mathrm{mmol} / \mathrm{L})$ on the palmitic acid diet. Serum total cholesterol concentrations on the lauric acid diet were also significantly higher 10.22 $\mathrm{mmol} / \mathrm{L}$ or $9 \mathrm{mg} / \mathrm{dL})$ than on the palmitic acid diet $(\mathrm{P}=0.0120 ; 95 \% \mathrm{Cl}, 0.02$ to 0.41 $\mathrm{mmol} / \mathrm{L})$. LDL cholesterol rose by $0.35 \mathrm{mmol} / \mathrm{L}$ or $14 \mathrm{mg} / \mathrm{dL}(\mathrm{P}<0.0001 ; 95 \% \mathrm{Cl}, 0.17$ to $0.52 \mathrm{mmol} / \mathrm{L})$ on the lauric acid diet and by $0.22 \mathrm{mmol} / \mathrm{L}$ or $9 \mathrm{mg} / \mathrm{dL}$ ( $P=0.0026$; $95 \% \mathrm{Cl}_{0}, 0.05$ to $\left.0.39 \mathrm{mmo} / \mathrm{L}\right)$ on the palmitic acid diet; the latter value was not significantly different from the increase on the lauric acid diet $(P=0.09 \uparrow 2 ; 95 \% \mathrm{Cl}$, -0.04 to $0.20 \mathrm{mmo} / \mathrm{L}$ ). Changes in LDL cholesterol concentrations on the two saturated fat diets were not dependent on subjects' LDL cholesterol concentrations on the oleic acid diet (figure 1). 
Table 2. Mean daly intake of nutrients by the 32 subjects while on the lauric acid diet, the palmitic acid diet and the oleic acid diet, as calculated from the recorded food intakes during two working days and two weekend days per period.*

\begin{tabular}{|c|c|c|c|}
\hline & $\begin{array}{l}\text { Lauric } \\
\text { Acid Diet }\end{array}$ & $\begin{array}{l}\text { Palmitic } \\
\text { Acid Diet }\end{array}$ & $\begin{array}{l}\text { Oeic } \\
\text { Acid Diet }\end{array}$ \\
\hline \multicolumn{4}{|l|}{ Energy } \\
\hline MJ/day & $9.3 \pm 2.7$ & $9.8 \pm 2.8$ & $9.4 \pm 2.4$ \\
\hline kcal/day & $2204 \pm 653$ & $2322+662$ & $2232+581$ \\
\hline Protein (En\%) & $14.3+3.0$ & $14.3+2.8$ & $14.0 \pm 3.3$ \\
\hline Fat $(E n \%)$ & $41.5 \pm 5.5$ & $41.0 \pm 5.4$ & $41.8 \pm 5.5$ \\
\hline Saturated FA & $24.3 \pm 3.6$ & $22.5 \pm 3.5$ & 14.543 .0 \\
\hline Lauric acid (C12:0) & $10.6 \pm 2.4$ & $1.9 \pm 0.8$ & $2.5 \pm 1.7$ \\
\hline Myristic acid (C14:0) & $4.2 \pm 0.8$ & $2.2 \pm 0.5$ & $1.9 \pm 0.6$ \\
\hline Palmitic acid (C16:0) & $5.9 \pm 1.5$ & $13.2 \pm 2.3$ & $5.7 \pm 1.1$ \\
\hline Monounsaturated FA & $11.1 \pm 2.1$ & $12.0 \pm 2.1$ & $20.2+3.0$ \\
\hline Oleic acid (cis-C18:1) & $10.3 \pm 1.9$ & $10.6 \pm 1.9$ & $19.0 \pm 2.8$ \\
\hline Polyunsaturated FA & $4.6 \pm 2.1$ & $4.8+2.1$ & $5.5 \pm 1.9$ \\
\hline $\begin{array}{l}\text { Linoleic acid } \\
\text { (cis,cis-C18:2) }\end{array}$ & $4.4 \pm 2.0$ & $4.4 \pm 2.0$ & $5.2 \pm 1.9$ \\
\hline Carbohydrates (En\%) & $43.9 \pm 5.6$ & $44.7 \pm 6.1$ & $44.3 \pm 6.1$ \\
\hline Alcohol $($ En\%) & $1.3 \pm 2.6$ & $0.9 \pm 2.1$ & $0.9 \pm 2.5$ \\
\hline Cholesterol (mg/MN) & $23.9 \pm 10.8$ & $22.8 \pm 8.5$ & $24.9 \pm 10.3$ \\
\hline Dietary fiber ( $g / M J)$ & $2.9 \pm 0.9$ & $2.8 \pm 0.8$ & $2.8 \pm 0.7$ \\
\hline
\end{tabular}

* Values are meanststandard deviations.

HDL cholesterol concentrations increased by $0.14 \mathrm{mmol} / \mathrm{L}$ or $5.4 \mathrm{mg} / \mathrm{dL}$ $(P<0.0001 ; 95 \% \mathrm{Cl}, 0.07$ to $0.22 \mathrm{mmol} / \mathrm{L})$ on the lauric acid diet as compared with the oleic acid diet. The lauric acid diet increased HDL cholesterol $(0.12 \mathrm{mmol} / \mathrm{L}$ or 4.6 $\mathrm{mg} / \mathrm{dL})$ as compared with the palmitic acid diet $(\mathrm{P}=0.0006 ; 95 \% \mathrm{Cl}, 0.04$ to 0.20 $\mathrm{mmol} / \mathrm{L})$. HDL cholesterol concentrations were the same on the palmitic acid diet and the oleic acid diet. The HDL to LDL cholesterol ratio and triacylglycerols did not differ between any of the three diets.

When the analyses included two women and one men who completed only two dietary periods, results were similar. 
Table 3. Serum lipid and lipoprotein cholesterol levels on the three dieis studied."

\begin{tabular}{|c|c|c|c|}
\hline & $\begin{array}{l}\text { Lauric } \\
\text { Acid Diet }\end{array}$ & $\begin{array}{l}\text { Palmitic } \\
\text { Acid Diet }\end{array}$ & $\begin{array}{c}\text { Oleilc } \\
\text { Acid Diet }\end{array}$ \\
\hline \multicolumn{4}{|c|}{ Total chalesterol (mmolli) } \\
\hline All & $5.90 \pm 1.02+\%$ & $5.69+0.93+$ & $5.42+1.02$ \\
\hline Women & $5.91 \pm 1.11+$ & $5.68 \pm 1.05 \dagger$ & $5.35 \pm 1.12$ \\
\hline Men & $5.89 \pm 0.94 \dagger$ & $5.70 \pm 0.79$ & $5.51 \div 0.90$ \\
\hline \multicolumn{4}{|c|}{ LDL cholesterol (mmol/L) } \\
\hline All : & $3.84 \pm 0.99+$ & $3.71 \pm 0.91 \dagger$ & $3.49 \pm 0.94$ \\
\hline Women & $3.82 \pm 1.02+$ & $3.67 \pm 0.99+$ & $3.35 \pm 0.97$ \\
\hline Men & $3.87 \pm 0.98$ & $3.76 \pm 0.83$ & $3.67 \pm 0.90$ \\
\hline \multicolumn{4}{|c|}{ HDL cholesterol (mmol/L) } \\
\hline All & $1.59 \pm 0.45 † *$ & $1.47 \pm 0.40$ & $1.44 \pm 0.38$ \\
\hline Women & $1.67 \pm 0.41$ t* & $1.58 \pm 0.33$ & $1.58 \div 0.37$ \\
\hline Men & $1.47 \pm 0.48+*$ & $1.32 \pm 0.44$ & $1.26 \pm 0.32$ \\
\hline \multicolumn{4}{|c|}{ Triacylglycerols (mmol/L) } \\
\hline All & $1.05 \pm 0.50$ & $1.11 \pm 0.54$ & $1.07 \pm 0.42$ \\
\hline Women & $0.93 \pm 0.33$ & $0.93 \pm 0.35$ & $0.92+0.32$ \\
\hline Men & $1.21 \pm 0.63$ & $1.35 \pm 0.65$ & $1.27 \pm 0.46$ \\
\hline \multicolumn{4}{|c|}{$H D L$ to $L D L$ ratio } \\
\hline All & $0.46 \pm 0.25$ & $0.44 \pm 0.21$ & $0.46 \pm 0.23$ \\
\hline Women & $0.48 \pm 0.21$ & $0.47 \pm 0.19$ & $0.51 \pm 0.20$ \\
\hline Men & $0.44 \pm 0.31$ & $0.39 \pm 0.24$ & $0.39 \pm 0.26$ \\
\hline
\end{tabular}

* Values are meanststandard deviations. Eighteen women and fourteen men consumed all three diets, for six weeks each, in random order. To convert values for total, $L D L$, and HDL cholesterol to milligrams per deciliter, multiply by 38.67. To convert values for triacylglycerols to milligrams per deciliter, multiply by 88.54 .

$\dagger$ Significantly different from the oleic acid diet, $P<0.02$.

* Significantly different from the palmitic acid diet, $P<0.02$. 
Table 4. Serum apolipoprotein A-I and B levels on the three diets studied."

\begin{tabular}{|c|c|c|c|}
\hline & $\begin{array}{l}\text { Lauric } \\
\text { Acid Diet }\end{array}$ & $\begin{array}{l}\text { Palmitic } \\
\text { Acid Dlet }\end{array}$ & $\begin{array}{c}\text { Oleic } \\
\text { Acid Diet }\end{array}$ \\
\hline \multicolumn{4}{|c|}{ Apolipoprotein A-I (mg/L) } \\
\hline All & $1826 \pm 395 \dagger$ & $1735 \pm 368$ & $1670 \pm 304$ \\
\hline Women & $1879 \pm 320 \dagger$ & $1811 \pm 306$ & $1752+318$ \\
\hline Men & $1757 \pm 478 \dagger$ & $1638 \pm 427$ & $1563+257$ \\
\hline \multicolumn{4}{|c|}{ Apolipoprotein B (mg/L) } \\
\hline All & $1206 \pm 343 \dagger$ & $1181+299+$ & $1123 \pm 316$ \\
\hline Women & $1178 \pm 338+$ & $1170 \pm 305+$ & $1069 \pm 317$ \\
\hline Men & $1242+358$ & $1195 \pm 302$ & $1192 \pm 314$ \\
\hline \multicolumn{4}{|c|}{ ApoA-I to ApoB ratio } \\
\hline All & $1.7 \pm 0.7$ & $1.6 \pm 0.6$ & $1.6 \pm 0.6$ \\
\hline Women & $1.8 \pm 0.7$ & $1.7 \pm 0.5$ & $1.8 \pm 0.6$ \\
\hline Men & $1.6 \pm 0.8$ & $1.5 \pm 0.7$ & $1.4 \pm 0.6$ \\
\hline
\end{tabular}

\footnotetext{
* Values are meanststandard deviations. Eighteen women and fourteen men consumed all three diets, for six weeks each, in random order.

+ Significantly different from the oleic acid diet, $P<0.02$.

* Significantly different from the palmitic acid diet, $P<0.02$.
}

ApoA-I and B concentrations are given in table 4. ApoA-I concentrations were increased on the lauric acid diet compared with the oleic acid (156 mg/L, $\mathrm{P}<0.0001$; $95 \% \mathrm{Cl}, 82$ to $231 \mathrm{mg} / \mathrm{L}$ ) and palmitic acid diets ( $90 \mathrm{mg} / \mathrm{L}, \mathrm{P}=0.0178,95 \% \mathrm{Cl}, 16$ to $165 \mathrm{mg} / \mathrm{L}$ ). The mean ratio of apoA-I to HDL cholesterol was $1181 \pm 169 \mathrm{mg} / \mathrm{mmol}$ on the lauric acid diet, $1212 \pm 184 \mathrm{mg} / \mathrm{mmol}$ on the palmitic acid diet, and $1188 \pm 162$ $\mathrm{mg} / \mathrm{mmol}$ on the oleic acid diet and did not differ significantly between the three diets. ApoB concentrations on the lauric and palmitic acid diets were both higher than on the oleic acid diet $(83 \mathrm{mg} / \mathrm{L}, P=0.0015 ; 95 \% \mathrm{Cl}, 26$ to $139 \mathrm{mg} / \mathrm{L}$ and $58 \mathrm{mg} / \mathrm{L}$, $\mathrm{P}=0.0142 ; 95 \% \mathrm{Cl}, 1$ to $114 \mathrm{mg} / \mathrm{L})$ but did not differ between the two saturated-fat diets. The apoB to $L D L$ cholesterol ratio was $317 \pm 59 \mathrm{mg} / \mathrm{mmol}$ on the lauric acid, $322 \pm 63 \mathrm{mg} / \mathrm{mmol}$ on the palmitic acid and $323 \pm 36 \mathrm{mg} / \mathrm{mmol}$ on the oleic acid diet and did not differ between the diets. The apoA-l to apoB ratio (table 4) and $L p(a)$ concentrations (table 5) did not differ between the three diets.

Responses to the diets did not differ significantly between men and women. 
Table 5. Plasma lipoprotein(a) levels on the three diets studied."

\begin{tabular}{lccc}
\hline & $\begin{array}{c}\text { Lauric } \\
\text { Acid Diet }\end{array}$ & $\begin{array}{c}\text { Palmitic } \\
\text { Acld Diet }\end{array}$ & $\begin{array}{c}\text { Oleic } \\
\text { Acid Diet }\end{array}$ \\
\hline $\begin{array}{l}\text { Lipoprotein }(a)(m g / L) \\
\text { All }\end{array}$ & $32(0$ to 929$)$ & $37(0$ to 1049) & $32(0$ to 726$)$ \\
Women & $40(0$ to 929$)$ & $40(0$ to 1049) & $32(0$ to 726$)$ \\
Men & $19(0$ to 765$)$ & $34(0$ to 627$)$ & $32(0$ to 792$)$ \\
\end{tabular}

* Values are median levels (ranges). Eighteen women and fourteen men consumed all three diets, for six weeks each, in random order.

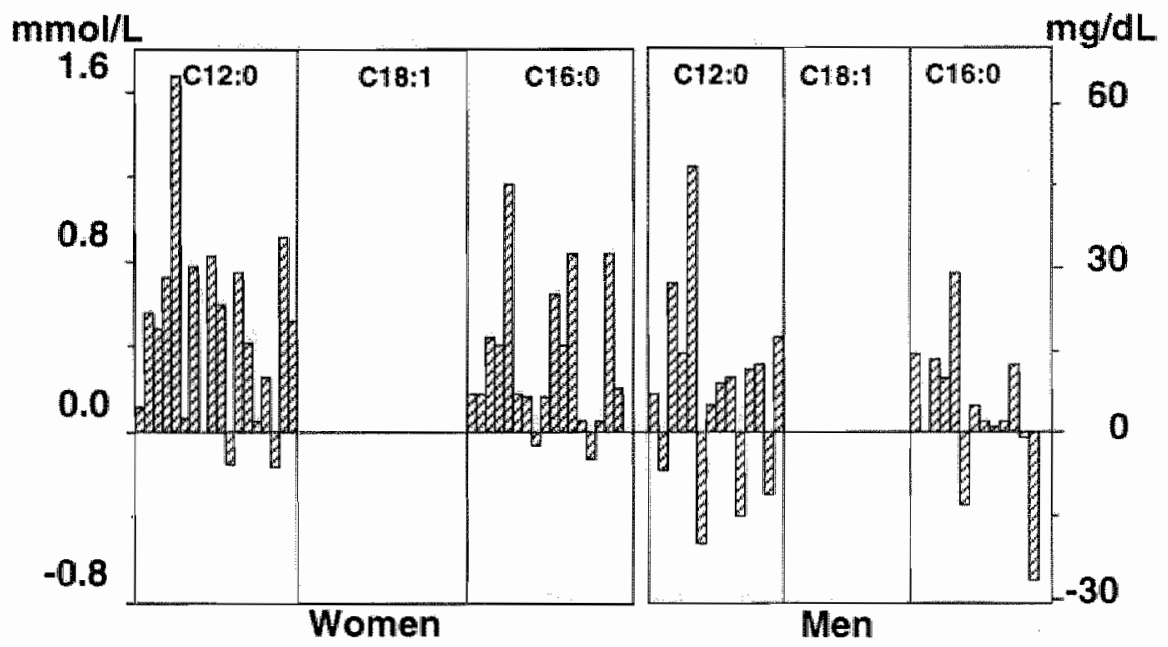

Figure 1. Individual changes in LDL cholesterol levels on diets high in lauric acid (C12:0) or palmitic acid (C16:0), relative to a diet high in oleic acid (C18:1). Subjects are sorted, from left to right, according to LDL cholesterol levels on the oleic acid diet (range 1.51 to $5.28 \mathrm{mmol} / \mathrm{L}$ ). 


\section{DISCUSSION}

\section{Lauric acid versus palmitic acid}

In this study with mixtures of natural fats, we found that a diet high in lauric acid increased serum total cholesterol concentrations compared with a diet high in palmitic acid. The cholesterol raising effect of lauric acid was due to a rise in both LDL and $\mathrm{HDL}$ cholesterol concentrations. In studies with synthetic lauric acid fats incorporated into liquid formula diets, contradictory results were found. Vergroesen and de Boer (20) reported increased serum total cholesterol concentrations of glyceryl trilaurate compared with synthetic tristearate or tripalmitate. Another study (7) showed that lauric acid transesterified with a high-oleic sunflower oil was less potent in raising total and LDL cholesterol concentrations than a natural fat high in palmitic acid. Earlier data of McGandy et al (21) were inconsistent. When trilaurate and tripalmitate were transesterified with a high-linoleic acid safflower oil, serum total and LDL cholesterol concentrations were the lowest on the diet high in lauric acid. Transesterification with olive oil, however, did not demonstrate a difference in the cholesterol-raising potency of lauric and palmitic acid. It is possible that the use of synthetic fats has contributed to these inconsistent results. In a synthetic fat the fatty acids are randomly distributed over the glycerol backbone, whereas in natural fats the distribution depends on the fat source and is not similar among the three positions. Studies on effects of fats with different positional distributions of palmitic and stearic acids, however, do suggest comparable effects on serum lipids and lipoproteins (22, 23). The position of palmitic and stearic acids on the triglyceride molecule does not change their effects on serum lipid concentrations $(22,23)$. Whether these effects can be extrapolated to lauric acid, is not known.

A possible confounding factor in our study might be the higher intake of myristic acid $(2 \mathrm{En} \%)$ on the lauric acid diet compared with the other two diets. The regression equations developed by Hegsted et al (2) suggested that myristic acid is the most potent cholesterol raising saturated fatty acid. Recent studies $(9,24)$ that compared side-by-side effects of myristic acid with those of palmitic acid yielded contradictory results. Zock et al (9) found that myristic acid raised serum total cholesterol about 1.5 and LDL cholesterol concentrations 1.3 times more than palmitic acid, which is less than predicted by the regression equations of Hegsted and co-workers (2). Tholstrup et al (24), on the contrary, found similar effects of myristic and palmitic acids on total and LDL cholesterol concentrations. Finally, Vergroesen and de Boer reported comparable effects of lauric and myristic acids on serum cholesterol concentrations (20). However, in our study lauric acid is still hypercholesterolemic relative to palmitic acid, even if we adjust our data for the possible potent cholesterolemic effect of myristic acid (9).

The effects of natural fats high in lauric acid have further been examined with coconut and palm kernel fat or mixtures of these two fats. These studies show, in general, increased total, LDL and HDL concentrations compared with palm oil $(3,4$, $12,25)$. 
About half of the cholesterol-raising effect of the lauric acid diet was due to increased HDL cholesterol concentrations (table 3). Elevated HDL cholesteral concentrations were also found by Denke and Grundy (7), although the difference did not reach statistical significance. Raised HDL concentrations are furthermore reported in studies on coconut fat versus palm oil (3) and in studies that specifically investigated mixtures of lauric and myristic acids versus palmitic acid $(12,24,25)$. Also myristic acid increased HDL cholesterol compared with palmitic acid (9).

\section{Palmitic acid versus oleic acid}

In this study, a $7.5 \mathrm{En} \%$ exchange from oleic acid for palmitic acid increased serum total cholesterol concentrations by $0.26 \mathrm{mmol} / \mathrm{L}$. This response was caused by increased LDL cholesterol without a concomitant rise in HDL cholesterol concentrations. Other studies on the effects of palmitic acid relative to oleic acid have reported similar findings (7-10). Some investigators, however, have hypothesized that palmitic acid is only hypercholesterolemic in situations where the LDL receptors are down-regulated (11). Thus, in normo-cholesterolemic lean subjects consuming diets with relatively small amounts of cholesterol and adequate linoleic acid concentrations, palmitic and oleic acids are supposed to be neutral as has been reported by $\mathrm{Ng}$ et al (12) and Choudhury et al (13). In the present study a downregulation of the LDL receptors is not expected because the subjects were normocholesterolemic while the diets were low in cholesterol and contained adequate amounts of linoleic acid. Nevertheless, palmitic acid was cholesterolemic relative to oleic acid. In addition, figure 1 does not suggest that changes in LDL cholesterol concentration are dependent on the subjects' concentration on the oleic acid diet. Also in other studies palmitic acid raised total and LDL cholesterol concentrations in normocholesterolemic subjects $(7,9,10)$, even when the diets were cholesterol free (7) or when subjects were young and lean (9). An important difference between these studies $(7-10,12,13)$ is total daily fat intake of the diets. Daily fat intake was $40 \mathrm{En} \%$ in studies that demonstrated hypercholesterolemic effects of palmitic acid (7-10) and around $32 \mathrm{En} \%$ in the studies that found similar effects of palmitic and oleic acids $(12,13)$. Therefore, it should be examined if total daily fat intake might moderate the cholesterolemic effect of palmitic acid.

\section{Apolipoproteins and Ilpoprotein(a)}

Changes in apolipoproteins $B$ and $A-1$ concentrations reflected those of LDL and HDL cholesterol, respectively. Differences belween diets did not result in altered apoB to LDL cholesterol or apoA-1 to $\mathrm{HDL}$ cholesterol ratios. It has been suggested that increased apoB to LDL cholesterol ratio and thus small LDL particles rich in apoB are associated with increased atherogenicity of the LDL particles (26). Mensink et al (27) have reported that a mix of saturated fatty acids decreased the apoB to LDL cholesterol ratio of saturated fatty acids compared with both trans- and cis-isomers of oleic acid. Results of Zock et al (9) indicated lower ratios on myristic and palmitic acid diets compared with oleic acid. The present results, on the contrary, do not indicate differences in apoB to $L D L$ ratio on the two diets high in saturated fatty acids. Also in 
the guinea pig no effects were found of different saturated fatty acids from palm kernel oil or palm oil on LDL particle size (28).

No differences were found in the concentrations of $L p(a)$ on the three diets. This finding agrees with the results of a recent study $(29$, abstr) which compared the effects of lauric plus myristic acid versus palmitic acid. In that study, however, stearic acid increased $L p(a)$ concentrations, which suggests that the different saturated fatty acids do not have similar effects on $L p(a)$. Results of another study from our lab suggested that a mixture of saturated fatty acids with 12 to 16 carbon atoms decreases $L p(a)$ concentrations compared with oleic acid (30). Other (31) and the present results do not indicate an $L p(a)$ lowering effect of saturates. We do not have an explanation for this apparent discrepancy.

Results from the four days food records and the daily records of the "free choice" fat products gave good confidence that the prescribed diets were actually eaten. Our findings therefore suggest that, at $40 \mathrm{En} \%$ of total fat intake, both lauric acid and palmitic acid are hypercholesterolemic compared with oleic acid. Lauric acid raises serum total cholesterol concentrations more than palmitic acid, which is partly due to a stronger rise in $\mathrm{HDL}$ cholesterol. 


\section{REFERENCES}

1. Keys A, Anderson JT, Grande F. Serum cholesterol response to changes in the diet. IV. Particular saturated falty acids in the diet. Metabolism 1965;14:776-786.

2. Hegsted DM, McGandy RB, Myers ML, stare FJ. Quantitative effects of dietary fat on serum cholesterol in man. Am J Clin Nutr 1965; 17:281-295.

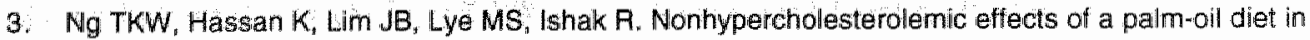
Malaysian wolunteers. Am J Clin Nutr 1991;53:10158-1020S.

4. Tholstrup T, Marckmann P, Jespersen J, Sandstrom B. Fat high in stearic acid favorably affects blood lipids and factor VIl coagulant activity in comparison with fats high in palmitic acid or high in myristic and lauric acids. Am J Clin Nutr 1994;59:371-377.

5. Mensink RP, Katan MB. Effect of dietary fatty acids on serum lipids and lipoproteins: a meta-analysis of 27 trials. Arterioscler Thromb 1992;12:911-919.

6. Dougherty RM, lacono JM. Dietary lauric acid has similar effects on blood cholesterol as paimitic acid in natural diets in man (abstract). FASEB $\cup 1992 ; 6: A 1680$.

7. Denke MA, Grundy SM. Comparison of effects of lauric acid and palmitic acid on plasma lipids and lipoproteins. Am J Clin Nutr 1992;56:895-898.

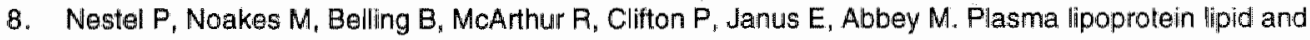
Lp[a] changes with substitution of elaidic acid for oleic acid in the diet. J Lipid Res 1992;33:10291036.

9. Zock PL, de Vries JHM, Katan MB. Impact of myristic acid versus palmitic acid on serum lipid and lipoprotein levels in healthy women and men. Arteriosel Thromb 1994;14:567-575.

10. Bonanome A, Grundy SM. Effect of dietary stearic acid on plasma cholesterol and lipoprotein leveis. N Engl I Med 1988;318:12444-1248.

11. Hayes KC, Khosla P. Dietary fatty acid thresholds and cholesterolemia. FASEB N 1992:6:26002607.

12. $\mathrm{Ng}$ TKW, Hayes KC, DeWitt GF, Jegathesan $M$, Satgunasingam $N$, Ong ASH, Tan D. Dielary palmitic and oleic acids exert similar effects on serum cholesterol and lipoprotein profiles in normocholesteremic men and women. J Am Coll Nutr 1992;11:383-390.

43. Choudhury N, Tan L, Truswell AS. Comparison of palmolein and olive oil: effects on plasma lipids and vitamin $E$ in young adults. Am J Cin Nutr 1995:61:1043\%1051.

14. Snedecor GW, Cochran WG. Statistical methods.7th ed. Ames, lowa: The lowa State University Press, 1980.

15. SAS Institute Inc. SAS: user's Guide Statistics, Version 5 Edition.Cary, NC: SAS Institute Inc, 1985.

16. Conover WJ. Practical nonparametric statistics. New York: John Wiley and Sons, 1980.

47. Stichting NEVO. NEVO tabel, Nederlands woedingstoffenbestand (Outch food composition table). Den Haag: Voorlichtingsbureau voor de Voeding. 1989.

18. de Vries $\mathrm{JHM}$, Zock PL, Mensink RP, Katan MB. Underestimation of energy intake by 3-d records compared with energy intake to maintain body weight in 269 nonobese adults. Am J Clin Nutr 1994:60:855-860.

19. Friedewald WT, Levy AI, Frederickson DS. Estimation of the concentration of low-density lipoprotein cholesterol in plasma, without use of preparative ultracentrifuge. Clin Chem 1972;18:499-502.

20. Vergroesen AJ, De Boer J. Effecten wan meervoudig onverzadigde en andere vetzuren in de voeding. Voeding 1971;32:278-290. 
21. McGandy RB, Hegsted DM, Myers ML. Use of semisynthetic lats in determining effects of specific dietary fatty acids on serum lipioss in man. Am J Clin Nutr 1970;23:1288-1298.

22. Grande $F$, Anderson JT, Keys A. Comparison of effects of palmitic and stearic acids in the diet on serum cholesterol in man. Am J Clin Nutr 1970;23:1184-1193.

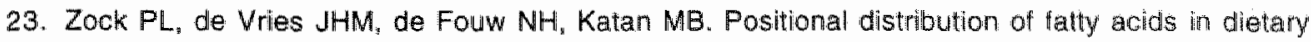
triglycerides: effects on fasting blood lipoprotein levels in humans. Am J Clin Nutr 1995;61:48-55.

24. Tholstrup T, Marckmann P, Jespersen J, Vessby B, Jarl A, Sandström B. Effect on blood lipids, coagulation, and fibrinolysis of a fat high in myristic acid and a falt high in palmitic acid. Arn $\cup$ Clin Nutr 1994;60:919-925.

25. Sundram K. Hayes $\mathrm{KC}$, Siru $\mathrm{OH}$. Dietary palmitic acid results in lower serum cholesterol than does a lauric-myristic acid combination in normolipemic humans. Am J Clin Nutr 1994;59:841-846.

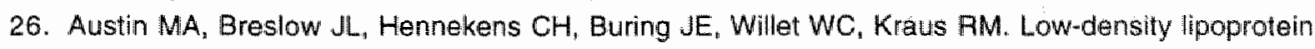
subclass patterms and risk of myocardial infarction. JAMA 1988;260:1917-1921.

27. Mensink RP, Katan MB. Effect of dietary trans fatty acids on high-density and low-density lipoprotein cholesterol levels in healthy subjects. N Engl I Med 1990;323:439-445.

28. Fernandez ML, Lin ECK, MCNamara DJ. Differential effects of saturated fatty acids on low density lipoprotein metabolism in the guinea pig. J Lipid Res 1992;33:1833-1842.

29. Tholstrup $T$, Vessby $B$, Sandström $B$. Effect of individual dietary saturated fatty acids on plasma lipoprotein[a] levels in young healthy men (abstract). Atherosclerosis 1994;109:279.

30. Mensink RP, Zock PL, Katan MB, Hornstra G. Effect of dietary cis and trans fatty acids on serum lipoprotein[a] levels in humans. $J$ Lipid Res 1992:33:1493-1501.

31. Brown SA, Morrisett J, Patsch JR, Reeves R, Gotto AM, Patsch W. Influence of short term dietary cholesterol and fat on human plasma Lp[a] and LDL levels. J Lipid Res 1991;32:1281-1289. 



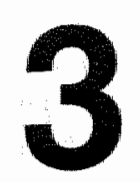

\title{
Effects of medium chain fatty acids (MCFA), myristic acid, and oleic acid on serum lipoproteins in healthy subjects
}

\author{
Elisabeth HM Temme, Ronald P Mensink, Gerard Hornstra \\ Based on: Journal of Lipid Research 1997;38:1746-1754.
}

\section{ABSTRACT}

In this study we investigated the effects on lipoproteins of medium chain fatty acids (MCFA) and myristic acid relative to those of oleic acid. Thirty-seven women and 23 men consumed a 3 wk run-in diet enriched in oleic acid followed by a 6 wk test diet rich in MCFA $(n=21)$, myristic $(n=20)$, or oleic acid $(n=19)$. Experimental fats were incorporated into solid foods. Total fat intake was $40 \mathrm{En} \%$ fat. The dietary compositions were the same except for $10 \mathrm{En} \%$, which was provided by MCFA, myristic or oleic acids, respectively. With the myristic acid diet, LDL cholesterol was $0.37 \mathrm{mmol} / \mathrm{L}$ higher compared with the oleic acid diet $(P=0.0064$ for difference in changes). The MCFA diet increased LDL cholesterol, though not significantly, with $0.23 \mathrm{mmol} / \mathrm{L}$ relative to the oleic acid diet $(P=0.0752)$. Compared with the oleic acid diet, HDL cholesterol concentrations increased with the myristic acid diet by 0.10 $\mathrm{mmol} / \mathrm{L}(\mathrm{P}=0.0273)$ but not with the MCFA diet. The MCFA diet slightly elevated triacylglycerol concentrations, but responses did not significantly differ between the diets. The MCFA diet significantly decreased the apoA-I to apoB ratio compared with both other diets $(P<0,02)$. We conclude that MCFA raise $L D L$ cholesterol concentrations slightly and affect the apoA-I to apoB ratio unfavorably compared with oleic acid. Myristic acid is hypercholesterolemic, although less than predicted earlier, and raises both LDL and HDL cholesterol concentrations compared with oleic acid. 


\section{INTRODUCTION}

Medium Chain Fatty Acids (MCFA) that have between six and ten carbon atoms are not only used in diets for patients with malabsorption disorders, but also in structured lipids like caprenin (50\% caprylic acid (C8:0) plus capric acid (C10:0), and $45 \%$ behenic acid (C22:0)). After absorption, the transport of MCFA through the blood differs from longer chain fatty acids. MCFA are not incorporated into triacylglycerols packaged with chylomicrons as longer chain fatty acids are, but are transported primarily through the portal vein to the liver and provide the body with a fapid source of energy (1). It has been suggested that effects of MCFA on serum cholesterol are similar to those of carbohydrates (2), but whether the effects of MCFA on different lipoproteins are indeed comparable remains to be determined. Studies carried out to investigate effects of MCFA on lipoproteins found total cholesterol levels similar to concentrations on western diets $(3-5)$, increased triacylglycerol concentrations $(3,4)$, and decreased HDL concentrations $(3,5)$. These studies, however, were of short duration (3) and were carried out with a limited number of subjects $(4,6)$. In addition, the amount of MCFA was not the only variable among the experimental diets (3-7).

Certain edible fats like coconut oil, palm kemel oil and butterfat do not only contain considerable amounts of MCFA, but are also rich in myristic acid. Myristic acid might be the most potent cholesterol-raising fatty acid $(8,9)$. Recent studies in healthy volunteers consuming diets enriched in myristic acid, however, yielded contradictory results $(10,11)$. Compared to palmitic acid, myristic acid raised total, $L D L$ and HDL cholesterol in one study (10) but only increased HDL cholesterol concentrations in another (11). In both studies, however, myristic acid was less cholesterolemic than predicted by the formula developed by Hegsted et al (8). We, therefore, decided to compare in healthy volunteers the effects on serum lipids and lipoproteins of an MCFA and a myristic acid enriched diet with those of a diet enriched in oleic acid.

\section{SUBJECTS AND METHODS}

\section{Subjects}

The volunteers were recruited via advertisements in local newspapers and university newsletters, via posters in university buildings and other public buildings and announcements on local radio and television. People responding to the advertisements were informed about the study purposes and requirements. 120 volunteers underwent the selection procedure which consisted of two fasting blood samples taken one week apart to determine serum lipids and lipoproteins, measurement of blood pressure, collection of a urine sample for determination of glucose and protein and a medical questionnaire. Seventy volunteers met our selection criteria. All had serum total cholesterol concentrations below $6.7 \mathrm{mmol} / \mathrm{L}$, blood pressures below $140 / 80 \mathrm{~mm} \mathrm{Hg}$, no glucosuria, no proteinuria and did not use any medication known to affect blood lipids, coagulation, fibrinolysis or platelet aggregation. All selected volunteers gave their written informed consent. 
During the study period seven subjects withdrew. One subject because of job commitments, two subjects because of jllness and four subjects because of reasons specifically related to the strict study protocol. Results of three subjects were excluded from analyses. Two subjects, after being enrolled, started to use medications known to affect blood lipids. The third subject was excluded because her results were highly deviant for most variables possibly due to stressful personal circumstances. LDL cholesterol concentrations of this subject were $3.86 \mathrm{mmol} / \mathrm{L}$ after the oleic acid run-in period and $4.91 \mathrm{mmol} / \mathrm{L}$ after the oleic acid test period.

Thus, analyses included 37 women and 23 men. Women were aged 22-60 y (mean $40 \mathrm{y}$ ), weighed $48-101 \mathrm{~kg}$ (mean $67 \mathrm{~kg}$ ), were between 155 and $183 \mathrm{~cm}$ in height (mean $167 \mathrm{~cm}$ ), while body mass indexes ranged between $20-30 \mathrm{~kg} / \mathrm{m} 2$ (mean $24 \mathrm{~kg} / \mathrm{m}^{2}$ ). The men were aged between $23-59 \mathrm{y}$ (mean $43 \mathrm{y}$ ), weighed $56-88 \mathrm{~kg}$ (mean $78 \mathrm{~kg}$ ), were between 163 and $190 \mathrm{~cm}$ in height (mean $178 \mathrm{~cm}$ ), and had bady mass indexes from 17 to $29 \mathrm{~kg} / \mathrm{m}^{2}$ (mean $25 \mathrm{~kg} / \mathrm{m}^{2}$ ). Nine women were postmenopausal and 10 women used oral contraceptives. Six women and 5 men smoked. In women fasting concentrations of serum lipids ranged from 3.64 to 6.38 $\mathrm{mmol} / \mathrm{L}$ (mean $5.28 \mathrm{mmol} / \mathrm{L}$ ) for total cholesterol 1.12 to $2.98 \mathrm{mmol} / \mathrm{L}$ (mean 1.65 $\mathrm{mmol} / \mathrm{L}$ ) for $\mathrm{HDL}$ cholesterol and 0.17 to $1.94 \mathrm{mmol} / \mathrm{L}$ (mean $0.74 \mathrm{mmol} / \mathrm{L}$ ) for trilacylglycerols. In men fasting concentrations of serum lipids ranged from 4.02 to $6.60 \mathrm{mmol} / \mathrm{L}$ (mean $5.43 \mathrm{mmol} / \mathrm{L}$ ) for total cholesterol, 0.77 to $1.65 \mathrm{mmol} / \mathrm{L}$ (mean 1.23 mmol/L) for HDL cholesterol and 0.07 to $2.72 \mathrm{mmo} / \mathrm{L}$ (mean $1.05 \mathrm{mmol} / \mathrm{L}$ ) for triacylglycerols.

\section{Design and statistical anallyses}

The trial, which was approved by the medical ethics committee of Maastricht University, had a parallel design. During the run-in period all volunteers consumed a diet high in oleic acid for three weeks. They were then divided into three groups. For the next six weeks (the test period), one group consumed the MCFA diet, a second group the myristic acid diet and a third group continued on the oleic acid diet. The groups were stratified for initial serum cholesteral concentrations and sex. The response to the experimental diet was calculated per subject as the change from the end of the run-in period to the end of the MCFA, myristic acid or oleic acid test period. Differences in responses of lipid and lipoprotein concentrations were examined with diet, sex and diet-and-sex interaction as independent variables. The data were analyzed with the General Linear Models (GLM) procedure of the SAS Program (12). When the analyses indicated a significant effect of diet $(P<0.05)$, the diets were compared pair-wise. In addition, $95 \%$ confidence intervals were calculated for the differences between the diets. The results were corrected for 3 -group comparisons by the Bonferroni correction. Because changes in lipoprotein(a) (Lp(a)) concentrations were not normally distributed, the untransformed individual changes of LP(a) were analyzed with the non-parametric Kruskal-Wallis test (13). The a priori power to detect a true difference in total cholesterol concentrations of $8 \%$ between two diets was $80 \%$. 


\section{Diets}

Before the study stanted, the subjects recorded their habitual food intake for two working days and one weekend day. From these food records, each subjects actual energy intake was calculated by using the Dutch food-composition table (14). The study diets were formulated at 13 levels of energy ranging from $5 \mathrm{MJ}$ to $22 \mathrm{MJ}$, so that each subject received a diet that met his or her energy needs. Diets used in the study consisted of products in which the normal fat was replaced by the experimental fats. The products included margarines and bakery products (bread, cookies, pies and cakes). According to the subjects' energy level, lists were computed that stated the amount of experimental products the subject had to eat each day (margarine, bread, and cookies) and each week (cake and pie). These solid foods supplied $63 \%$ ( 25 En\%) of the total fat energy. The remaining $37 \%(15 \mathrm{En} \%)$ of the total fat intake had to be chosen from a list of "free-choice" fat-containing products. These products were given points according to their fat contents. One point was equal to one gram of fat. Each subject was required to eat a certain number of points daily again corresponding with his or her energy intake, and to list the products chosen daily on a special form. The fat composition of the calculated diets was similar except for approximately $10 \%$ of total energy intake, which was provided by MCFA, myristic acid or oleic acid, respectively.

Products were not labeled in the run-in period and were coded with a yellow, red or blue label in the test period to blind the subjects as to the nature of the diets. Products were handed out on an individual basis and were free of charge. Subjects came at least once a week to the university to receive a new supply of products, to be weighed, and to receive new forms to list the free-choice items.

Subjects recorded their food intake on one weekend and two weekdays in the last week of both the run-in and the test period. They were also asked to maintain the same activity level, and smoking and drinking habits throughout the study. They recorded in diaries any signs of illness, medication used, alcohol consumption, menstrual cycle and any deviations from the study protocal.

\section{Experimental fats}

Special experimental fats were developed (Grünau GMBH, Illertissen, Germany). The fat high in MCFA was made by interesterification of $34.0 \%$ palm stearin, $47.6 \%$ high oleic sumfllower oil, $8.4 \%$ sunflower oil, and $40 \%$ medium chain fatty acid (MCT) oil. The composition of the MCT oil was $33.3 \% \mathrm{C} 6: 0,25.3 \% \mathrm{C} 8: 0$, and $41.5 \% \mathrm{C} 10: 0$. The myristic acid fat was made by interesterification of a blend of $34 \%$ palm stearin, $17 \%$ high oleic sunflower oil, $9 \%$ sunflower oil and $40 \%$ trimyristin. The oleic acid fat consisted of a blend of $30 \%$ paim stearin and $70 \%$ high oleic sunflower oil. Margarines were made from the fats and consisted of $83 \%$ fat and $17 \%$ water.

Sn-2 fatty acid composition of the margarines was determined using the Grignard reagent -allyl magnesium- to partially deacylate triacylglycerols leading to a representative mixture of sn-2 monoacylglycerols (15). In addition, the fatty acid composition of total triacylglycerols was determined (see table 1). The percent of each fatty acid at the $s n-2$ position was calculated from the total and the $s n-2$ fatty acid 
compositions. For example, the percent of myristic acid present at the $5 n-2$ position in the experimental margarine as a percent of total proportion myristic acid is:

sn-2 myristic acid / ( $3 \times$ total myristic acid) $\times 100$.

\section{Blood sampling and analyses}

Blood was sampled after an overnight fast and after subjects abstained from drinking alcohol the preceding day and from smoking on the morning before blood sampling. Blood was sampled at the end of the run-in period (week 2 and week 3) and in weeks 6,8 and 9 of the test period. Blood was drawn with minimum stasis using a $1.2 \mathrm{~mm}$ needle (Strauß Kanule, Luer, Wächtersbach, Germany) with the volunteer in a recumbent position. First, $15 \mathrm{~mL}$ blood was taken for additional measurements (to be reported elsewhere), while the last $10 \mathrm{~mL}$ blood was drawn into a $10 \mathrm{~mL}$ clotting-tube for serum lipid and lipoprotein measurements. All venipunctures were performed by the same person, at the same location, and for each subject generally at the same time of the same day of the week.

Total cholesterol (CHOD-PAP method; Monotest cholesterol, Boehringer Mannheim, Mannheim, Germany), HDL cholesterol (precipitation method; Monotest cholesterol, Boehringer Mannheim, Mannheim, Germany) and triacylglycerols (GPOTrinder; Sigma Diagnostics, St Louis, MO) were analyzed enzymatically. The coefficient of variation within runs was $1.0 \%$ for total cholesterol, $2.6 \%$ for HDL cholesterol and $1.5 \%$ for triacylglycerols. LDL cholesterol was calculated using the Friedewald equation (16).

Apolipoprotein (apo) $\mathrm{A}-\mathrm{I}$ and $\mathrm{apoB}$ were measured in serum by using an immunoturbidimetric reaction (UNII-KIT apoA-I and UNI-KIT apoB, Roche, Basel, Switzerland) and antiserum raised in sheep and rabbits, respectively. The coefficients of variation within runs were $1.1 \%$ for apoA-I and $1.5 \%$ for apoB.

Lipoprotein(a) (Lp(a)) was measured in serum by an enzyme linked immunosorbent assay (ELISA) (TintElyseLp(a), Biopool, Umea, Sweden). The Lp(a) from the sample was bound to the Lp(a) antibodies in the wells. Peroxidase conjugated $L p(a)$-antibodies where then used to tag the bound $L p(a)$. After washing away unbound antibodies, the peroxidase substrates were added. The extinction of the yellow color that developed was directly proportional to the amount of $L p(a)$ present in the sample. The coefficient of variation was $6.3 \%$ within runs. 


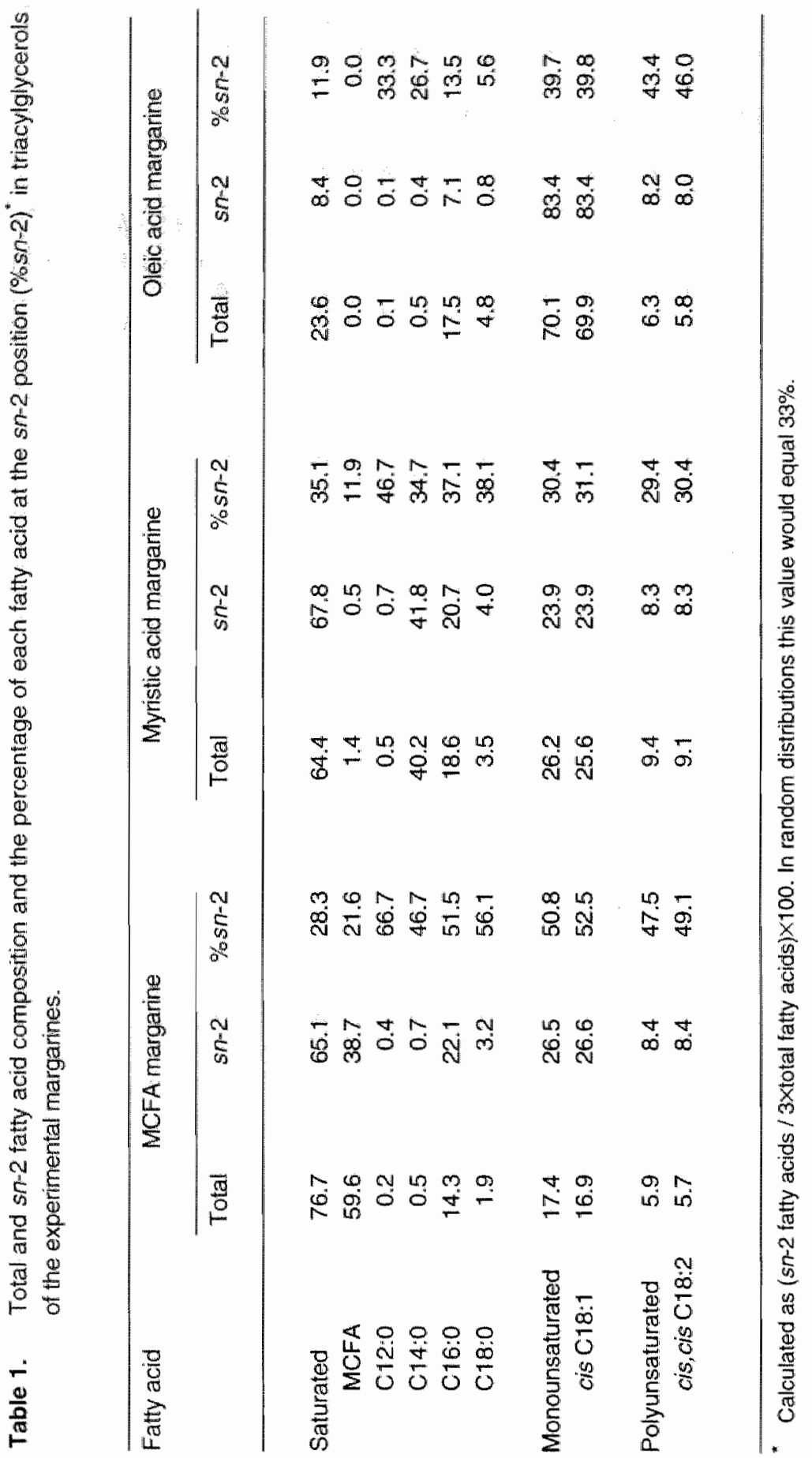


Serum was obtained by centrifugation at $2000 \mathrm{~g}\left(10 \mathrm{~min}, 4^{\circ} \mathrm{C}\right)$ one hour after venipuncture and stored at $-80^{\circ} \mathrm{C}$. The lipid and lipoprotein concentrations obtained for the two sampling days at the end of the run-in (week 2 and week 3 ) and the test period (week 8 and week 9) were averaged for data analyses. Samples of apoA-1, apoB and $L p(a)$ from these two sampling days, however, were pooled and analyzed as such. All samples from one subject were analyzed within one run.

Fatty acid composition of serum total lipids at the end of the run-in and at the end of the test period was determined in samples pooled according to diet and sex. Serum lipids were extracted with a modified Folch extraction (17), and transmethylated to their corresponding methyl esters (18), which were then quantified on a gas chromatograph, with a polar capillary column (CP Sil 88 , Chrompack, Middelburg, The Netherlands) as described before (19).

\section{RESULTS}

\section{Diets and dietary adherence}

Table 1 shows the total and $s n-2$ fatty acid composition of the experimental margarines and the percentage of each fatty acid at the $s n-2$ position. In the MCFA margarine, $22 \%$ of MCFA was attached to the $s n-2$ position and the remaining $78 \%$ to either the $s n-1$ or the $s n-3$ position. Palmitic acid, oleic acid and linoleic acid, the other major fatty acids in this fat were mainly on the sn-2 position. In the myristic acid margarine, myristic acid and the other major fatty acids (palmitic, oleic and linoleic acids) were equally distributed among each position of the glycerol molecule.

The composition of the diets, as determined by a three days food record, is given in table 2. The average intake of oleic acid was $15.1 \mathrm{En} \%$ during the run-in period and decreased in the test period to $6.6 \mathrm{En} \%$ with the MCFA and to $6.3 \mathrm{En} \%$ with the myristic acid diet. It was exchanged for extra MCFA or myristic acid. Oleic acid intake during the oleic acid diet did not change from the run-in to the test period. Changes of other nutrients, except for En\% saturated and monounsaturated fatty acids, did not significantly differ among the diets.

Dietary adherence was confirmed by determination of serum total fatty acid composition. Serum fatty acids with the MCFA diet group showed minor increases in the proportions of total fatty acids in capric acid (from $0.1 \%$ to $0.2 \%$ ), myristic acid (from $1.7 \%$ to $2.0 \%$ ) and stearic acid (from $5.6 \%$ to $6.2 \%$ ). With the myristic acid diet the proportion of myristic acid increased from $2.1 \%$ to $3.2 \%$ of total fatty acids. The proportion of oleic acid with the oleic acid diet was similar after the run-in and test period $(23.0 \%$ and $24.0 \%$ ) but decreased with both the MCFA (from $22.2 \%$ to $18.3 \%$ ) and myristic acid diets (from $25.1 \%$ to $18.8 \%$ ).

Records of "free choice" fat-containing items during the experiment showed minimum deviation from the prescribed grams of "free choice" fat (mean \pm standard deviation: $0 \pm 6 \%$ ). The largest discrepancies were recorded during the first week of the run-in period, when the subjects had to familiarize themselves with the protocol. 
Table 2. Mean daily intake of nutrients as calculated from the recorded food intakes during two weekdays and one weekend day in the run-in and the test period with diets enriched in MCFA ( $n=21)$, myristic acid $(n=20)$ or oleic acid $(n=19)$."

\begin{tabular}{|c|c|c|c|}
\hline $5 \quad 2$. & $\begin{array}{c}\text { MCFA } \\
\text { Diet }\end{array}$ & $\begin{array}{l}\text { Myristic } \\
\text { Acid Diet }\end{array}$ & $\begin{array}{c}\text { Oleic } \\
\text { Acid Diet }\end{array}$ \\
\hline \multicolumn{4}{|l|}{ Energy (Md/day) } \\
\hline Rum-in & $9.2 \pm 3.0$ & $11.0 \pm 3.6$ & $9.8 \pm 2.2$ \\
\hline Test period & $9.1 \pm 2.8$ & $10.9+2.9$ & $9.5 \pm 2.0$ \\
\hline Change & $-0.1 \pm 1.1$ & $-0.2 \pm 1.6$ & $-0.4 \pm 1.4$ \\
\hline \multicolumn{4}{|l|}{ Fat (En\%) } \\
\hline Run-in & $38.7 \pm 6.5$ & $38.4 \pm 4.6$ & $39.7 \pm 3.2$ \\
\hline Test period & $40.4 \pm 3.7$ & $39.7 \pm 4.5$ & $40.0 \pm 3.9$ \\
\hline Change & $1.7 \pm 5.1$ & $1.3 \pm 4.3$ & $0.3 \pm 4.1$ \\
\hline \multicolumn{4}{|l|}{ Saturates } \\
\hline Run-î̀n & $11.3 \pm 2.0$ & $11.3 \pm 1.4$ & $11.7 \pm 1.4$ \\
\hline Test period & $21.3 \pm 2.4$ & $21.0+2.2$ & $11.6 \pm 1.9$ \\
\hline Change & $10.0 \pm 2.2$ & $9.6 \pm 2.1$ & $-0.1+2.0$ \\
\hline \multicolumn{4}{|l|}{ MCFA ${ }^{\dagger}$} \\
\hline Run-in & $0.0 \pm 0.0$ & $0.0+0.0$ & $0.0 \pm 0.0$ \\
\hline Test period & $9.9 \pm 1.9$ & $0.0 \pm 0.0$ & $0.0 \pm 0.1$ \\
\hline Change & $9.9 \pm 1.9$ & $0.0 \pm 0.0$ & $0.0 \pm 0.1$ \\
\hline \multicolumn{4}{|l|}{ Myristic acid $†$} \\
\hline Run-in & $0.1 \pm 0.2$ & $0.1 \pm 0.1$ & $0.0 \pm 0.0$ \\
\hline Test period & $0.0 \pm 0.0$ & $9.7 \pm 1.6$ & $0.1 \pm 0.0$ \\
\hline Change & $-0.1 \pm 0.1$ & $9.6 \pm 1.6$ & $0.0 \div 0.0$ \\
\hline \multicolumn{4}{|l|}{ Oleic acid $†$} \\
\hline Run-in & $15.0 \pm 4.2$ & $14.8 \pm 2.3$ & $15.7 \pm 1.6$ \\
\hline Test period & $6.6 \pm 1.3$ & $6.3 \pm 1.0$ & $16.7 \pm 2.8$ \\
\hline Change & $-8.5 \pm 4.0$ & $-8.5 \pm 2.1$ & $0.9 \pm 2.3$ \\
\hline \multicolumn{4}{|l|}{ Linoleic acid } \\
\hline Run-in & $4.0 \pm 0.8$ & $4.0 \pm 0.9$ & $3.7 \pm 0.5$ \\
\hline Test period & $4.0+0.6$ & $4.0 \pm 0.8$ & $4.0 \pm 0.5$ \\
\hline Change & $0.0 \pm 0.7$ & $0.0 \pm 0.8$ & $0.3+0.8$ \\
\hline
\end{tabular}


Table 2 continued.

\begin{tabular}{|c|c|c|c|}
\hline & $\begin{array}{c}\text { MCFA } \\
\text { Diet }\end{array}$ & $\begin{array}{l}\text { Myristic } \\
\text { Acid Diet }\end{array}$ & $\begin{array}{c}\text { Oleic } \\
\text { Acid Diet }\end{array}$ \\
\hline \multicolumn{4}{|l|}{ Carbohydrates } \\
\hline Run-in & $47.4 \pm 5.5$ & $46.4 \pm 5.2$ & $46.3 \pm 4.0$ \\
\hline Test period & $44.0 \pm 5.5$ & $45.4 \pm 5.6$ & $44.6 \pm 4.9$ \\
\hline Change & $-3.4 \pm 4.9$ & $-1.0 \pm 5.5$ & $-1.7 \pm 4.3$ \\
\hline \multicolumn{4}{|l|}{ Protein } \\
\hline Run-in & $11.8 \pm 2.8$ & $11.9 \pm 1.3$ & $12.4 \pm 1.9$ \\
\hline Test period & $13.3 \pm 3.8$ & $12.2+2.4$ & $12.5 \pm 2.6$ \\
\hline Change & $1.5 \pm 2.2$ & $0.3 \pm 1.3$ & $0.2+2.1$ \\
\hline \multicolumn{4}{|l|}{ Alcohol (mg/MJ) } \\
\hline Run-in & $2.0+2.2$ & $3.1 \pm 3.6$ & $1.6+2.6$ \\
\hline Test period & $2.2 \pm 3.7$ & $2.6 \pm 4.0$ & $2.8 \pm 5.5$ \\
\hline Change & $0.2 \pm 2.5$ & $-0.5 \pm 2.5$ & $1.2+3.9$ \\
\hline \multicolumn{4}{|c|}{ Cholesterol (mg/MJ) } \\
\hline Run-in & $16.3 \pm 4.1$ & $14.4 \pm 3.1$ & $15.8 \pm 5.0$ \\
\hline Test period & $17.0 \pm 4.7$ & $14.8 \pm 5.8$ & $14.3 \pm 4.7$ \\
\hline Change & $0.7 \pm 5.5$ & $0.4 \pm 5.3$ & $-1.5 \pm 4.4$ \\
\hline \multicolumn{4}{|l|}{ Fiber $(\mathrm{g} / \mathrm{MJ})$} \\
\hline Run-in & $2.4 \pm 0.3$ & $2.2 \pm 0.4$ & $2.4 \pm 0.4$ \\
\hline Test period & $2.3 \pm 0.3$ & $2.5 \pm 0.5$ & $2.4 \pm 0.5$ \\
\hline Change & $-0.1 \pm 0.3$ & $0.3 \pm 0.5$ & $-0.1 \pm 0.7$ \\
\hline
\end{tabular}

"Values are meanststandard deviations.

† As provided by the experimental fats only.

Mean body weight (means \pm standard deviations) in the MCFA group was $70 \pm 10$ $\mathrm{kg}$ after the run-in and $70 \pm 10 \mathrm{~kg}$ after the MCFA diet, in the myristic acid group $72 \pm 9$ $\mathrm{kg}$ after the run-in and $72 \pm 10 \mathrm{~kg}$ after the myristic acid diet and in the oleic acid group $71 \pm 12 \mathrm{~kg}$ after the run-in and $71 \pm 12 \mathrm{~kg}$ after the oleic acid diet. Body weights within the diet groups did not differ from the run-in to the end of the test periods.

\section{Serum lipid and lipoproteins}

Mean changes of serum total, LDL and HDL cholesterol concentrations are given in table 3 and in figure 1. Serum total cholesterol concentration increased by 0.55 $\mathrm{mmol} / \mathrm{L}$ when the subjects switched to the myristic acid diet. This change was significantly different from the change with the oleic acid diet (difference in changes of $0.40 \mathrm{mmol} / \mathrm{L} ; \mathrm{P}=0.0057 ; 95 \%$ confidence interval ( $\mathrm{Cl}$ ), 0.10 to $0.69 \mathrm{mmol} / \mathrm{L}$ ). The difference in changes between the MCFA and the oleic acid diet group was 0.23 $\mathrm{mmol} / \mathrm{L}(\mathrm{P}=0.0912 ; 95 \% \mathrm{Cl},-0.06$ to $0.52 \mathrm{mmol} / \mathrm{L})$. LDL cholesterol concentrations 
were 0.37 mmol/L higher with the myristic acid diet compared with the oleic acid diet $(\mathrm{P}=0.0064 ; 95 \% \mathrm{Cl}, 0.09$ to $0.64 \mathrm{mmol} / \mathrm{L})$. The change of $\mathrm{LDL}$ cholesterol with the MCFA diet did not significantly differ from the change with the oleic acid diet (difference in changes of $0.23 \mathrm{mmol} / \mathrm{L} ; \mathrm{P}=0.0752 ; 95 \% \mathrm{Cl},-0.04$ to $0.50 \mathrm{mmol} / \mathrm{L}$ ) and the change with the myristic acid diet (difference in changes of $-0.14 \mathrm{mmol} / \mathrm{L}$; $\mathrm{P}=0.284 ; 95 \% \mathrm{Cl},-0.41$ to $0.13 \mathrm{mmol} / \mathrm{L})$.
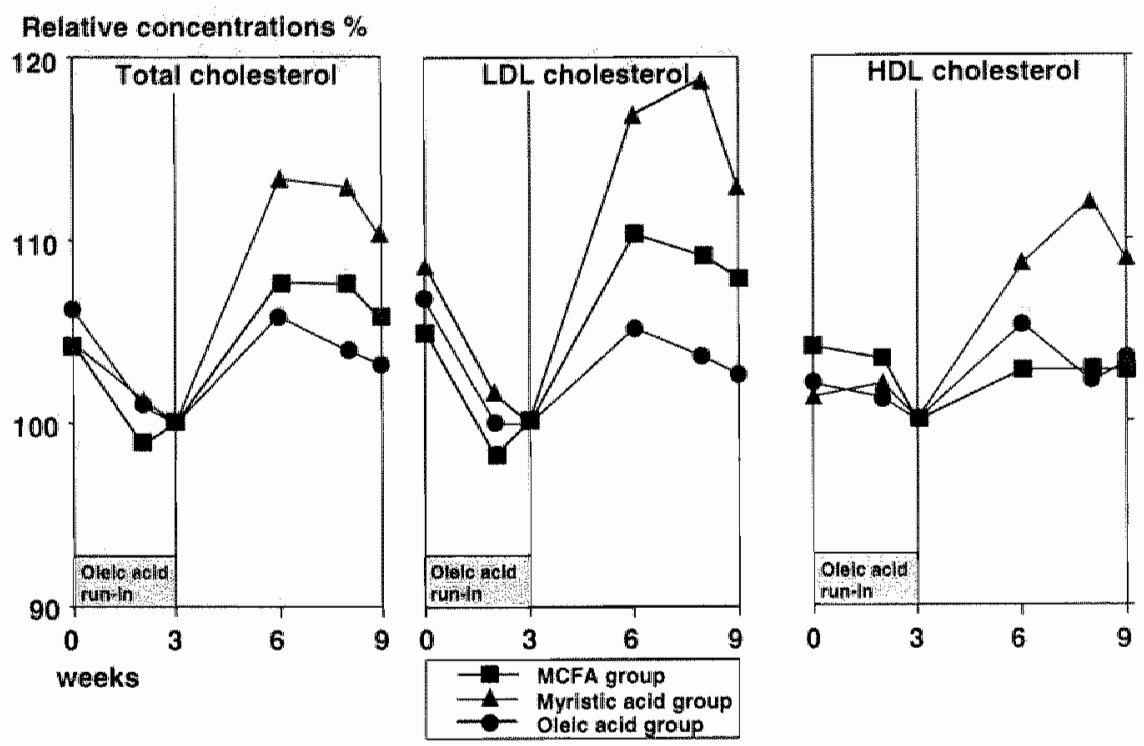

Figure 1. Relative concentrations of serum total, LDL and HDL cholesterol concentrations on diets enriched in MCFA $(n=21)$, myristic $(n=20)$ or oleic acids $(n=19)$. Concentrations of lipids and lipoproteins in week 3 were defined as $100 \%$.

The HDL cholesterol concentration was higher with the myristic acid diet compared with the MCFA diet (difference in changes of $0.11 \mathrm{mmol} / \mathrm{L} ; \mathrm{P}=0.0086 ; 95 \%$ $\mathrm{Cl}_{1} 0.02$ to $0.21 \mathrm{mmol} / \mathrm{L}$ ), and compared with the oleic acid diet (difference in changes of $0.10 \mathrm{mmol} / \mathrm{L} ; P=0.0273 ; 95 \% \mathrm{Cl}, 0.00$ to $0.19 \mathrm{mmo} / \mathrm{L}$ ). The MCFA diet did not raise HDL cholesterol concentrations compared with the oleic acid diet. Although the change in triacylglycerol concentrations with the MCFA diet was greater compared with the myristic acid diet, effects were not significantly different (difference in changes of $0.19 \mathrm{mmol} / \mathrm{L} ; \mathrm{P}=0.0873 ; 95 \% \mathrm{Cl},-0.05$ to $0.44 \mathrm{mmol} / \mathrm{L}$ ). The total cholesterol to HDL ratio increased with the MCFA diet. However, this increase was not significantly different from the change on the other diets. 
Table 3. Serum lipids and lipoprotein concentrations on diets enriched in MCFA, myristic of oleic acids:

\begin{tabular}{|c|c|c|c|}
\hline & $\begin{array}{c}\text { MCFA } \\
\text { Diet }\end{array}$ & $\begin{array}{l}\text { Myristic } \\
\text { Acid Diet }\end{array}$ & $\begin{array}{c}\text { Oleic } \\
\text { Acid Diet }\end{array}$ \\
\hline \multicolumn{4}{|c|}{ Total cholesterol (mmol/L) } \\
\hline Run-in & $5.26 \pm 0.58$ & $5.15 \pm 0.70$ & $5.03 \pm 0.88$ \\
\hline Test period & $5.65 \pm 0.42$ & $5.77 \pm 0.88$ & $5.19 \pm 0.87$ \\
\hline Change & $0.39 \pm 0.39$ & $0.55 \pm 0.51 \dagger$ & $0.16 \pm 0.39$ \\
\hline \multicolumn{4}{|c|}{ HDL cholesterol ( $\mathrm{mmol} / \mathrm{L})$} \\
\hline Run-in & $1.49 \pm 0.32$ & $1.52 \pm 0.54$ & $1.52 \pm 0.32$ \\
\hline Test period & $1.51 \pm 0.32$ & $1.65 \pm 0.60$ & $1.55 \pm 0.32$ \\
\hline Change & $0.02 \pm 0.11 *$ & $0.13 \pm 0.16$ & $0.04 \pm 0.14$ \\
\hline \multicolumn{4}{|c|}{ LDL cholesterol $(\mathrm{mmol} / \mathrm{L})^{\$}$} \\
\hline Run-in & $3.35 \pm 0.67$ & $3.13 \pm 0.76$ & $3.07 \pm 0.81$ \\
\hline Test period & $3.67 \pm 0.63$ & $3.59 \pm 0.88$ & $3.16 \pm 0.83$ \\
\hline Change & $0.32 \pm 0.36$ & $0.46 \pm 0.51 \dagger$ & $0.09 \pm 0.36$ \\
\hline \multicolumn{4}{|c|}{ Triacylglycerols (mmol/L) } \\
\hline Run-in & $0.92 \pm 0.42$ & $1.15 \pm 0.81$ & $0.98 \pm 0.43$ \\
\hline Test periad & $1.02 \pm 0.56$ & $1.11 \pm 0.66$ & $1.04 \pm 0.49$ \\
\hline Change & $0.11 \pm 0.29$ & $-0.09 \pm 0.47$ & $0.06 \pm 0.26$ \\
\hline \multicolumn{4}{|c|}{ Total cholesterol:HDL cholesterol ratio } \\
\hline Run-in & $3.73 \pm 1.09$ & $3.84 \pm 1.50$ & $3.49 \pm 1.14$ \\
\hline Test period & $3.95 \pm 1.08$ & $3.92 \pm 1.63$ & $3.48 \pm 0.97$ \\
\hline Change & $0.21 \pm 0.34$ & $0.08 \pm 0.48$ & $0.00 \pm 0.44$ \\
\hline
\end{tabular}

\footnotetext{
* Values are meanststandard deviations.

t Significantly different from the oleic acid diet, $P<0.02$.

* Significantly different from the myristic acid diet, $P<0.02$.

$\$$ Calculated with Friedewald equation.
}

ApoA-I concentrations increased with the myristic acid diet compared with the MCFA diet (difference in changes of $119 \mathrm{mg} / \mathrm{L} ; \mathrm{P}=0.0093 ; 95 \% \mathrm{Cl}, 22$ to $216 \mathrm{mg} / \mathrm{L}$ ) (Table 4). Changes in apoB concentrations were not significantly different among the three diets. ApoA-I to ApoB ratios significantly decreased with the MCFA compared with the myristic (difference in changes of $-0.15 ; \mathrm{P}=0.0127 ; 95 \% \mathrm{Cl},-0.27$ to -0.02 ) and the oleic acid diet (difference in changes of $-0.14 ; \mathrm{P}=0.0197 ; 95 \% \mathrm{Cl},-0.27$ to $-0.01)$. 
Table 4. Apolipoprotein $A$. and apolipoprotein $B$ concentrations on diets enriched in $M C F A$, myristic or olleic acids."

\begin{tabular}{cccc}
\hline & $\begin{array}{c}\text { MCFA } \\
\text { Diet }\end{array}$ & $\begin{array}{c}\text { Myristic } \\
\text { Acid Diet }\end{array}$ & $\begin{array}{c}\text { Oleic } \\
\text { Acid Diet }\end{array}$ \\
\hline $\begin{array}{c}\text { ApoAl (mg/L) } \\
\text { Run-in }\end{array}$ & $1508 \pm 265$ & $1556 \pm 354$ & $1523 \pm 226$ \\
Test period & $1489 \pm 217$ & $1656 \pm 396$ & $1564 \pm 239$ \\
Change & $-19 \pm 209$ & $100 \pm 115$ & $41 \pm 92$ \\
ApoB (ming) & $898 \pm 153$ & $922 \pm 165$ & $859 \pm 215$ \\
Run-in & $980 \pm 134$ & $998 \pm 201$ & $892 \pm 217$ \\
Test period & $82 \pm 106$ & $77 \pm 124$ & $32 \pm 70$ \\
Change & & & $1.89 \pm 0.60$ \\
ApoA-1:ApoB ratio & $1.74 \pm 0.47$ & $1.76 \pm 0.59$ & $1.86 \pm 0.56$ \\
Run-in & $1.57 \pm 0.42$ & $1.74 \pm 0.58$ & $-0.03 \pm 0.16$ \\
Test period & $-0.17 \pm 0.24+*$ & $-0.02 \pm 0.17$ & \\
Change & & & \\
\hline
\end{tabular}

\footnotetext{
* Values are meanststandard deviations.

+ Significantly different from the oleic acid diet, $P<0.02$.

* Significantlly different from the myristic acid diet, $P<0.02$.
}

Lp(a) concentrations decreased with the myristic acid diet compared with the oleic acid diet ( $P=0.0083$ for difference in changes); (table 5 ). Changes in $L p(a)$ concentrations with the MCFA diet did not differ from those with the myristic acid and the oleic acid diets. Changes in $L p(a)$ concentrations were more pronounced in subjects with higher $L p(a)$ values with the oleic acid run-in period.

For all variables, responses to the diets were similar in women and men.

Table 5. Lipoprotein (a) concentrations on diets enriched in MCFA, myristic or oleic acids."

\begin{tabular}{|c|c|c|c|c|c|c|c|}
\hline \multirow{2}{*}{ Lipoprotein(a) (mg/l } & \multicolumn{2}{|c|}{$\begin{array}{c}\text { MCFA } \\
\text { Diet }\end{array}$} & \multicolumn{2}{|c|}{$\begin{array}{l}\text { Myristic } \\
\text { Acid Diet }\end{array}$} & \multicolumn{3}{|c|}{$\begin{array}{c}\text { Oleic } \\
\text { Acid Diet }\end{array}$} \\
\hline & & & & & & & \\
\hline Run-in & 43 & $(0$ to 677$)$ & 89 & (1 to 691 ) & & 105 & $(0$ to 767$)$ \\
\hline Test period & 95 & $(3$ to 597$)$ & 54 & (2 to 689) & & 118 & $(0$ to 782$)$ \\
\hline Change & 0 & $(-297$ to 95$)$ & -4 & $(-164$ to 202$)$ & $\dagger$ & 13 & $(-34$ to 190$)$ \\
\hline
\end{tabular}

\footnotetext{
Values are given as median levels (ranges)

$\dagger$ Significantly different from the oleic acid diet, $P<0.02$.
} 


\section{DISCUSSION}

In this project we studied the effects on serum lipids and lipoproteins of MCFA, myristic and oleic acids. Results of the food records, serum total fatty acid composition and the daily records of the "free choice" products used indicated good compliance to the strict protocol. The energy percentage of the studied fatty acids was planned to be the only difference among the diets. To achieve this, MCFA and myristic acid were given to the subjects with synthetic fats. As in dairy fat, MCFA from the MCFA fat were mainly attached to the $s n-1$ or $s n-3$ positions of the glycerol molecule. In the myristic acid fat, myristic acid and other saturates were equally distributed among the $5 n-2$ and $s n-1,3$ positions. Myristic acid rich fat sources as palm kemel or coconut fat have myristic acid mainly at the $s n-1,3(20)$, whereas dairy fat carries half of the total proportion of myristic acid at the $s n-2$ position (21). So far, dietary experiments comparing fats rich in palmitic acid $(22,23)$ and stearic acid $(24)$ suggested that the positionall distribution of these saturates did not affect lipid and lipoprotein concentrations. One small study reported that randomized butter oil was less hypercholesterolemic than a non-randomized butter oil diet (25). Although this may suggest that our results underestimate the cholesterol-raising effects of natural fats rich in MCFA and myristic acid, the results of that study (25) are difficult to interpret as only eight subjects were involved. Larger studies are necessary to examine whether the positional distribution of MCFA and myristic acid influences their cholesterolemic effects.

\section{The effects of MCFA}

The exchange of oleic acid by MCFA increased serum total and LDL cholesterol concentrations. The responses, however, did not differ significantly from the responses in the oleic acid and myristic acid diet groups. Other studies have reported similar serum total or LDL cholesterol concentrations with MCFA and western experimental or western habitual diets (3-5). These latter diets were high in saturated fatty acids, which cause higher plasma cholesterol levels than high oleic acid diets (26). Therefore, these earlier studies can also be interpreted as demonstrating a moderate cholesterol-raising effect of MCFA compared with oleic acid. In agreement, a recent study (27) demonstrated plasma total and LDL cholesterol raising effects of both diets rich in MCFA or palmitic acid compared with a diet rich in a high oleic acid sunflower oil.

Although the MCFA diet slightly increased triacyiglycerol concentrations compared with myristic acid, triacylglycerol responses were not signiticantly different among the three diets. Other authors $(3,4)$ reported considerably elevated serum triacylglycerol concentrations with MCFA diets. In these studies $(3,4)$, however, diets provided $32 \mathrm{En} \%$ as MCFA, whereas in the present study only 10 En\% MCFA was given. MCFA probably raise triacylglycerols in a dose dependent manner as McGandy et al (4) demonstrated that a diet with 18 En\% MCFA caused a smaller increase of serum triacylglycerol concentrations than a diet with 32 En\% MCFA (4). In agreement with our results, diets with 6 En\% MCFA did not significantly increase 
serum triacylglycerol concentrations (5). However, in studies that applied diets with high energy percentages of MCFA $(3,27)$ increased triacylglyceral concentrations did not affect the composition of the VLDL particles (3) or the ratio of triacylglycerol to VLDL cholesterol concentrations (27).

Compared with the oleic acid diet, the MCFA diet did not change HDL cholesterol nor did it change apoA-I concentrations. Also Cater et al (27) demonstrated similar HDL cholesterol concentrations on diets rich in MCFA or oleic acid. Diets enriched in carbohydrates, however, showed significantly decreased HDL cholesterol and apoA-I concentrations and similar LDL cholesterol concentrations compared with oleic acid (28). Thus, effects of MCFA on HDL cholesterol and apoA-I concentrations are likely to differ from those of carbohydrates, but this hypothesis needs to be confirmed in studies that compare the effects of MCFA and carbohydrates side-by-side.

In addition to slightly raised LDL cholesterol concentrations after the MCFA diet, other potent lipid predictors of coronary heart disease $(29,30)$-the ratio of apoA- 1 to apoB and the total to HDL cholesterol ratio-, were unfavorably changed by this diet, although the latter ratio was not signifficantly different among the three diets.

\section{The effects of myristic acid}

Serum total cholesterol concentrations with the myristic acid diet increased with $0.55 \mathrm{mmol} / \mathrm{L}$ when $10 \mathrm{En} \%$ from oleic acid was replaced by myristic acid. This change was the result of both an increase in both LDL and HDL cholesterol concentrations. Zock et al (10) found an increase in total cholesterol of $0.66 \mathrm{mmol} / \mathrm{L}$ when the intake of myristic acid increased by $10 \mathrm{En} \%$ at the expense of oleic acid. Changes are smaller than predicted from the regression equations of Hegsted et al (8). This equation estimates that total cholesterol concentrations would increase with 2.19 mmol/L when 10 En\% from oleic acid is replaced by myristic acid.

The HDL cholesterol raising effect of myristic acid was also found by other investigators $(10,11)$. In our earlier study (31), a comparable increase of $10 \%$ was found when $8 \mathrm{En} \%$ of lauric acid was exchanged for oleic acid. Raised HDL cholesterol concentrations were also reported in studies on coconut versus palm oil (32) and in studies that specifically investigated mixtures of lauric and myristic acids versus palmitic or oleic acids $(33,34)$. In addition, higher HDL cholesterol concentrations on western diets compared with MCFA diets $(3,5)$ might also be due to increased intakes of lauric or myristic acids with the western diets. It is possible that a lower plasma cholesterol ester transfer protein (CETP) activity may have contributed to the higher HDL cholesterol concentration on the myristic acid diet. An in vitro study indeed indicated a lower rate of CETP-mediated transfer of lauric or myristic acid rich cholesteryl esters from synthetic HDL compared with longer chain saturated fatty acids (35). The inverse relation between CETP activity and HDL cholesterol concentrations was also demonstrated in human studies comparing diets rich in trans fatty acids with those rich in linoleic or oleic acids $(36,37)$. However, as compared with a safflower oil diet two myristic acid rich diets - one high in butter fat and the other high in coconut fat-, induced similar HDL cholesterol concentrations, but the cholesterol ester transfer activity was increased on the butter and not on the 
coconut fat diet (38). Clearly, more studies are needed to clarify the regulatory mechanism behind changes in HDL cholesterol concentrations.

Myristic acid decreased $L p(a)$ compared with oleic acid which emphasized that $L p(a)$ concentrations were regulated independently from LDL cholesterol concentrations. From another study (39) it was concluded that oleic acid raised $L p(a)$ levels relative to a mixture of saturated fatty acids. In our previous study we did not observe decreased $L p(a)$ concentrations when comparing lauric or palmitic acids with oleic acid (31). The suggestion, however, that myristic acid in particular decreases $L p(a)$ concentrations is not supported by a recent study reporting similar $L p(a)$ concentrations after diets rich in myristic or palmitic acids (40).

To summarize, the MCFA diet increased total and LDL cholesterol slightly, though not significantly, but not HDL cholesterol concentrations compared with the oleic acid diet. The MCFA diet unfavorably affected the apoA-I to apoB ratio compared with both other diets. Myristic acid is a hypercholesterolemic saturated fatty acid although responses on serum total cholesterol concentrations are smaller than has been suggested earlier (8). Part of the cholesterolemic effect of myristic acid is due to increased HDL cholesterol concentrations.

\section{ACKNOWLEDGMENTS}

We appreciate the analyses of the sn-2-monoglyceride fatty acid composition of the margarines by Dr C-E Høy and Dr H Mu (Department of Biochemistry and Nutrition, Technical University of Denmark, Lyngby, Denmark). 


\section{REFERENCES}

1. Guillot $E_{\text {. Vaugelade }}$, Lemarchal P, Rerat A. Intestinal absorption and liver uptake of medium-chain fatty acids in non-anaesthetized pigs. $B r$ J Nutr 1993;69:431-443.

2. Grundy $S M$, Denke MA. Dietary influences on senum lipids and lipoproteins. I Lipid Res $1900 ; 31: 1149-1172$.

3. Swift LL, Hill JO, Peters JC, Greene HL. Plasma hipids and lipoproteins during 6 d of maintenance feeding with long-chain, medium-chain, and mixed-chain triglycerides. Am J Clin Nutr 1992;56:881886.

4. McGandy RB, Hegsted DM, Myers ML. Use of semisynthetic fats in determining effects of specific dietary fatty acids on serum lipids in man. Am J Clin Nutr 1970;23:1288-1298.

5. Wardlaw GM, Snook UT, Park S, Patel PK, Pendley FC, Lee M, Jandacek RJ. Relative effects on serum lipids and apolipoproteins of a caprenin-rich diet compared with diets rich in palm oily palmkernel ofl or butter. Am J Cinn Nutr 1995;61:535-542.

6. Hashim SA, Arteaga A, van Itallie TB. Effect of saturated medium-chain triglycenide on serum-lipids in man. Lancet 1960;1:1105:1108.

7. Beveridge IMR, Connell WF, Haust HL, Mayer GA. Dietary cholesterol and plasma cholesteral levels in man. Can J Biochem Physiol 1959;37:575-582.

8. Hegsted DM, McGandy AB, Myers ML, Stare FJ. Quantitative effects of dietary fat on serum cholesterol in man. Am J Clin Nutr 1965;17:281-295.

9. Hayes KC Khosla P. Dietary fatty acid thresholds and cholesterolemia. FASEB I 1992;6:26002607.

10. Zock PL, de Vries JHM, Katan MB. Impact of myristic acid versus palmitic acid on serum lipid and lipoprotein levels in healthy women and men. ArteriosclerThromb 1994;14:567-575.

11. Tholstrup T, Marckmann P, Jespersen J, Vessby B, Jart A, Sandström B. Effect on blood lipids. coagulation, and fibrinolysis of a fat high in myristic acid and a fat high in palmitic acid. Am J Clin Nutr 1994;60:919-925.

12. SAS Institute Inc. SAS: user's Guide Statistics, Version 5 Edition.Cary, NC: SAS Institute Inc, 1985.

13. Slegel S, Castellan NJ. Nonparametric Statistics for the Behavioral Sciences. Singapore: McGraw-Hill Book Co, $1988: 1.399$.

14. Stichting NEVO. NEVO tabol, Nederlands woedingstoffenbestand (Dutch foad composition table). Den Haag: Voorlichtingsbureau woor de Voeding, 1989.

15. Becker $\mathrm{CC}$, Rosenquist $\mathrm{A}_{\mathrm{e}}$ Holmer $\mathrm{G}$. Regiospecific analysis of triacylglycerols using allyl magnesium bromide. Lipids 1993:28:147-149.

16. Firiedewald WT, Lewy RI, Frederickson DS. Estimation of the concentration of low-density lipoprotein cholesterol in plasma, without use of preparative ultracentrifuge. Clin Chem 1972:18:499-502.

17. Folch J, Lees $M_{1}$ Sloane Stanley $\mathrm{GH}$. A simple method for the isolation and puritication of total lipides from animal tissues. J Bial Chem 1957;226:497-509.

18. Morrison WR. Smith LM. Preparation of fatty acid methylesters and dimethylacetals from lipids with boron fluoride methanol. J Lipid Res 1964:5:600-608.

19. vam Haaster CMCJ, Engels W, Lemmens PJMR, Hornstra G, van der Vusse GJ. Formation of prostanoids and hydroxy fatty acids by stimulated rat peritoneal mast cells: role of the dietary fat type. Biochim Biophys Acta 1993;1 67:147-154. 
20. Small DM. The effects of glyceride structure on absoption and metaboism. Annw Rev Nutr $1991: 11: 413-434$.

21. Jensen JG, Ferris AM, Lammi-Keefe CJ. The composition of milk fat. J Dairy Sci 1991:74:32283243.

22. Zock PL, de Vries JHM, de Fouw NH, Katan MB. Positional distribution of tatty aclds in dietary triglycerides: effects on fasting blood lipoprotein levels in humans. Am J Clin Nutr 1995;61:48-55.

23. Nestel $P J_{s}$ Noakes $M$, Belling GB, McArthur $R$, Clifton PM. Effect on plasma lipids of interesterifying a mix of edible oils. Am J Clin Nutr 1995;62:950-955.

24. Grande F. Anderson JT, Keys A. Comparison of effects of palmitic and stearic acids in the diet on serum cholesterol in man. Am J Clin Nutr 1970;23:1184-1193.

25. Christophe A, Matthys F, Geers R, Verdonk G. Nutritrional studies with randomized butter. Cholesterolemic effects of butter-oill and randomized butter-oil in man. Arch Int Physiol Biochim $1978 ; 86: 413-415$.

26. Mensink RP, Katan MB. Effect of dietary trans fatty acids on high-density and low-density lipoprotein cholesterol levels in healthy subjecis. N Engl J Med 1990;323:439-445.

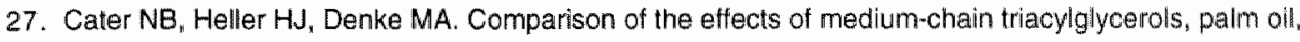
and high oleic acid sunflower oll on plasma triacylglycerol fatty acids and lipid and lipoprotein cancentrations in humans. Am J Clin Nutr 1997;65:41-45.

28. Mensink PP, de Groot MJM, van den Broeke LT, Severijnen-Nobels AP, Demacker PNM, Katan MB. Effect of monounsaturated fatty acids versus complex carbohydrates on serum lipoproteins and apolipoproteins in healthy men and women. Metabolism 1989;38:172-178.

29. Gardner CD, Fortmann SP, Krauss RM. Association of small low-density lipoprotein particles with the incidence of coronary artery disease in men and women. J Am Med Assoc 1996;276:875-881.

30. Kwiterovich Jr PO, Coresh J, Smith HH, Bachorik PS, Derby CA, Pearson TA. Comparison of the plasma levels of apolipoprotein B and A-I, and other risk factors in men and women with premature coronary artery disease. Am J Cardiol 1992;69:1015-1021.

31. Temme EHM, Mensink RP. Hornstra G. Comparison of the effects of diets enriched in lauric, palmitic, or oleic acids on serum lipids and lipoproteins in healthy women and men. Am $J$ Clin Nufr $1996 ; 63: 897-903$.

32. Ng TKW. Hassan K, Lim JB, Lye MS, Ishak F. Nonhypercholesterolemic effects of a palm-oil diet in Malaysian volunteers. Am J Cin Nutr 1991:53:1015S-1020S.

33. Ng TKW, Hayes KC, DeWitt GF, Jegathesan $M$, Satgunasingam $N_{i}$ Ong ASH, Tan D. Diatary paimitic and oleic acids exert similar effects on serum cholesterol and lipoprotein profiles in momocholesteremic men and women. J Am Coll Nutr 1992:11:383-390.

34. Sundram K, Hayes $\mathrm{KC}$, Siru $\mathrm{OH}$. Dietary palmitic acid resuits in lower serum cholesterol than does a lauric-myristic acid combination in normolipemic humans. Am J Cin Nutr 1994;59:841-846.

35. Green SR, Pittman RC. Comparative acyl specificities for transfer and selective uptake of high density lipoprotein cholesteryl esters. J Lipid Res 1991;32:457-467.

36. van Tol A, Zock PL, van Gent $T$, Scheek $L M$, Katan MB. Dietary trans tatty acids increase serum cholesterylester transfer protein activity in man. Atherosclerosis 1995;115:129=134.

37. Abbey $M$, Nestel PJ. Plasma cholesteryl ester transfer protein activity is increased when transia elaidic acid is substituted for cis-oleic acid in the diet. Atherosclerosis 1994;106:99-107. 


\section{Chapter 3}

38. Cox C, Mann J, Sutheriand W, Chisholm A, Skeaff M. Effects of coconut oil, butter, and safflower oil on lipids and lipoproteins in persons with moderately elevated cholesterol levels. I Lipid Res $1995: 36: 1787 \cdot 1795$.

39. Mensink AP, Zock PL, Katan MB, Hornstra G. Effect of dietary cis and trans fatty acids on serum hipoprotein[a] levels in humans. J Lipid Res 1992;33:1493-1501.

40. Tholstrup T. Marckmann P, Vessby B, Sandstrom B. Effects of fats high in individual saturated fatty acids on plasma lipoproiein(a) levels in young heathy men. J Lipid Res 1995;36:1447-1452. 


\title{
4
}

\section{Dietary induced changes in lipoproteins and mood}

\author{
Elisabeth HM Temme, Ronald P Mensink, Gerard Hornstra
}

Submitted for publication

\begin{abstract}
Adverse effects of lowering cholesterol concentrations on mortality of non-illness related diseases have been reported from epidemiological studies. The hypothesized mechanism associates decreased serum cholesterol concentrations with a more negative mood state. Little information, however, is available on the effects of dietaryinduced changes in lipoprotein concentrations on mood. In this study, sixty normocholesterolemic subjects ( 37 women and 23 men) first consumed a 3 wk run-in diet enriched in oleic acid. For the next 6 weeks, 19 subjects continued with the oleic acid diet, 21 subjects with an MCFA enriched diet, while 20 subjects received a diet high in myristic acid. Total diets contained 40 percent of energy from fat and the nutrient composition was the same in each diet except for $10 \mathrm{En} \%$, which was provided by MCFA, myristic or oleic acids. Ten mood states were measured with 100 $\mathrm{mm}$ visual analog scales. In addition, scores of state and trait anxiety were determined with Spielbergers' state-trait anxiety inventory (STAl). Serum total cholesterol levels increased with $0.40 \mathrm{mmol} / \mathrm{L}$ on the myristic acid diet compared with the oleic acid diet ( $P=0.0057$ for difference in changes). Changes in scores of mood did not differ between the three diets, and mood scores were not correlated with lipoprotein concentrations. Also changes in state anxiety or trait anxiety did not differ between the diets, but trait anxiety scores tended to associate with HDL concentrations $(r=0.24 ; P=0.0650$ after the run-in and $r=0.31 ; P=0.0148$ after the test period). In conclusion, our data indicate unchanged mood after changes in lipoproteins when a 6 wk oleic acid diet is compared with a myristic acid or MCFA rich diet.
\end{abstract}




\section{INTRODUCTION}

A meta-analysis of six randomized primary prevention trials demonstrated th lowering serum cholesterol concentrations was associated with increased deaths wolence, suicides or accidents (1). It was hypothesized that reduced seru cholesterol concentrations cause decreased serolonin levels in the brain or th synapses, which might be related with a more negative mood state (2). Indeed, lo cholesterol concentrations have been associated with low concentrations of plasm serotonin (3) and tryptophan (4), the precursor for serotonin. In addition, th functioning of the synaptic membranes -i.e. release and uptake of neurotransmitter: and receptor function- may be affected by membrane fluidity as affected by fatty aci composition and membrane cholesterol content, which alter after modifying the intak of certain dietary fatty acids (see for review (5)).

In human subjects, studies on diet-induced changes in cholesterol concentration: and mood are scarce. Recently, we carried out an intervention study in health! normocholesterolemic women and men to investigate the effects of diets enriched ir saturated fatty acids (Medium Chain Fatty Acids (MCFA) or myristic acid) relative tc those of monounsaturated fatty acids (oleic acid). As changes in serum cholestero concentrations through dietary fatty acid alterations were expected, the effects on mood were measured.

\section{SUBJECTS AND METHODS}

\section{Subjects}

Sixty subjects ( 37 women and 23 men) completed this controlled dietary experiment. Women were aged 22-60 y (mean $40 \mathrm{y}$ ), weighed $48-101 \mathrm{~kg}$ (mean 67 $\mathrm{kg}$ ), were between 155 and $183 \mathrm{~cm}$ in height (mean $167 \mathrm{~cm}$ ), and had body mass indexes from $20-30 \mathrm{~kg} / \mathrm{m}^{2}$ (mean $24 \mathrm{~kg} / \mathrm{m} 2$ ). The men were aged between $23-59 \mathrm{y}$ (mean $43 \mathrm{y}$ ), weighed $56.88 \mathrm{~kg}$ (mean $78 \mathrm{~kg}$ ). were between 163 and $190 \mathrm{~cm}$ in height (mean $178 \mathrm{~cm}$ ), and had body mass indexes from 17 to $29 \mathrm{~kg} / \mathrm{m}^{2}$ (mean 25 $\mathrm{kg} / \mathrm{m}^{2}$ ). Nine women were postmenopausal and 10 women used oral contraceptives. Six women and 5 men smoked. In women fasting concentrations of serum lipids ranged from 3.64 to $6.38 \mathrm{mmol} / \mathrm{L}$ (mean $5.28 \mathrm{mmol} / \mathrm{L}$ ) for total cholesterol. 1.12 to $2.98 \mathrm{mmol} / \mathrm{L}$ (mean $1.65 \mathrm{mmol} / \mathrm{L}$ ) for $\mathrm{HDL}$ cholesterol and 0.17 to $1.94 \mathrm{mmol} / \mathrm{L}$ (mean $0.74 \mathrm{mmol} / \mathrm{L}$ ) for triacylglycerols. In men fasting concentrations of serum lipids ranged from 4.02 to $6.60 \mathrm{mmol} / \mathrm{L}$ (mean $5.43 \mathrm{mmol} / \mathrm{L}$ ) for total cholesterol, 0.77 to 1.65 $\mathrm{mmol} / \mathrm{L}$ (mean $1.23 \mathrm{mmol} / \mathrm{L}$ ) for $\mathrm{HDL}$ cholesterol and 0.07 to $2.72 \mathrm{mmol} / \mathrm{L}$ (mean 1.05
mmol/L) for triacylglycerols.

\section{Diets and design}

The main purpose of the experiment was to test the effects of diets enriched in MCFA, myristic or oleic acid on lipoprotein concentrations and hemostatic factors of the blood. Details of this study have been published previously (6). The trial had a 
parallel design and was approved by the medical ethics committee of Maastricht University. During a $3 \mathrm{wk}$ run-in period, all subjects consumed a diet high in oleic acid. They were then randomly divided into three groups. For the next six weeks, one group consumed the MCFA diet $(n=21)$, a second group the myristic acid diet $(n=20)$ and a third group continued with the oleic acid diet $(n=19)$. The groups were stratified for initial serum cholesterol concentrations and sex.

Before the study started, the subjects recorded habitual food intake for two working days and one weekend day. From this food record each subjects actual energy intake was calculated by using the Dutch food-composition table (7). The study diets were formulated at 13 levels of energy (5 MJ to $22 \mathrm{MJ}$ ), so that each subject received a diet that met his or her energy needs. Diets used in the study consisted of products in which the normal fat was replaced by the experimental fats. The products included margarines and bakery products (bread, cookies, pies and cakes). Based on the subjects' energy intake, the amount of experimental products the subject had to eat each day (margiarine, bread, and cookies) and each week (cake and pie) were calculated and used. These solid foods supplied $63 \%(25$ En\%) of the total fat energy. The remaining $37 \%(15 \mathrm{En} \%)$ of the total fat intake had to be chosen from a list of "free-choice" fat-containing products. These products were given points according to their fat contents. One point was equal to one gram of fat. Each subject was required to eat a certain number of points daily, again corresponding with his or her energy intake, and to list the products chosen daily on a special form. The fat composition of the calculated diets was similar except for approximately $10 \%$ of total energy intake, which was provided by MCFA, myristic acid of oleic acid, respectively. The composition of the experimental fats has been described elsewhere (6).

\section{Scores of mood}

On each day of the final week of the run-in (week 3 ) and of the experimental period (week 9), subjects were asked to rate on $100 \mathrm{~mm}$ lines (visual analog scale (VAS)) ten items depicting ten different mood states. The ten items included annoyance, despair (mood state of depression/dejection), moodiness, irritation (mood state of anger/hostillity), tiredness, boredom (mood states of fatigue/inertia), brightness, pleasure (mood state of vigor/activity), self confidence and tenseness (mood state of tension/anxiety). The $100 \mathrm{~mm}$ lines for each item were printed on separate sheets of paper. Each day, the items were presented in a different order. The items were balanced so that for half of the items the left hand side of the line reflected the positive mood, while this was reversed for the other half. For analyses, the last mentioned items were reversed, so that $0 \%$ corresponded with the most positive and $100 \%$ with the most negative mood. The subject rated the ten items at the end of each day just before retiring for the night. 


\section{State and trait anxiety inventories}

On the last day of the run-in and the experimental periods the subjects came to the university for a fasting blood sample. Afterwards the subjects' state and trait anxiety scores were measured with the Dutch versions of the Spielberger State-Trait Anxiety Inventory (STAl) (8). State anxiety is defined as "a transient arousal state of anxilety; an emotional condition marked by subjective feelings of tension and stress, which vary in intensity and fluctuate in time an by increased activity of the nervous system. Trait anxiety, on the other hand, is the general disposition to anxiety; the tendency to react to situations experienced as threatening by increasing intensities of state anxiety" (9).

Each inventory consists of 20 quotes, that are used by people to describe themselves (for example "I am happy" or "I am nervous"). The subjects were asked to rate every quote on a scale ranging from 1 (hardly ever) to 4 (all the time) according to how they had been feeling at the specific moment that they filled out the inventory (state anxiety inventory) or in general (trait anxiety inventory). Total scores for the state anxiety or trait anxiety were calculated by summing the scores for the quotes; the total score therefore ranged from 20 to 80 . The test-retest correlations for the trait scale were on average 0.82 (for retesting after 5 to 202 days) for psychiatric outpatients and 0.75 for students (for retesting after 118 days) (9). The state scale, which is supposed to be inconsistent with time, indeed has a low test-retest reliability ( 0.40 (for retesting after 5 to 202 days in psychiatric outpatients) and 0.28 (for retesting after 118 days in students) (9). The STAI has been validated in students undergoing examinations, who had higher state anxiety and similar trait anxiety (44 for state and 35 for trait anxiety) compared with control students ( 34 for state and 35 for trait anxiety). The trait anxiety scores have been validated in patients diagnosed with ( 48 for state and 52 for trait anxiety) or without ( 41 for state and 45 for trait anxiety) anxiety problems, and in frequent ( 37 for state and 37 for trait anxiety) or occasional visitors ( 35 for state and 34 for trait anxiety) of the general practitioner (9). Strong correlations exist between anxiety and depression scores (9).

\section{Statistical analysis}

Daily VAS on mood were averaged per item, per week. For each item, changes from the run-in to the test periods were calculated. Differences in responses of mood scores were examined with diet as independent variable. Responses of scores of self confidence, boredom and despair were not normally distributed and were evaluated with the non-parametric Kruskal-Wallis test (10). Other scores were analyzed with the General Linear Models (GLM) procedure of the SAS Program (11). Of the total of 9240 scores of mood, $97(=1 \%)$ were missing. The missing items were left out from the calculated means.

For the state and the trait inventory, respectively, the scores on the 20 quotes were summed. If questions were not answered ( 8 of 2400 questions), a score of 2 was used as suggested (9). One subject did not complete the trait questionnaire after the run-in period. Trait of the test and run-in period for this subject have been assumed to be similar. Spearman correlation coefficients were calculated between 
changes in lipid and lipoprotein concentrations, and changes in mood and state and trait anxiety scores. To investigate whether the subjects' general disposition to anxiety was associated with lipoprotein concentrations we, in addition, calculated Spearman correlation coefficients between trait anxiety scores and lipid and lipoprotein concentrations after both the run-in and the test period.

\section{RESULTS}

Serum total cholesterol levels increased by $0.55 \mathrm{mmol} / \mathrm{L}$ or $11 \%$ with the myristic acid diet and by $0.39 \mathrm{mmol} / \mathrm{L}$ or $7 \%$ with the MCFA diet during the test period. With the oleic acid diet, the serum total cholesterol concentrations also slightly increased by $5 \%$. The response with the myristic acid diet was significantly different from the response with the oleic acid diet (difference in changes of $0.40 \mathrm{mmol} / \mathrm{L}$; $P=0.0057)$. HDL cholesterol concentrations increased with the myristic acid as compared with the MCFA diet (difference in changes of $0.11 \mathrm{mmol} / \mathrm{L} ; \mathrm{P}=0.0086$ ) and the oleic acid diet (difference in changes of $0.10 \mathrm{mmol} / \mathrm{L} ; \mathrm{P}=0.0273$ ). Changes in $\mathrm{HDL}$ cholesterol concentrations with the MCFA diet and the oleic acid diet did not differ. Triacylglycerol concentrations were not significantly changed by the three diets.

Scores of mood at the end of the run-in and changes from run-in to test period are given in table 1. No differences were observed between the changes on the three different diets. Of the mood scores, scores of moodiness after the run-in period were associated with triacylglycerol concentrations $(r=0.26 ; P=0.0443)$. Other mood scores did not significantly correlate with lipid or lipoprotein concentrations (data not shown).

State and trait anxiety scores are given in table 2. Changes in state and trait anxiety did not differ between the three diets. Trait anxiety after the run-in was strongly correlated to trait anxiety after the experimental period (rho $=0.82, P<0.0001$; results of all subjects combined). With state anxiety this correlation was smaller (rho $=0.60, P<0.0001$; results of all subjects combined). Trait anxiety scores after the test period correlated positively with $\mathrm{HDL}$ concentrations $(r=0.31 ; P=0.0148)$ and negatively with total to $\mathrm{HDL}$ cholesterol $(r=-0.28 ; P=0.0320)$ and $L D L$ to $\mathrm{HDL}$ cholesterol ratios $(r=-0.29 ; P=0.0272$ ) (table 3$)$. Correlations were less pronounced after the run-in period; $r=0.24, P=0.0650$ for $\mathrm{HDL}$ concentrations; $r=-0.22 . P=0.0787$ for the totall to HDL cholesterol ratio; and $r=-0.25, P=0.0524$ for the $L D L$ to $H D L$ cholesterol ratio. 
Table 1. Scores of mood after diets enriched in MCFA $(n=21)$, myristic acid $(n=20)$ or oleic acid $(n=19)$."

\begin{tabular}{|c|c|c|c|c|c|c|}
\hline & \multicolumn{2}{|c|}{ MCFA Diet } & \multicolumn{2}{|c|}{ Myristic Acld Diet } & \multicolumn{2}{|c|}{ Oleic Acid Diet } \\
\hline & Run-in & Change & Run-in & Change & Run-in & Change \\
\hline \multicolumn{7}{|c|}{ Depression/Dejection } \\
\hline Annoyance & $21 \pm 18$ & 349 & $23 \pm 21$ & $1 \div 7$ & $23 \pm 16$ & $4+9$ \\
\hline Despair & $19 \pm 20$ & $0+7$ & $21 \pm 21$ & $1 \pm 10$ & $23 \pm 16$ & 119 \\
\hline \multicolumn{7}{|l|}{ Anger/Hostility } \\
\hline Moodiness & $23 \pm 20$ & $1 \pm 6$ & $29 \pm 17$ & $0 \pm 7$ & $25 \pm 16$ & $-1 \pm 6$ \\
\hline Irritation & $25 \pm 20$ & $1 \pm 10$ & $31 \pm 17$ & $-1 \pm 10$ & $25 \pm 14$ & $1 \pm 7$ \\
\hline \multicolumn{7}{|l|}{ Fatigue/mertia } \\
\hline Tiredness & $43 \pm 17$ & $0+9$ & $41 \pm 19$ & $0 \pm 7$ & $38 \pm 15$ & $1+8$ \\
\hline Boredom & $17 \pm 16$ & $-1 \pm 8$ & $18+20$ & $11 \pm 6$ & $11 \pm 7$ & $2+9$ \\
\hline \multicolumn{7}{|l|}{ Vigor/Activity } \\
\hline Brightness & $32+20$ & $0 \pm 8$ & $33 \pm 19$ & $1 \pm 6$ & $30 \pm 17$ & $-3 \pm 8$ \\
\hline Pleasure & $32+18$ & $-0 \pm 7$ & $34 \pm 15$ & $1 \pm 6$ & $33 \pm 16$ & $0 \pm 6$ \\
\hline \multicolumn{7}{|l|}{ Tension/Anxiety } \\
\hline Self Contidence & $28+21$ & $0 \pm 6$ & $29 \pm 18$ & $2+5$ & $30+17$ & $0 \pm 7$ \\
\hline Tenseness & $28 \pm 20$ & $1 \pm 12$ & $35 \pm 16$ & $1 \pm 11$ & $31 \pm 17$ & $-2 \pm 10$ \\
\hline
\end{tabular}

* Values are means \pm standard deviations $(\%) .0 \%$ corresponds with the most positive mood, $100 \%$ with the most negative mood.

Table 2. State and trait anxiety scores after run-in (week 3 ) and changes from run-in to test period (week 9):"

\begin{tabular}{|c|c|c|c|c|c|c|}
\hline & \multicolumn{2}{|c|}{ MCFA Diet } & \multicolumn{2}{|c|}{ Myristic Acid Diet } & \multicolumn{2}{|c|}{ Oleic Acid Diet } \\
\hline & Run-in & Change & Run-in & Change & Rum-in & Change \\
\hline State anxiety & $33.0 \pm 8.0$ & $-1.0 \pm 7.4$ & $32.4 \pm 6.2$ & $-0.7 \pm 4.8$ & $35.0 \pm 11.7$ & $-0.9+8.9$ \\
\hline Trait anxiety & $31.9 \pm 6.9$ & $1.0 \pm 6.8$ & $35.0 \pm 7.0$ & $-0.1 \pm 5.0$ & $35.4 \pm 11.1$ & $-0.5 \pm 4.2$ \\
\hline
\end{tabular}

* Values are meanststandard deviations. 
Table 3. Spearman correlation coefficients between trait anxiety and serum lipids and lipoprotein concentrations at the end of the run-in period and test period.

\begin{tabular}{lcc}
\hline & $\begin{array}{c}\text { Trait anxiety } \\
\text { Run-in }\end{array}$ & $\begin{array}{c}\text { Trait anxiety } \\
\text { Test Period }\end{array}$ \\
\hline Total cholesterol & -0.01 & -0.02 \\
LDL cholesterol & -0.12 & -0.12 \\
HDL cholesterol & 0.24 & $0.31 \dagger$ \\
Triacylglycerols & 0.03 & 0.00 \\
Total to HDL cholesterol ratio & -0.22 & $-0.28 \dagger$ \\
LDL to HDL cholesterol ratio & -0.25 & $-0.29 \dagger$ \\
\hline
\end{tabular}

t $P<0.05$.

\section{DISCUSSION}

This study found lower serum total cholesterol concentrations in subjects on a diet, of six weeks duration, rich in oleic acid compared with a myristic acid rich diet. The diet-induced changes in serum cholesterol were not associated with altered scores of mood or anxiety. In our study, a difference of $6 \%$ in total cholesterol concentrations was found between the myristic and the oleic acid groups. This is modest compared with reductions of $13 \%$ in two long term dietary interventions with normocholesterolemic subjects, included in the meta-analysis that found an association between total cholesterol lowering and deaths not related to illness (1).

Other studies that especially focused on cholesterol-lowering and mood after drug $(12,13)$ or diet (14) interventions found similar results as we did. Long-term treatment during one (13) or three years (15) with cholesterol-lowering drugs did not affect emotional well-being as assessed by a quality of life questionnaire (13) or the shortened profile of mood states questionnaire (15). Also only four weeks administration of cholesterol-lowering drugs did not indicate effects on mood measured with the hospital anxiety scale (16). Results of a serum cholesterollowering education program, in which measurements of psychological well-being (with Hopkins Symptom Checklist) were included decreased feelings of hostility and depression in the treated compared with the control group were found (14). In that study (14), however, the control subjects lacked the attention given to the treated subjects, which might have influenced the results. In addition the only small changes $(2.7 \%)$ in serum cholesterol concentrations that were found between groups (14) were not very likely to have major effects on psychological well-being through changes in serotonin concentrations. In the study that found low plasma serotonin in 
men with low serum cholesterol concentrations, serum cholesterol levels were $42 \%$ lower compared with the reference group (3).

The association between trait anxiety and HDL cholesterol concentrations needs to be confirmed in further studies. So far, few studies in this field have determined complete lipid profiles. Higher HDL cholesterol, besides lower total cholesterol concentrations, have been reported from patients with major depression disorders compared with controls (17). On the other hand Maes et al (18) reported lower HDL cholesterol concentrations in subjects with major depression compared with controls.

In conclusion, our data indicate unchanged mood after changes in lipoprotein concentrations, when an 6 wk oleic acid diet is compared with a myristic acid or MCFA rich diet in normocholesterolemic subjects. Data from these type of studies on the effects of fatty acid composition on serum lipids and mood, however, are still very limited and need to be extended with future research.

\section{ACKNOWLEDGMENTS}

We thank Dr A Jansen (Faculty of Psychology, Department of Mental Health Sciences and Experimental Psychopathology, Maastricht University) for her advise on the psychological test methods. 


\section{REFERENCES}

1. Muldoon MF, Manuck SB, Matthews KA. Lowering cholesterol concentrations and mortality: a quantitative review of primary prevention trials. BMU 1990;301:309-314.

2. Engelberg H. Low serum cholesterol and suicide. Lancet 1992;339:727-729.

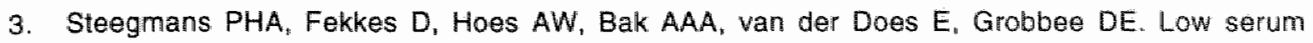
cholesterol concentration and serotonin metabolism in men. BMJ 1996;312:221.

4. Steegmans PHA. Laag serumcholesterol, depressies en geweldadige dood; Serotonine als mogelijke schakel (Low serum cholesterol, depression, and violent death; serotonin as possible link). Voeding 1996;6:20-21.

5. Hibbein JR, Salem Jr N. Dietary polyunsaturated fatty acids and depression: when cholesterol does not satisfy. Am J Clin Nutr 1995;62:1-9.

6. Temme EHM, Mensink RP, Hornstra G. Effects of medium chain fatty acids, myristic acid, and oleic acid on serum lipoproteins in healthy subjects. J Lipid Res 1997;38:1746-1754.

7. Stichting NEVO. NEVO tabel, Nederlands voedingstoffenbestand (Dutch food composition table). Den Haag: Voorlichtingsbureau voor de Voeding, 1989.

8. Spielberger CD, Gorsuch RL, Lushene RE. STAl manual for the State Trait Anxiery Inventory. Palo Alto: Consulting Press, 1970.

9. van der Ploeg HM, Defares PB, Spielberger CD. Zelfbeoordelingsvragenlijst; een Nederlandse bewerking van de Spielberger State-Trait anxiety Inventory. Lisse: Swets\&Zeitlinger, 1980.

10. Siegel S, Castellan N. Nonparametric statistics for the behavioural sciences. Singapore: MoGraw-Hill, 1988.

11. SAS Institute Inc. SAS: user's Guide Statistics, Version 5 Edition.Cary, NC: SAS Institute Inc, 1985.

12. Lines C. Hazards of reducing cholesterol. BMJ 1994;309:541.

13. Downs JA, Oster G, Santanello NC. HMG COA reductase inhibitors and quality of life. JAMA 1993;269:3107-3108.

14. Weidner $\mathrm{G}$, Connor SL, Hollis JF, Connor WE. Improvements in hostility and depression in relation to dietary change and cholesterol lowering. Ann int Med 1992;117:820-823.

15. Wardle J, Armitage J, Collins R. Wallendszus $K$, Keech $A$. Lawson A. Randomised placebo controlled trial of effect on mood of lowering cholesterol concentration. BMJ 1996;313:75-78.

16. Harrison RWS, Ashton $\mathrm{CH}$. Do cholesterol-lowering agents affect braim activity? A comparison of simvastatin, pravastatin, and placebo in healthy volunteers. Br J Clin Pharmacol 1994;37:231-236.

17. Olusi SO, Fido AA. Serum lipid concentrations in patients with major depressive disorders. Biol Psychiatry 1996;40:1128-1131.

18. Maes M, Smith R, Christophe A, Vandoolaeghe $E$, Van Gastel A, Neels $H$, Demedts P. Wauters A, Meltzer HY. Lower serum high-density lipoprotein cholesterol (HDL-C) in major depression and in depressed men with serious suicidal attemps: relationship with immune-inflammatory markers. Acta Psychiatr Scand 1997:95:212-221. 



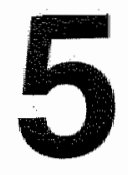

\title{
Individual saturated fatty acids and effects on whole blood aggregation in vitro.
}

\author{
Elisabeth HM Temme, Ronald P Mensink and Gerard Hornstra. \\ Submitted for publication
}

\section{ABSTRACT}

In two studies we have compared the effects of four different saturated fat diets (Medium Chain Fatty Acids (MCFA), lauric acid, myristic and palmitic acid) with the effect of a monounsaturated oleic acid diet on in vitro whole blood aggregation in healthy women and men. STUDY 1 had a cross-over study design with three diet periods of each six weeks, and examined the effects of diets enriched in lauric, palmitic or oleic acids. STUDY 2 had a parallel study design. After a 3 week oleic acid run-in diet, three groups were formed which consumed either an MCFA, myristic acid or oleic acid rich diet for six weeks. Eighteen women and 14 men were included in STUDY 1 and 37 women and 23 men in STUDY 2. All subjects were healthy and aged 20-60 yr. The experimentall diets were the same in nutrient composition except for on average 8 En\% (STUDY 1) or 10 En\% (STUDY 2) which was provided by either MCFA, lauric acid, myristic acid, palmitic acid or oleic acid. Blood samples were taken at the end of each dietary period. Whole blood platelet aggregation, anticoagulated with recombinant hirudin was assessed after administration of collagen (final concentration (fc): $0.38 \mu \mathrm{g} / \mathrm{mL}$ ) in STUDY 1 and collagen (fc: $0.22 \mu \mathrm{g} / \mathrm{mL}$ ) or ADP (fc: $1.25 \mu \mathrm{mol} / \mathrm{L}$ ) in STUDY 2. Collagen-induced formation of thromboxane $(T x) A_{2}$, measured as $T_{x B}$, was evaluated in STUDY 1 only. The aggregation velocity between the saturated fatty acid diets and the monounsaturated fatty acid diet did not differ. $\mathrm{TxB}_{2}$ concentrations measured in collagen activated blood samples, which correlated significantly with aggregation velocity, did not differ between the lauric or the palmitic compared with the oleic acid diet. A stepwise regression analysis indicated that red blood cell count was negatively related with collagen- and ADP. induced aggregations. We conclude that the exchange of 8-10 En\% from oleic acid for MCFA, lauric, myristic or palmitic acid does not affect in vitro whole blood aggregation induced by collagen. ADP-induced aggregation is not affected winen 10 En\% from oleic acid is exchanged for MCFA or myristic acid. 


\section{INTRODUCTION}

Blood platelets play an important role in the etiology of coronary heart disease. Activated platelets provide tissue factor, membrane phospholipid surface, and other regulatory compounds which are necessary for the coagulation process. Increased platelet reactivity for ADP was demonstrated in middle aged men at risk for coronany heart disease (1) and in patients with coronary heart disease (2). Also, the protective effect of aspirin against myocardial infarction suggests a major role of platelets in the development of coronary heart disease $(3,4)$, as it inhibits platelet synthesis of thromboxane $A_{2}\left(T x A_{2}\right)$.

Different types of dietary fatty acids have been demonstrated to change the reactivity of platelets. Renaud and coworkers (5) found increased thrombin-induced, and decreased ADP-induced platelet rich plasma (PRP) aggregation when farmers switched from high saturated fat diets to high polyunsaturated fat diets for one year. Mutanen and coworkers (6) demonstrated lower ADP- and collagen-induced PRP aggregation on a dairy fat diet compared with diets rich in unsaturated fatty acids from rapeseed or sunflower oil. $\mathrm{Ng}$ et al (7), in addition, found increased thromboxane $\mathrm{B}_{2}$ $\left(T \times B_{2}\right)$ in collagen-activated whole blood comparing diets rich in coconut with palm oil. This observation (7) suggested that the various saturated fatty acids have different effects on platelet activity and that thromboxane dependent aggregation increases after diets rich in fatty acids from coconut oil (i.a. MCFA, lauric and myristic acid). However, effects of specific saturated fatty acids on platelet aggregation have hardly been investigated systematically.

Platelet aggregation is frequently measured with the optical density technique using citrated PRP and activators of aggregation such as ADP, collagen or thrombin. This technique might not always be preferable, since it does not take into account the possible role of short-lived plasmatic components and of red and white blood cells. in this present study, therefore, the effects of diets enriched in MCFA, lauric, myristic and palmitic acid on aggregation in whole blood in vitro were investigated and compared with those of oleic acid.

\section{METHODS}

\section{Design and statistical analysis}

The project consisted of two different studies also designed to investigate the effects of separate saturated fatty acids on lipoproteins, coagulation and fibrinolysis as reported elsewhere $(8,9)$. The protocols of both studies had been approved by the ethical committee of Maastricht University. All subjects had given their written informed consent.

In the first study (STUDY 1) the effects of lauric acid, palmitic acid and oleic acid were investigated with a cross-over study design. The three different diets were consumed by 32 healthy subjects, 18 women and 14 men, for six weeks separated by wash out periods from two or three weeks. The second study (STUDY 2) examined 
the effects of MCFA and myristic acid versus oleic acid with a parallel study design. After a run-in period of three weeks, in which 60 volunteers, 37 women and 23 men, consumed an oleic acid diet, the subjects were divided into three groups; the first group received an MCFA diet $(n=21)$, the second group a myristic acid diet $(n=20)$ and the last group continued with the oleic acid diet $(n=19)$.

Data were analyzed using the General Linear Models (GLM) procedure of the Statistical Analyses System. In STUDY 1, the aggregation parameters at the end of each dietary period were analyzed with diet, period and diet-and-sex interaction as independent variables. Data of $\mathrm{TxB}_{2}$ were logarithmic transformed before analysis, because they were not normally distributed. In STUDY 2, changes in aggregation parameters from the end of the run-in to the end of the experimental period were analyzed with diet, sex and diet-and-sex interaction as independent variables. Pearson correlation coefficients were calculated between aggregation velocity and hematologic parameters. Correlations were calculated when subjects consumed the oleic acid diet during the experimental period (STUDY 1) or the run-in period (STUDY 2). To determine the relationship between hematologic parameters and aggregation in whole blood, a stepwise regression procedure (forward selection) was performed with whole blood aggregation velocity as dependent and the main hematologic parameters -platelet count, red blood cell count and white blood cell count- as independent variables. The significance level for entry in the model was set at 0.05 .

In both studies differences in responses between women and men were evaluated with unpaired $t$-tests.

\section{Subjects}

Details of both studies have been described in chapter 2 and chapter 3 . Briefly, STUDY 1 included 32 subjects, 18 women and 14 men, aged between 20 and 60 years (mean, 41 years old). The women had body mass indexes from 19 to $30 \mathrm{~kg} / \mathrm{m}^{2}$ (mean $25 \mathrm{~kg} / \mathrm{m}^{2}$ ), the men had body mass indexes from 22 to $31 \mathrm{~kg} / \mathrm{m}^{2}$ (mean 25 $\mathrm{kg} / \mathrm{m}^{2}$ ). Four women and 5 men were smokers. Six women were postmenopausal and 2 women used oral contraceptives. STUDY 2 included 60 subjects, 37 women and 23 men, aged between 22 and 60 years (mean, 41 years old). Women had body mass indexes between 20 and $30 \mathrm{~kg} / \mathrm{m}^{2}$ (mean $24 \mathrm{~kg} / \mathrm{m}^{2}$ ) and the men between 17 and $29 \mathrm{~kg} / \mathrm{m}^{2}$ (mean $25 \mathrm{~kg} / \mathrm{m}^{2}$ ). Nine women were postmenopausal and 10 women used oral contraceptives. Six women and 5 men smoked.

\section{Diets}

The diets of both studies consisted of products in which the normal fat was replaced by experimental fats. Total fat energy was on average 40 percent of energy (En\%). The experimental fats supplied $70 \%$ of the total fat energy in the first and $63 \%$ in the second study. The nutrient composition of the calculated diets was similar except that approximately 8 En\% (STUDY 1) or 10 En\% (STUDY 2) of oleic acid was exchanged for lauric acid or palmitic acid (STUDY 1) and for MCFA or myristic acid 
(STUDY 2). These differences were achieved by the use of special experimental fats. The lauric acid tat was a mixture of palm kernel $(75 \%)$ (Wesco Karlshamns, Zaandijk, the Netherlands) and a high oleic acid sunflower oll (25\%) (Trisun; SVO enterprises, Wickliffe, USA). The palmitic acid fat consisted of dairy fat (55\%) (FDF, Leeuwarden, The Netherlands), palmstearin (36\%) (Aarhus oil, Aarhus, Denmark) and sunflower of $(9 \%)$ and the fat high in oleic acid of dairy fat $(37 \%)$ and high oleic acid sunflower off $(63 \%)$. Cholesterol was added to the fats high in lauric and oleic acid, so that all fats contained $145 \mathrm{mg}$ of cholesterol per $100 \mathrm{~g}$ of fat. The fat high in MCFA was made by interesterification of $34.0 \%$ palm stearin, $17.6 \%$ high oleic acid sunflower oil, $8.4 \%$ sunflower oil, and $40 \%$ medium chain triglyceride (MCT) cil. The composition of the MCT oil was $33.3 \%$ C6:0, 25.3\% C8:0, and $41.5 \%$ C10:0. The myristic acid fat was made by interesterification of a blend of $34 \%$ palm stearin, $17 \%$ high oleic acid sunflower oil, $9 \%$ sunflower oil and $40 \%$ trimyristin. The oleic acid fat consisted of a blend of $30 \%$ palm stearin and $70 \%$ high oleic sunflower oil (Grünau GMBH, Illertissen, Germany). Margarines were made from the fats and consisted of $83 \%$ fat and $17 \%$ water. The experimental margarines were given as such and were incorporated in bread, biscuits, pies, cakes (STUDY 1 and STUDY 2), cheeses and custards (STUDY 1 only).

The study diets were formulated at different levels of energy, so that each subject received a diet that met his or her energy needs. According to these energy levels lists were computed which stated the amount of experimental products the subject had to eat each day or each week. Products were handed out on an individual basis and were free of charge. $30 \%$ (STUDY 1 ) and $37 \%$ (STUDY 2) of the total fat intake was free of choice. The subject could choose these "free" products from a list of fat containing products. Subjects came at least once a week to a special room in the university to get a new supply of products and to be weighted. They were also asked to maintain the same activity level, smoking and drinking habits throughout the study. Any changes were written down in a special diary as well as medication used. illnesses, daily alcohol use and menstrual cycle.

\section{Blood sampling and measurements}

Blood was sampled after an ovemight fast and after abstinence from drinking the preceding day and smoking on the morning before blood sampling. Blood for platelet aggregation was sampled at the end (week 6) of each period in STUDY 1 and at the end of the run-in (week 3) and the end of the experimental period (week 9) in STUDY 2. Blood was sampled with a minimum of stasis and using a $1.2 \mathrm{~mm}$ needle (Strauß Kanule, Luer, Wächtersbach, Germany) with the subject in recumbent position. All venipunctures were performed by the same person, at the same location, and for each subject generally at the same time of the same day of the week.

The first $3-4 \mathrm{~mL}$ blood was collected in an EDTA tube to count the number of platelets (Hematology system, Technicon Instruments Corporation, Tarrytown, NY, USA) in STUDY 1 and to measure complete hematologic parameters in STUDY 2 (Coulter microdiff 18, Coulter Corporation, Miami, USA). Then, $1.5 \mathrm{~mL}$ of blood was collected in a tube containing $67 \mu \mathrm{g} / \mathrm{mL}$ recombinant desulphatohirudin variant 1 
(TMRevasc; a gift from Novartis Pharma AG, Horsham, Great Britain). Whole blood aggregation was immediately measured after blood sampling using a whole blood aggregometer (Chrono-log whole blood aggro-meters, model 500 (STUDY 1 and STUDY 2) and model 540 (STUDY 2)) (Chrono-log Corporation, Haverton, PA, USA). $1 \mathrm{~mL}$ of blood was transferred to a pre-warmed plastic cuvet and the electrodes were inserted in the cuvettes. The sample was stirred at $1000 \mathrm{rpm}$, kept at $37^{\circ} \mathrm{C}$ and allowed to reach equilibrium. After calibrating the instrument, $10 \mu$ of the aggregation inducer (collagen or ADP) was added. Aggregation curves were registered for 15 minutes and the velocity was expressed as the steepest slope of the aggregation curve $(\Omega /$ minute). When aggregation curves of ADP-induced aggregation consisted of two curves the steepest slope of the first curve was determined.

In STUDY 1, platelet aggregation was induced by addition of collagen (Collagen Horm, Hormon Chemie, Munich, Germany) at a final concentration of $0.38 \mathrm{\mu g} / \mathrm{mL}$. In STUDY 2, collagen- and ADP. (Sigma Chemical Co, St Louis, MO, USA) induced aggregation were measured. Final concentrations were $0.22 \mu \mathrm{g} / \mathrm{mL}$ for collagen and $1.25 \mu \mathrm{mol} / \mathrm{L}$ for ADP. Samples of the subjects were measured at the same channel of the aggregometer along the study. Due to an occasional technical problem with the aggregometers, aggregation values of some subjects are missing, which has been emphasized in the tables.

After 15 minutes of activation, collagen-activated aggregation samples from STUDY 1 were centrifuged in an eppendorf centrifuge for 3 minutes to measure $T \times B_{2}$ production. The plasma samples were then immediately snap-frozen and stored at $-80^{\circ} \mathrm{C}$. The $\mathrm{TxB}_{2}$ concentration was determined with an Enzyme Immunoassay (Cayman Chemical Company, Ann Harbor, MI, USA). Coefficient of variation within runs was $6.1 \%$. Samples from one subject were analyzed within one run.

\section{RESULTS}

\section{Dietary composition}

The mean daily energy intake and the composition of the diets was determined from four days food records in STUDY 1 and three days food records in STUDY 2 . In addition, duplicate portions of food and drinks consumed have been collected by the subjects for two days (STUDY 1). Lipids of these portions were extracted and fatty acid composition determined.

In STUDY 1, total fat intake was $41.5 \mathrm{En} \%$ with the lauric acid diet, $41.0 \mathrm{En} \%$ with the palmitic acid diet and $41.8 \mathrm{En} \%$ with the oleic acid diet. As determined from the duplicate portions, the difference in lauric acid was $7.3 \mathrm{En} \%$ between the lauric and the oleic acid diet, while the palmitic acid diet was $6.1 \mathrm{En} \%$ higher in palmitic than the oleic acid diet. The lauric acid diet contained also some (average $1.8 \mathrm{En} \%$ ) more myristic acid than the other two diets. The diets did not differ with respect to linoleic acid or o-linolenic acid intakes (10).

In STUDY 2, the average intake of fat was $39 \mathrm{En} \%$. The average intake of oleic acid was 15.1 En\% during the run-in period and decreased in the test period to 6.6 
En\% with the MCFA and to 6.3 En\% with the myristic acid diet. It was exchanged for extra MCFA or myristic acid. Oleic acid intake during the oleic acid diet did not change from the run-in to the test period. Changes of other nutrients, except for En\% saturated and monounsaturated fatty acids, did not significantly differ between the diets.

Relative to the oleic acid diet, fatty acid composition of pooled serum samples in both studies $(8,10)$ did not indicate significant changes in the proportions of linoleic acid, $\alpha$-linolenic acid, arachidonic acid or total polyunsaturated fatty acids.

\section{Platelet aggregation and $\mathrm{TxB}_{2}$}

Table 1 shows that collagen-induced aggregation velocity and $T \times B_{2}$ production after 6 weeks consumption of diets enriched in lauric, palmitic or oleic acids did not differ significantly between the diets. Also, diets rich in MCFA and myristic acid (STUDY 2) did not affect collagen- and ADP-induced aggregation velocity differently as compared with a diet rich in oleic acid (table 2).

In STUDY 1, logarithmic transformed values of $\mathrm{TXB}_{2}$ concentrations correlated with aggregation velocity $(r=0.42 ; P=0.0165, r=0.48 ; P=0.0055, r=0.39 ; P=0.0274$, for subjects on the lauric, palmitic or oleic acid diet, respectively).

Collagen-induced aggregation velocity did not differ between men and women in STUDY 1. Collagen- and ADP-induced aggregation velocities after the run-in period in STLIDY 2, however, were significantly higher in women compared with men $(P=0.0020$ and $P=0.0010$, respectively). The data of collagen-induced aggregation velocity of the females consuming the oleic acid diet (oleic acid diet period in STUDY 1 and oleic acid run-in period in STUDY 2) were combined to determine differences between pre- and postmenopausal women. Collagen-induced aggregation velocity was (means \pm standard deviations) $5.2 \pm 1.8 \Omega / \mathrm{min}$ in premenopausal women not on contraceptives ( $n=27$, one missing value), $6.6 \pm 1.4 \Omega / \mathrm{min}$ in premenopausal women on contraceptives $(n=11$, one missing value) and $5.9 \pm 2.2 \Omega / \mathrm{min}$ in postmenopausal women $(n=15)$ and did not differ significantly between these groups of women. ADP. induced aggregation velocity, which was only measured in STUDY 2, was $6.6 \pm 1.9$ $\Omega /$ min in premenopausal women not on contraceptives $(n=17$, one missing value), $5.6 \pm 1.2 \Omega / \mathrm{min}$ in premenopausal women on contraceptives $(n=10)$ and $5.7 \pm 1.1 \Omega / \mathrm{min}$ in postmenopausal women $(n=9)$ and did not differ in a significant different way between these women. 
Table 1. Aggregation velocity ( $\Omega / \mathrm{min}$ ) induced by collagen ( $1 \mathrm{co} .0 .38 \mathrm{\mu g} / \mathrm{mL}$ ) and plasma thromboxane $\mathrm{B}_{2}$ concentrations of collagen activated blood in 32 healthy subjects consuming diets enriched in laurio acid, palmitic acid or oleic acid (STUDY 1):

\begin{tabular}{lccc}
\hline & $\begin{array}{c}\text { Lauric Acid } \\
\text { Diet }\end{array}$ & $\begin{array}{c}\text { Palmitic Acid } \\
\text { Diel }\end{array}$ & $\begin{array}{c}\text { Oleic Acid } \\
\text { Diet }\end{array}$ \\
\hline $\begin{array}{l}\text { Collagen-induced aggregation velocity }(\Omega / \mathrm{min}) \\
\text { All }\end{array}$ & $5.5 \pm 1.4$ & $5.2 \pm 1.5$ & $5.6 \pm 1.7$ \\
$\quad$ Women & $5.8 \pm 1.2$ & $5.0 \pm 1.8$ & $5.6 \pm 1.7$ \\
$\quad$ Men & $5.1 \pm 1.7$ & $5.0 \pm 1.8$ & $5.5 \pm 1.8$ \\
Thromboxane B2 (ng/mL) & $17.3 \pm 5.4$ & $17.7 \pm 5.8$ & $16.5 \pm 5.5$ \\
All & $17.6 \pm 6.2$ & $16.9 \pm 6.1$ & $15.7 \pm 6.1$ \\
$\quad$ Women & $16.9 \pm 4.5$ & $18.7 \pm 5.5$ & $17.5 \pm 4.7$ \\
Men & & & \\
\hline
\end{tabular}

Values are given as means \pm standard deviations

Table 2. Aggregation velocity ( $\Omega / \mathrm{min})$ induced by collagen $(0.22 \mu \mathrm{g} / \mathrm{mL})$ or by ADP $(1.25$ $\mu$ mol/L) on diets enriched in MCFA $(n=18)$, myristic acid $(n=20)$ or oleic acid $(n=19)$ (STUDY 2).*

\begin{tabular}{|c|c|c|c|c|c|c|}
\hline & \multicolumn{2}{|c|}{ MCFA Diet } & \multicolumn{2}{|c|}{ Myristic Acid Diet } & \multicolumn{2}{|c|}{ Oleic Acid Diet } \\
\hline & Run-in & Change & Run-in & Change & Run-in & Change \\
\hline \multicolumn{7}{|c|}{ Collagen-induced aggregation velocity ( $\Omega / \mathrm{min})$} \\
\hline Allt & $5.0 \pm 2.2$ & $0.4 \pm 2.7$ & $5.4 \pm 1.8$ & $0.3 \pm 1.8$ & $4.8 \pm 1.9$ & $0.1 \pm 2.6$ \\
\hline Women ${ }^{\#}$ & $6.1 \pm 1.7$ & $-0.5 \pm 2.1$ & $6.0 \pm 1.9$ & $0.3 \pm 1.7$ & $4.9 \pm 2.4$ & $0.1 \pm 3.0$ \\
\hline Men & $2.9 \pm 1.4$ & $2.2+2.9$ & $4.5 \pm 1.1$ & $0.3 \pm 2.0$ & $4.6 \pm 0.8$ & $0.2 \pm 1.9$ \\
\hline \multicolumn{7}{|c|}{ ADP-induced aggregation velocity ( $\Omega / \mathrm{min})$} \\
\hline All & $5.6 \pm 1.8$ & $0.1+2.0$ & $5.2 \pm 1.4$ & $-0.2 \pm 1.5$ & $5.9 \pm 1.3$ & $-0.2 \pm 1.5$ \\
\hline Women ${ }^{*}$ & $6.0+2.0$ & $-0.2 \pm 1.7$ & $6.0 \pm 1.4$ & $-0.4 \pm 1.6$ & $6.3 \pm 1.4$ & $0.0 \pm 1.3$ \\
\hline Men & $5.0 \pm 1.1$ & $0.5 \pm 2.6$ & 4. $1 \pm 0.5$ & $0.1 \pm 1.3$ & $5.3+0.9$ & $-0.6 \pm 1.8$ \\
\hline
\end{tabular}

Values are giwen as meanstistandard deviations

t Values of one woman and one man are missing in the myristic acid group and one woman and one man in the oleic acld group.

* Values of women after the run-in period (all subjects combined) are significantly different from those of men. $P<0.01$. 


\section{Hematologle parameters}

Platelet count in STUDY 1 did not change throughout the study and did not differ between women and men (data not shown). Platelet counts correlated significantly with platelet aggregation velocity $(r=0.40 ; P=0.0217, r=0.47 ; P=0.0069, r=0.48$; $P=0.0049$, on the lauric, palmitic or oleic acid diet, respectively).

In STUDY 2 more hematologic parameters were measured (table 3). Although changes did not differ significantly between the three diets, a trend was observed for a decreased mean platelet volume with the myristic acid (mean response of $-0.2 \mathrm{fL}$; $P=0.0006$ ) compared with the MCFA diet (difference of changes $-0.3 \mathrm{fL} ; \mathrm{P}=0.0659$, $95 \%$ confidence interval -0.7 to $0.1 \mathrm{fL}$ ).

After the run-in period in STUDY 2, red blood cell concentrations were higher in men than in women $\left(4.9 \pm 0.3 \times 10^{12 / L}\right.$ versus $\left.4.4 \pm 0.3 \times 10^{12} / \mathrm{L} ; \mathrm{P}<0.0001\right)$. Other red blood cell related parameters -hemoglobin and hematocrit- were also higher in men compared with women, whereas platelet count and mean platelet volume did not differ between the two sexes (see table 3 ). Whereas collagen-induced aggregation was not correlated with platelet count $(r=0.20 ; P=0.1368)$. ADP-induced aggregation velocity was $(r=0.39 ; P=0.0026)$. Both collagen- and $A D P$-induced aggregation velocity were inversely correlated with the concentration of red blood cells $(r=-0.38$; $P=0.0035$ for collagen-induced aggregation, $P=-0.48 ; P=0.0001$ for $A D P$-induced aggregation). 


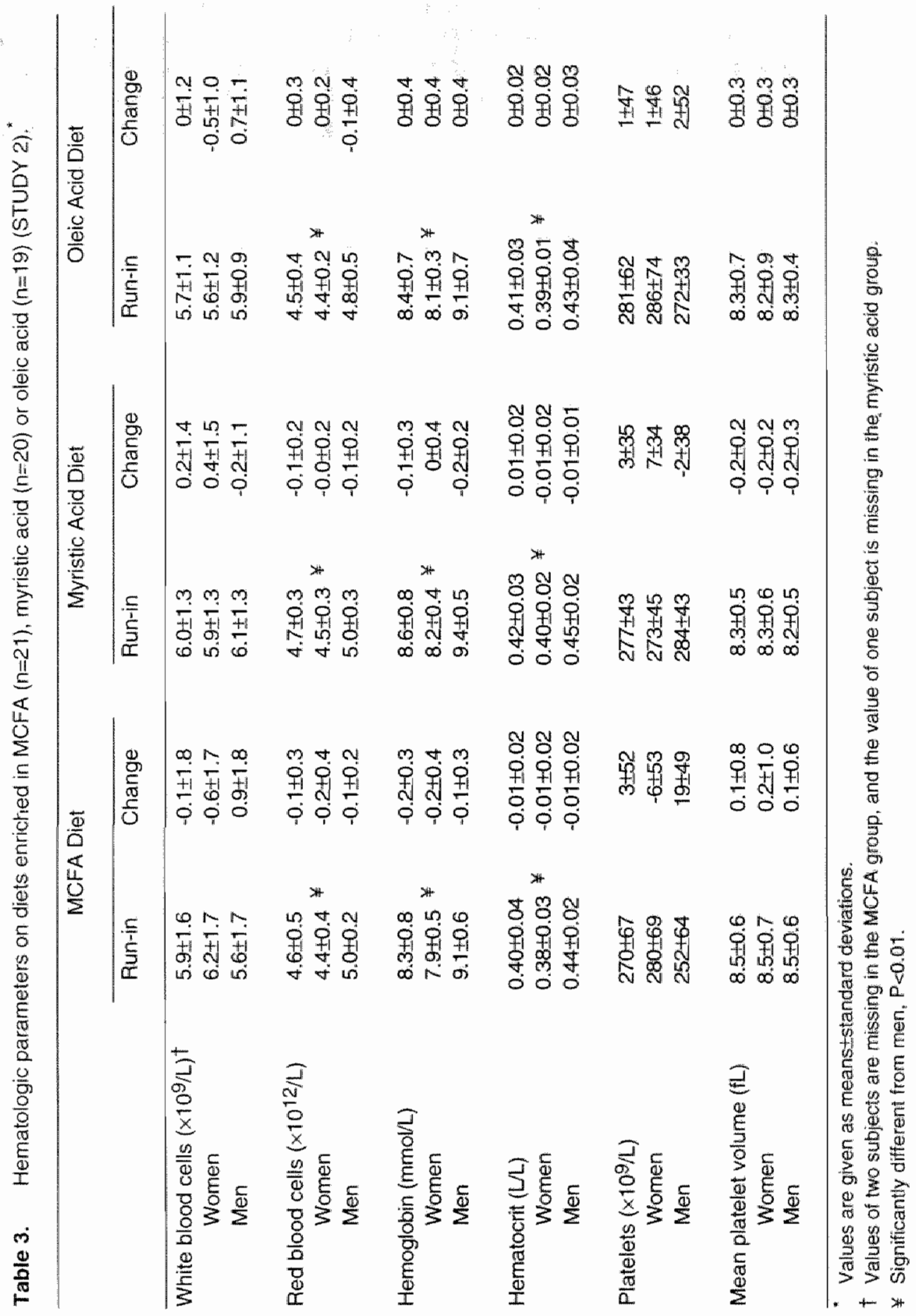


Independent hematologic determinants of whole blood platelet aggregation velocity as measured after the run-in period in STUDY 2 were evaluated with a stepwise forward regression anallysis and are shown in table 4 . The red blood cell count was negatively related to collagen- and ADP-induced aggregations. ADPinduced aggregation was also, but to a lesser extent positively associated with platelet count.

Table 4. Independent hematologic determinants of whole blood aggregation velocity in vitro as determined from a fowward stepwise regression procedure.

\begin{tabular}{|c|c|c|c|}
\hline \multirow[t]{2}{*}{ Dependent variable * } & \multirow[b]{2}{*}{$\begin{array}{l}\text { Parameter } \\
\text { estimate }\end{array}$} & \multicolumn{2}{|c|}{ Partial } \\
\hline & & $R^{2}$ & $P$ \\
\hline \multicolumn{4}{|l|}{ Collagen-induced aggregation } \\
\hline Intercept & 13.811 & & \\
\hline Red blood cell count $\left(\times 10^{12 / L}\right)$ & -1.896 & 0.15 & 0.0032 \\
\hline \multicolumn{4}{|l|}{ ADP-induced aggregation } \\
\hline Intercept & 10.404 & & \\
\hline Red blood cell count $\left(\times 10^{12 / L}\right)$ & -1.631 & 0.21 & 0.0003 \\
\hline Platelet count $\left(\times 10^{9} / \mathrm{L}\right)$ & 0.009 & 0.13 & 0.0023 \\
\hline
\end{tabular}

* Dependent variable =Platelet count and Red blood cell count and White blood cell count.

\section{DISCUSSION}

Compared with monounsaturated fatty acids (oleic acid), diets enriched in saturated fatty acids (MCFA, lauric acid, myristic acid or palmitic acid) did not change aggregation velocity in vitro in whole blood samples anticoagulated with hirudin. From measurements in PRP, Mutanen et al (6) reported lower ADP- and collageninduced aggregations after consumption of diets rich in dairy fat compared with diets rich in rapeseed oil (oleic acid and $\alpha$-linolenic acid) or sunflower oil (linoleic acid). It was suggested (6) that these effects were due to differences in the linoleic acid and $\alpha$ linolenic acid ratio of diets and not to the exchange of saturated for monounsaturated fatty acids. In our study, the diets given did not differ with respect to linoleic acid (STUDY 1 and 2) or $\alpha$-linolenic acid (STUDY 1) content as determined from the recorded food intakes (STUDY 2) (8) or the duplicate portions (STUDY 1) (10). Therefore, the present study does not necessarily contradict this suggestion (6), but can also not confirm because collagen- and ADP-induced aggregation have now been measured in whole blood samples. Earlier, Renaud and co-workers (5) also reported increased ADP-induced aggregation when farmers replaced their saturated 
fat diets for one year with diets rich in linoleic acid. For the next three years, when they increased the intake of oleic and $\alpha$-linolenic acid at the expense of hinoleic acid ADP. induced PRP aggregation was similar to levels on the saturated fat diet. Both replacements, however, reduced collagen- and thrombin-induced aggregation compared with the saturated fat diet. Therefore it remains uncertain whether this ratio of dietary linoleic acid and $\alpha$-linolenic acid might also be important for aggregations induced with other stimuli than ADP.

One of the mechanisms to alter platelet aggregation is via the production of $\mathrm{TXA}_{2}$, which is synthesized by platelets and promotes platelet aggregation, and of PGil. which is produced by endothelial cells and inhibits platelet aggregation. Both eicosanoids are derived from arachidonic acid, an important membrane phospholipid, the concentrations of which can be altered by changes in dietary fatty acid composition. Our results did not indicate changles in the $T \times B_{2}$ concentrations (a $\mathrm{Tx}_{\mathrm{A}} \mathrm{A}_{2}$ metabolitey after diets rich in lauric or palmitic acids compared with oleic acid, in collagen activated samples. Others, however, showed that diets rich in coconut oil (lauric and myristic acids) compared with palm oil (palmitic acid) or olive oill (oleic acid) increased the concentrations of $\mathrm{TxB}_{2}$ in collagen-activated whole blood samples, whereas the concentration of 6-ketoPGF 1 (a PGI/2-metabolite) decreased compared with palm oil (7). The experimental periods in our and their (7) study were of the same duration. The exchange of lauric acid for palmitic acid in our study, however, was smaller ( $7 \mathrm{En} \%$ instead of $12 \mathrm{En} \%$ exchanged), which might have influenced the results. Aggregation was not measured in that study (7).

Our results seem in agreement with those of Mustad et al (11), who did not indicate an altered excretion of eicosanoid metabolites $\left(T_{x B_{2}}\right.$ and 6 -ketoPGF $1 \alpha$ in urine after 26 days consumption of diets enriched in butter fat compared with cocoa butter or milk chocolate (4 En\% lauric plus myristic acid was exchanged for stearic acid). This lack of changes was observed despite an increased in the proportion of arachidonic acid in platelet phospholipid membranes with the butter fat compared with the cocoa butter diet (11). Whether urinary $T \times B_{2}$ really reflects platelet thromboxane biosynthesis, however, has been disputed (12).

The components of blood that were related to whole blood aggregation most were red blood cell counts and platelet counts, the latter for ADP-induced aggregation only. The observed inverse association between red blood cell count and whole blood aggregation was also present in the study that demonstrated a marked association between ADP-induced whole blood aggregation and prevalent ischemic heart disease $(2,13)$ and a cross sectional study in elderly subjects (14). However, for collagen-induced whole blood aggregation, this association was not observed (14). This inverse association might explain the sex differences in ADP-induced aggregation velocity, as women have lower red blood cell counts than men. Why the gender differences were less pronounced with the collagen-induced aggregation is not clear, as also for collagen-induced aggregation an inhibitory effect of red blood cells was demonstrated.

We conclude that the combined action of the blood components on in vitro whole blood aggregation induced by collagen is not affected by the exchange of $8-10$ En\% 
Chapter 5

from oleic acid for MCFA, lauric, myristic or palmitic acid. Also, a $10 \mathrm{En} \%$ exchange from oleic for MCFA or myristic acid does not affect ADP-induced aggregation.

\section{ACKNOWLEDGMENTS}

We thank Novartis Pharma AG (Horsham, Great Britain) for the provision of recombinant desulphatohirudin (TMRevasc). 


\section{REFERENCES}

1. Thaulow E, Erikssen J, Sandvik L, Stomorken H, Cohn PF. Blood platelel count and function are related to total and cardiovascular death in apparently healthy men. Circulation 1991:84:613-617.

2. Elwood PC. Beswick AD, Sharp DS, Yarnell JWG, Rogers S, Renaud S. Whole blood platelet impedance aggregometry and ischemic heart disease. Anteriosclerosis 1990;10:1032-1036.

3. Antiplatelet Trialists' Collaboration. Secondary prevention of vascular disease by prolonged antiplatelel treatment. $\mathrm{Br}$ Med $\mathrm{J} 1988 ; 296: 320-331$.

4. Steerling Committee of the Physicians' Health study. Final report on the aspirim component of the ongoing Physicians' Health Study. N Engl J Med 1989;321:129-135.

5. Renaud $S$, Godsey $F$, Dumont $E_{\text {, Thevenon }}$, Ortchanian $E_{n}$ Martin JL. Influence of long-tarm diet modification on platelet function and composition in Moselle larmers. Am J Clin Nutr 1986:43:136* 150.

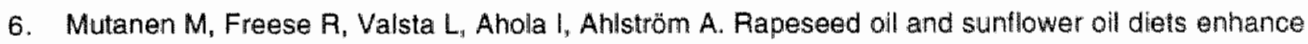
platelel in vitro aggregation and thromboxane production in healthy men when compared with milk fat or habitual diets. Thromb Haemostas 1992;67:352-356.

7. Ng TKW, Hayes KC, DeWitt GF, Jegathesan $M$, Satgunasingarn $N$, Ong ASH, Tan D. Dietary palmitic and aleic acids exert similar effects on serum cholesterol and lipoprotein profiles in normocholesterolemic men and women. J Am Coll Nutr 1992;11:383-390.

8. Temme EHM, Mensink RP, Hornstra G. Effects of medium chain fatty acids, myristic acid, and oleic acid on serum lipoproteins in healthy subjects. J Lipid Res 1997;38:1746-1754.

9. Temme EHM, Mensink RP, Hornstra G. Comparison of the effects of diets enriched in lauric, palmitic. or oleic acids on serum lipids and lipoproteins in healthy women and men. Am $J$ Clim Nutr $1996 ; 63: 897-903$.

10. Temme EHM, Mensink RP, Hornstra G. Effects of diets enriched in lauric, palmitic or oleic acids on blood coagulation and fibrinolysis. Chapter 6 .

11. Mustad VA, Kris-Etherton PM, Derr J, Reddy $\mathrm{CC}_{*}$ Pearson TA. Comparison of the effects of diets rich in stearic acid versus myristic acid and lauric acid on platelet falty acids and excretion of thromboxane $\mathrm{A}_{2}$ and PGlz metabolites in healthy young men. Metabolism 1993;42;463-469.

12. Catella F, Nowak J. Fitzgerald GA. Measurement of renal and nom-renal eicosanoid synthesis. Ams of Med 1986;81:23-29.

13. Sharp DS, Beswick AD, O'Brien JR, Renaud S, Yarnell JWG, Elwood PC. The association of plateiel and red cell count with platelet impedance changes in whole blood and light-scattering changes in platelet rich plasma: evidence from the Caerphilli Collaborative heart disease study. Thromb Haemost 1990;64:211-215.

14. Emery $\mathrm{JD}_{\mathrm{n}}$ Leifer DW, Moura GL, Southern $\mathrm{P}$, Morrissey JH, Lawrence JB. Whole-blood platelet aggregation predicts in vitro and in wivo hemostatic function in the elderly. Anterioscler Thromb Vasc Biol 1995; 15:748-753. 



\section{6}

\section{Effects of diets enriched in lauric, palmitic or oleic acids on blood coagulation and fibrinolysis}

Elisabeth HM Temme, Ronald P Mensink, Gerard Hornstra

Submitted for publication

\section{ABSTRACT}

In this study we compared the effects of specific saturated fatty acids (lauric acid and palmitic acid) with those of a monounsaturated fatty acid (oleic acid) on coagulation and fibrinolytic parameters in healthy women and men. Eighteen women and fourteen men consumed, in random order, three experimental diets, each for six weeks. The diets consisted of solid foods and approximately $70 \%$ (28 percent of energy (En\%)) of the fat calories was supplied. As determined from the duplicate portions, in the lauric acid diet $7.3 \mathrm{En} \%$ and in the palmitic acid diet $6.1 \mathrm{En} \%$ of oleic acid was exchanged for lauric or palmitic acid, respectively. The lauric acid diet also contained some (average $1.8 \mathrm{En} \%$ ) more myristic acid. Factor VII amidolytic (factor VIlam) activity responses to the saturated fat diets were significant only in women but not in men. Compared with the oleic acid diet, the female subjects showed a $9 \%$ increase with the lauric acid diet $(P=0.0036 ; 95 \% \mathrm{Cl}, 3$ to $14 \%)$ and a $10 \%$ increase with the palmitic acid diet $\left(P=0.0011 ; 95 \% \mathrm{Cl}_{8} 5\right.$ to $\left.16 \%\right)$. Antithrombin activity tended to decrease with the lauric compared with the oleic acid diet (decrease of $7 \%$ ), only in men. For all subjects combined, fibrinogen concentrations tended to increase to a comparable degree, with the lauric $(17 \mathrm{mg} / \mathrm{dL})$ and the palmitic acid diets $(18 \mathrm{mg} / \mathrm{dL})$. Fragment $1+2$ concentrations did not differ between the diets.

Plasminogen Activator Inhibitor (PAl) activity was higher on the palmitic acid compared with the oleic acid diet $(2.3 \mathrm{U} / \mathrm{mL} ; \mathrm{P}=0.0098 ; 95 \% \mathrm{Cl}, 0.4$ to $4.3 \mathrm{U} / \mathrm{mL})$ and the lauric acid diet $(2.2 \mathrm{U} / \mathrm{mL} ; \mathrm{P}=0.0123 ; 95 \% \mathrm{Cl}, 0.2$ to $4.1 \mathrm{U} / \mathrm{mL})$.

From this study we conclude that a diet rich in lauric or palmitic acid, compared with a diet rich in oleic acid, unfavorably influences the plasma coagulant capacity, in a gender specific manner. 


\section{INTRODUCTION}

The coagulant capacity of the blood is important in the evolution of cardiovascular diseases as is suggested from the results of epidemiological studies. Fibrinogen (1, 2) and factor VII coagulant activity (factor VIIC) $(1,2)$ are independent risk markers for the development of coronary heart disease. In addition, high plasminogen activator inhibitor (PAl) concentrations are positively associated with the reoccurrence of coronary events (3).

Controlled dietary experiments have now indicated that plasma activities of coagulation or fibrinolytic parameters may be affected by the fatty acid composition of the diet $(4,5)$. Mitropoulos et al (4) found increased factor Vllc activity after 4 wk consumption of a diet rich in saturated fatty acids compared with unsaturated fatty acids. In addition, Almendingen et al (5) reported increased fibrinogen concentrations after a diet enriched with butterfat compared with a partially hydrogenated fish oil diet, while PAI activity was decreased with a butterfat diet compared with a partially hydrogenated soybean oil diet.

Recent studies (6-8) also suggested that the individual saturated fatty acids may differently affect the coagulant capacity of plasma. The effects of lauric acid, however, were not assessed in these studies (6-8), while only young and lean males were enrolled. In the present study we, therefore, investigated, in a 6 week cross-over trial, the effects of diets enriched with lauric acid $\left(\mathrm{C}_{12: 0)}\right.$ or palmitic acid $\left(\mathrm{C}_{16: 0)}\right.$ with those of a diet enriched in oleic acid (C18:1) on plasma coagulation and fibrinolytic parameters in healthy women and men.

\section{SUBJECTS AND METHODS}

\section{Design and statistical analysis}

This project was also designed to investigate, with a cross-over study design, the effects of the diets enriched in lauric, palmitic or oleic acids on serum lipids and lipoproteins (9). Each participant consumed each of the three different diets during three periods, each of six weeks duration. Before the study, the subjects were categorized according to sex. Subjects were then randomly divided into six groups in such way that each group contained about the same number of subjects of both sexes. Each group received the diets in a different order. The dietary periods were interrupted by washout periods of 2 (between first and second diet-period) and 3 (between second and third diet-period) weeks, respectively. During these periods, the participants consumed their habitual diets. The protocol of the study had been approved by the local ethics committee and all volunteers had given their written informed consent.

Data were analyzed with diet, period and diet-and-sex interaction as independent variables using the general linear models (GLM) procedure of the Statistical Analysis System (10). When a significant diet or diet-and-sex interaction effect was observed 
$(\mathrm{P}<0.05)$, the three diets were compared pairwise. Analysis were corrected for 3 group comparisons by the Tukey method (11). In addition "diet-and-period interaction was checked and did not reveal any significant carry-over effects of the coagulation and fibrinolytic parameters. Whether age was related with the response to the diets of coagulation and fibrinolytic factors was examined by including a diet and age interaction term into the statistical model. This interaction term never reached statistical significance, indicating that the changes in the coagulation or fibrinolytic parameters to the diets were not related to age.

Pearson correlations were calculated between significant changes in lipoproteins and significant changes in coagulation and fibrinolytic factors for all subjects and according to gender. Only correlations with $\mathrm{P}<0.02$ were considered relevant.

\section{Subjects}

Volunteers were recruited via advertisements in local newspaper and posters in public buildings. After they had been thoroughly informed about the purpose and protocol of the study, the subjects underwent the selection procedure. The 43 people selected for the study met all of our eligibility criteria: aged 20-60 year, not taking a prescribed or reducing diet, not anemic, blood pressure below $140 / 80 \mathrm{mmHg}$, serum total cholesterol concentrations lower than $6.5 \mathrm{mmol} / \mathrm{L}$ and not using medications known to affect lipoproteins and hemostatic parameters. Eleven subjects withdrew because of reasons specifically related to the strict study protocol (six subjects), job or study commitments (two subjects), family circumstances (two subjects) and illness (one subject). Thirty-two subjects, 18 women and 14 men, completed the study. The women were between 22 and 60 years old (mean $40 \mathrm{y}$ ), weighed $51-96 \mathrm{~kg}$ (mean 69 $\mathrm{kg}$ ), were between 156 and $183 \mathrm{~cm}$ in height (mean $166 \mathrm{~cm}$ ) and had body mass indexes from 19 to $30 \mathrm{~kg} / \mathrm{m}^{2}$ (mean $25 \mathrm{~kg} / \mathrm{m}^{2}$ ). The men were between 23 and 59 years old (mean $43 \mathrm{y}$ ), weighed $71-101 \mathrm{~kg}$ (mean $81 \mathrm{~kg}$ ), were between 175 and 188 $\mathrm{cm}$ (mean $179 \mathrm{~cm}$ ) in height, and had body mass indexes from 22 to $31 \mathrm{~kg} / \mathrm{m}^{2}$ (mean $25 \mathrm{~kg} / \mathrm{m}^{2}$ ). Four women and 5 men were smokers. Two women used oral contraceptives and 6 women were postmenopausal.

\section{Diets}

The experimental margarines supplied $70 \%$ of the total fat energy and were given with solid foods. Total fat intake, in this semi-controlled trial, was on average 41 energy percent ( $\mathrm{En} \%$ ) fat. The fatty acid composition of the diets, as determined from the collected duplicate portion samples, was almost identical between diets with the main exception that in the lauric acid diet $7.3 \mathrm{En} \%$ acid and in the palmitic acid diet $6.1 \mathrm{En} \%$ of oleic acid was exchanged for lauric acid or palmitic acid, respectively. These differences were achieved by the use of special experimental fats. The fat high in lauric acid was a mixture of palm kernel $(75 \%)$ (Wesco; Karlshamns, Zaandijk, The Netherlands) and a high oleic acid sunflower oil (Trisun; SVO enterprises, Wickliffe, USA) $(25 \%)$, the fat high in palmitic acid consisted of dairy fat $(55 \%)$ (FDF, Leeuwarden, The Netherlands), palmstearin (36\%) (Aarhus oil, Aarhus, Denmark) and the high oleic acid sunflower oil $(9 \%)$, and the fat high in oleic acid of dairy fat 
$(37 \%)$ and the high oleic acid sunflower oil $(63 \%)$. The fatty acid composition of these fats has been described before (9). Cholesterol was added to the fats high in lauric and oleic acids, so that all fats contained $145 \mathrm{mg}$ of cholesterol per $100 \mathrm{~g}$ of fat. Margarines were made from the fats and consisted of $83 \%$ fat and $17 \%$ water. The experimental margarines were given as such and were incorporated in bread, biscuits, pies, cakes, cheeses and custards.

Before the study started, the subjects recorded habitual food intake on two working days and one weekend day. From this record their energy intake was calculated. The study diets were formulated at different levels of energy, so that each subject received a diet that met his or her energy needs. According to these energy levels, lists were computed which stated the amount of experimental products the subject had to eat each day or each week. Products were coded with colored labels to blind the subjects as to the nature of the diets and were handed out on an individual basis. $30 \%$ of total fat intake was free and subjects could choose them from listed "free choice" fat containing products. Subjects came at least once a week to a special room at the university to get a new supply of products and to be weighed. They were also asked to maintain the same activity level, smoking and drinking habits throughout the study. Any changes as well as medication used, illnesses, daily alcohol use and menstrual cycle were written down in a special diary.

The subjects collected a duplicate portion of the food and drinks consumed for two days at the end of each dietary period. Duplicate portions were pooled according to treatment group. Lipids from the duplicate portions were extracted with the Soxhlet method. The fatty acids were transmethylated to their corresponding methylesters, which were quantified on a gas chromatograph, with a polar capillary column (CP Sil 88, Chrompack, Middelburg, The Netherlands) as described before (12).

\section{Blood sampling and measurements}

Blood was sampled in week 5 and at the end (week 6 ) of each period after an overnight fast and after subjects abstained from drinking alcohol the preceding day and smoking on the morning before blood sampling. The samples of week 5 and 6 of each period were pooled prior to analyses. Blood was sampled with a minimum of stasis and by using a $1.2-\mathrm{mm}$ needle (Strauß Kanule, Luer, Wächtersbach, Germany) with the subject in a recumbent position. All venipunctures were performed by the same person, at the same location, and for each subject generally at the same time of the same day of the week.

The first $5 \mathrm{~mL}$ blood was used for measurement of hematologic parameters and platelet aggregation, to be reported elsewhere. Then, two portions of $5 \mathrm{~mL}$ blood were collected in tubes containing a mixture of citrate, theophylline, adenosine and dipyridamole (CTAD). One tube was immediately placed on ice and centrifuged at $\left.2000 \mathrm{~g} \mathrm{(10} \mathrm{minutes,} 4^{\circ} \mathrm{C}\right)$ and used for measurement of PAll activity. The second CTAD tube was centrifuged at $2000 \mathrm{~g}\left(10\right.$ minutes, $\left.4^{\circ} \mathrm{C}\right)$ followed by centrifugation at $11,500 \mathrm{~g}\left(30\right.$ minutes $\left._{4} 4^{\circ} \mathrm{C}\right)$ and used for measurement of coagulation factors. Finally, a $10 \mathrm{~mL}$ clotting tube was filled to determine lipids and lipoproteins. All samples from 
one subject were analyzed within one run. Standard pool plasmas were obtained from normolipidemic subjects, and prepared by the same methods as described above. Samples were stored at $-80^{\circ} \mathrm{C}$ before analyses.

Factor VII, Factor $X_{n}$ antithrombin, plasminogen, $\alpha_{2}$-antiplasmin activities were assessed with chromogenic assays (Coaset FVII, Coatest FX, Coamatic antithrombin, Coamatic Plasminogen, Coatest Antiplasmin, Chromogenix, Mölndal, Sweden). Plasma fibrinogen concentrations were measured by the method of Clauss (13). The factor VII amidolytic activity (factor VIlam) assay is based on the two stage principle, using human placenta thromboplastin. In stage one, factor VII in the test sample complexes with thromboplastin and $\mathrm{Ca}^{++}$. This complex activates factor $\mathrm{X}$, which is present in excess in the reagent mixture. Factor VII is completely converted into activated factor VII during this process and accordingly there is no interference in the assay of preactivated factor VII. In stage two the generated activated factor $X$ hydrolyses the chromogenic substrate. The coefficients of variation within runs were $5.8 \%$ for factor VIlam, $4.8 \%$ for factor $X, 5.2 \%$ for antithrombin, $5.9 \%$ for plasminogen, $5.3 \%$ for $\alpha_{2}$-antiplasmin and $8.8 \%$ for fibrinogen. Activities were expressed as percentage of a reference plasma. PAl activity was measured with a chromogenic assay (Spectrolyse(R)(pL) PAl, Biopool, Umea, Sweden). Coefficient of variation within runs was $4.0 \%$. Prothrombin activation fragment $1+2$ was measured with an enzymelinked immunosorbent assay (ELISA) (Thrombonostika F1.2, Organon Teknika, Durnham, USA). $10 \mu \mathrm{l}$ of the $10 \mathrm{nmol}$ fragment $1+2$ calibrator was added to the sample wells to obtain concentrations in the linear area of the calibration curve. Coefficient of variation within runs was $10.1 \%$.

Fatty acid composition of serum total lipids at the end each dietary period was determined in samples pooled according to treatment group. In this way six pooled samples per diet were obtained. Serum lipids were extracted with a modified Folch extraction (14). The fatty acids were transmethylated to the corresponding methy! esters (15), which were quantified on a gas chromatograph, with a polar capillary column (CP Sil 88, Chrompack, Middelburg. The Netherlands) as previously described (12).

\section{RESULTS}

\section{Subjects and dietary adherence}

Body weights (means \pm standard deviations) of the subjects did not differ between the three diets and were $74 \pm 12 \mathrm{~kg}$ with the lauric, $75 \pm 12 \mathrm{~kg}$ with the palmitic and $74 \pm 11 \mathrm{~kg}$ with the oleic acid diet.

The mean daily energy intake and the fatty acid composition of the diets was determined with a four days food records (9) and from the lipids extracted from two days duplicate portions (table 1). Total fat intake did not differ between the three diets and was $41 \mathrm{En} \%$ on average. As determined from the duplicate portion samples, the 
difference in lauric acid was 7.3 En\% between the lauric and the oleic acid diet, while the palmitic acid diet was 6.1 En\% higher in palmitic acid than the oleic acid diet. The lauric acid diet contained also some (average $1.8 \mathrm{En} \%$ ) more myristic acid than the other two diets.

The mean amount of fat consumed as "free-choice" fat items as listed daily in the subjects diaries, agreed with the calculated amount and was $1 \pm 3$ gram (meantstandard deviation) less than prescribed.

Table 1. Fatty acid composition of the experimental diets rich in lauric, palmitic or oleic acids, as determined from GC fatty acid analysis of lipids extracted from two days duplicate portions."

\begin{tabular}{lrrr}
\hline & $\begin{array}{c}\text { Lauric } \\
\text { Acid Diet }\end{array}$ & $\begin{array}{c}\text { Palmitic } \\
\text { Acid Diet }\end{array}$ & $\begin{array}{c}\text { Oleic } \\
\text { Acid Diet }\end{array}$ \\
\hline & & Percent of energy & \\
Fat $t$ & $41.5 \pm 5.5$ & $41.0 \pm 5.4$ & $41.8 \pm 5.5$ \\
SAFA & $25.2 \pm 1.3$ & $23.6 \pm 0.9$ & $16.7 \pm 2.6$ \\
$\leq$ C10:0 & $0.8 \pm 0.1$ & $0.6 \pm 0.1$ & $0.5 \pm 0.1$ \\
C12:0 & $10.8 \pm 1.2$ & $3.3 \pm 0.9$ & $3.5 \pm 1.7$ \\
C14:0 & $4.3 \pm 0.3$ & $2.7 \pm 0.2$ & $2.3 \pm 0.5$ \\
C16:0 & $6.5 \pm 1.2$ & $12.6 \pm 1.3$ & $6.5 \pm 0.9$ \\
C18:0 & $2.3 \pm 0.3$ & $3.5 \pm 0.2$ & $3.1 \pm 0.3$ \\
Others & $0.4 \pm 0.2$ & $0.8 \pm 0.4$ & $0.6 \pm 0.1$ \\
MUFA & & & $19.3 \pm 2.9$ \\
C18:1(n-9) & $12.0 \pm 0.9$ & $13.1 \pm 0.9$ & $18.4 \pm 2.9$ \\
C18:1(n-9in) & $11.0 \pm 1.0$ & $11.6 \pm 1.0$ & $0.4 \pm 0.1$ \\
Others & $0.3 \pm 0.1$ & $0.8 \pm 0.2$ & $0.5 \pm 0.2$ \\
PUFA & $0.8 \pm 0.2$ & $0.7 \pm 0.4$ & $5.4 \pm 0.5$ \\
C18:2(n-6) & & & $4.2 \pm 0.4$ \\
C18:3(n-3) & $4.3 \pm 0.7$ & $4.7 \pm 1.6$ & $0.3 \pm 0.1$ \\
Others & $3.2 \pm 0.3$ & $3.2 \pm 1.6$ & $0.9 \pm 0.4$ \\
\hline
\end{tabular}

Values are meanststandard deviations. Duplicate portions were pooied according to treatment group and analyzed as such. Values are the mean of six pooled samples.

1 As determined from the four days food records.

SAFA: saturated fatty acids, MUFA: monounsaturated fatty acids, PUFA: polyunsaturated fatty acids. 
The fatty acid composition of serum total lipids is shown in table 2. The percentages of lauric $(\mathrm{C} 12: 0)$ and myristic $(\mathrm{C} 14.0)$ acids significantly increased with the lauric acid diet compared with both the palmitic acid $(\mathrm{C} 16: 0)$ and the oleic acid $(C 18: 1(n-9))$ diets. Palmitic acid increased with the palmitic acid diet compared with the oleic and the lauric acid diets. Serum oleic acid levels were lower but palmitolieic acid (016:1(n-7)) levels were higher with the saturated fatty acid diets compared with the oleic acid diet. The three diets did not affect the serum content of polyunsaturated fatty acids in a significant different way.

Table 2. Fatty acid composition of serum total lipids on diets enriched in lauric, palmitic or oleic acids.*

\begin{tabular}{|c|c|c|c|}
\hline & $\begin{array}{l}\text { Lauric } \\
\text { Acid Diet }\end{array}$ & $\begin{array}{l}\text { Palmitic } \\
\text { Acid Diet }\end{array}$ & $\begin{array}{c}\text { Oleic } \\
\text { Acid Diet }\end{array}$ \\
\hline & \multicolumn{3}{|c|}{$\%$ of total fatty acids } \\
\hline SAFA & $32.7 \pm 0.7$ & $33.0 \pm 4.7$ & $31.5 \pm 0.9$ \\
\hline $12: 0$ & $0.5 \pm 0.2 t \neq$ & $0.2+0.0$ & $0.2+0.0$ \\
\hline $14: 0$ & $2.9 \pm 0.4 † ¥$ & $2.3 \pm 0.2$ & $2.4 \pm 0.4$ \\
\hline $16: 0$ & $21.1 \pm 0.6$ & $22.4 \pm 1.2 \dagger$ & $20.4 \pm 0.6$ \\
\hline $18: 0$ & $6.3 \pm 0.4$ & $6.4 \pm 0.3$ & $6.5 \pm 0.4$ \\
\hline MUFA & $23.0 \pm 1.3+$ & $23.4 \pm 1.5 \dagger$ & $26.5+2.3$ \\
\hline $16: 1(n-7)$ & $1.9 \pm 0.1+$ & $2.1 \pm 0.3+$ & $1.6 \pm 0.1$ \\
\hline $18: 1(n-9)$ & $18.1 \pm 1.2 \dagger$ & $18.1 \pm 1.0+$ & $21.0 \pm 2.3$ \\
\hline PUFA $\quad(n-6)$ & $41.6 \pm 1.4$ & $40.9+2.0$ & $39.2 \pm 1.8$ \\
\hline $18: 2(n-6)$ & $3.2 .9 \pm 1.4$ & $32.6 \pm 2.4$ & $30.6 \pm 1.8$ \\
\hline $20: 4(n-6)$ & $6.7 \pm 0.7$ & $6.3 \pm 0.7$ & $6.7 \pm 0.6$ \\
\hline PUFA $\quad(n-3)$ & $2.7 \pm 0.2$ & $2.7 \pm 0.2$ & $2.7 \pm 0.9$ \\
\hline $18: 3(n-3)$ & $0.6 \pm 0.2$ & $0.5 \pm 0.1$ & 0.440 .0 \\
\hline $20: 5(n-3)$ & $0.6 \pm 0.1$ & $0.6 \pm 0.1$ & $0.7 \pm 0.7$ \\
\hline $22: 6(n-3)$ & $1.6 \pm 0.2$ & $1.5=0.2$ & $1.6 \pm 0.3$ \\
\hline
\end{tabular}

* Fatty acids are determined in six pooled serum samples. Values are given as meanststendard deviation.

$\dagger$ Significantily different from the oleic acid diet, $P<0.02$.

\# Significantly different from the palmitic acid diet, $P<0.02$.

SAFA: saturated fatty acids, MUFA: monounsiaturated fatty acids, PUFA: polyunsaturated fatty acids.

\section{Blood coagulation and fibrinolytic parameters}

Table 3 and 4 show the levels of the coagulation and fibrinolytic parameters at the end of each dietary period. Factor VIlam activity responses to the diets differed between women and men, as indicated by the highly significant diet-and-sex 
interaction term ( $P=0.0071)$. Women showed a $9 \%$ increase with the lauric acid diet $(\mathrm{P}=0.0036 ; 95 \% \mathrm{Cl}, 3$ to $14 \%)$ and a $10 \%$ increase with the palmitic acid diet $(\mathrm{P}=0.0011 ; 95 \% \mathrm{Cl}, 5$ to $16 \%)$, both compared with the oleic acid diet. In men, no significant differences in factor Vllam activities were found. On the oleic acid diet, factor VIlam activities (mean and range) in premenopausal women not using contraceptives $(n=10)$, pre-menopausal women on contraceptives $(n=2)$ and postmenopausal women $(n=6)$ were $101 \%(53 \%-135 \%), 117 \%(83 \%-151 \%)$ and $107 \%(91 \%-133 \%)$ respectively. In figure 1 individual changes in factor Vllam after the diets are shown, when subjects are sorted according to factor Vllam activity on the oleic acid diet. The responses to the diets did not differ with higher factor VIlam activity on the oleic acid diet. In addition, responses to the saturated fat diets of contraceptive users or postmenopausal women were not clearly higher compared with the responses of premenopausal women not using contraceptives.

Table 3. Coagulation parameters on diets enriched in lauric, palmitic or ole ic acids."

\begin{tabular}{|c|c|c|c|}
\hline & $\begin{array}{c}\text { Lauric } \\
\text { Acid Diet }\end{array}$ & $\begin{array}{l}\text { Palmitic } \\
\text { Acid Diet }\end{array}$ & $\begin{array}{c}\text { Oleic } \\
\text { Acid Diet }\end{array}$ \\
\hline \multicolumn{4}{|c|}{ Factor Vliam activity ( $\%$ of standard) } \\
\hline All & $109+24 t$ & $108+25 \dagger$ & $103+21$ \\
\hline Women & $114 \pm 27 \dagger$ & $115 \pm 26 \dagger$ & $105 \pm 23$ \\
\hline Men & $102 \pm 19$ & $99 \pm 21$ & $100 \pm 19$ \\
\hline \multicolumn{4}{|c|}{ Factor $X$ activity ( $\%$ of standard) } \\
\hline All & $115 \pm 19$ & $115 \pm 22$ & $116 \pm 20$ \\
\hline Women & $110 \pm 16$ & $108+20$ & $112+17$ \\
\hline Men & $121 \pm 20$ & $125 \pm 20$ & $121 \pm 22$ \\
\hline \multicolumn{4}{|c|}{ Antithrombin activity ( $\%$ of standard) } \\
\hline All & $111 \pm 12$ & $113 \pm 13$ & $114 \pm 14$ \\
\hline Women & $110 \pm 11$ & $110 \pm 12$ & $111 \pm 11$ \\
\hline Men & $112+13$ & $117 \pm 14$ & $118 \pm 17$ \\
\hline \multicolumn{4}{|c|}{ Fibrinogen (mg/dL) } \\
\hline All & $291 \pm 76$ & $291 \pm 71$ & $274+66$ \\
\hline Women & $288+80$ & $288 \pm 69$ & $270+62$ \\
\hline Men & $294 \pm 72$ & $295 \pm 76$ & $279 \pm 72$ \\
\hline \multicolumn{4}{|c|}{ Fragment $1+2(\mathrm{nmol} / \mathrm{L})$} \\
\hline All & $1.28 \pm 0.68$ & $1.33 \pm 0.70$ & $1.30 \pm 0.64$ \\
\hline Women & $1.28 \pm 0.59$ & $1.29 \pm 0.64$ & $1.30 \pm 0.70$ \\
\hline Men & $1.28 \pm 0.79$ & $1.38 \pm 0.80$ & $1.30 \pm 0.57$ \\
\hline
\end{tabular}

\footnotetext{
Values are meanststandard deviations. Eighteen women and fourteen men consumed all three diets, for six weeks each, in random order.

$\dagger$ Significantly different from the oleic acid diet, $P<0.02$.
} 
Antithrombin activity, although not significantly, decreased by $4 \%, \mathrm{P}=0.0235 ; 95 \%$ $\mathrm{Cl},-7$ to $-0.3 \%$ ) with the lauric compared with the oleic acid diet. This effect was more apparent in men (decrease of $7 \% ; \mathrm{P}=0.0350 ; 95 \% \mathrm{Cl},-13$ to $-0.5 \%$ ) than in women (decrease of $1 \% ; \mathrm{P}=0.2063 ; 95 \% \mathrm{Cl}_{1}-4$ to $2 \%$ ), but the diet-and-sex interaction term was not significant $(P=0.2407)$.

Fibrinogen concentrations increased not significantly by $17 \mathrm{mg} / \mathrm{dL} \quad(P=0.0302$; $95 \% \mathrm{Cl}, 1$ to $33 \mathrm{mg} / \mathrm{dL})$ with the lauric acid diet and by $18 \mathrm{mg} / \mathrm{dL} .(\mathrm{P}=0,0219 ; 95 \% \mathrm{Cl}$, 1 to $34 \mathrm{mg} / \mathrm{dL}$ ) with the palmitic acid diet. The responses to the saturated fat diets did just not reach statistical significance when the Tukey correction was applied. Responses to the diets were similar for women and men.

Factor $X$ activities and fragment $1+2$ concentrations did not change differently with the three diets.

For the fibrinolytic parameters, plasminogen and $\alpha_{2}$-antiplasmin activity did not differ between the three diets either. PAl activity, however, increased with the palmitic acid diet compared with both the lauric acid (difference of $2.2 \mathrm{U} / \mathrm{mL} ; \mathrm{P}=0.0123 ; 95 \%$ $\mathrm{Cl}, 0.2$ to $4.1 \mathrm{U} / \mathrm{mL}$ ) and the oleic acid diet (dlifference of $2.3 \mathrm{U} / \mathrm{mL} ; \mathrm{P}=0.0098 ; 95 \% \mathrm{Cl}$, 0.4 to $4.3 \mathrm{U} / \mathrm{mL}$ ). The effects of PAl activity did not differ between women and men and were not related to the values measured after the oleic acid period (figure 2).

Table 4. Fibrinolytic parameters on diets enriched in lauric, palmitic or oleic acids."

\begin{tabular}{lccc}
\hline & $\begin{array}{c}\text { Lauric } \\
\text { Acid Diet }\end{array}$ & $\begin{array}{c}\text { Palmitic } \\
\text { Acid Diet }\end{array}$ & $\begin{array}{c}\text { Oleic } \\
\text { Acid Diet }\end{array}$ \\
\hline $\begin{array}{l}\text { Plasminogen activity (\% of standard) } \\
\text { All }\end{array}$ & $124 \pm 17$ & $125 \pm 16$ & $122 \pm 14$ \\
Women & $124 \pm 20$ & $127 \pm 17$ & $123 \pm 16$ \\
Men & $123 \pm 1.4$ & $122 \pm 14$ & $120 \pm 13$ \\
an-antiplasmin activity (\% of standlard) & $110 \pm 20$ & $115 \pm 19$ & $112 \pm 16$ \\
All & $107 \pm 20$ & $110 \pm 20$ & $110 \pm 19$ \\
Women & $113 \pm 19$ & $121 \pm 18$ & $115 \pm 8$ \\
Men & $13.6 \pm 6.9$ & $15.7 \pm 6.2$ & $13.4 \pm 5.1$ \\
All activity (U/mL) & $13.9 \pm 6.2$ & $14.8 \pm 5.7$ & $12.6 \pm 5.1$ \\
Women & $13.2 \pm 7.9$ & $17.0 \pm 6.8$ & $14.4 \pm 5.0$ \\
Men & & & \\
\hline
\end{tabular}

\footnotetext{
Values are means \pm standard deviations. Elghteen women and fourteen men consumed al three diets, for six weeks each, in random order.

$\dagger$ Significantly different from the oleic acid diet, $P<0.02$.

\# Significantly different from the palmitic acid diet, $P<0.02$.
} 
Change in tactor Vilam activity (\%)

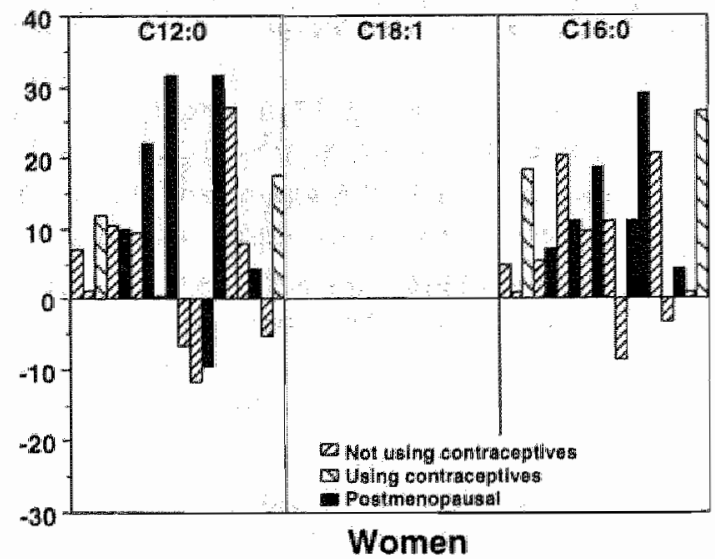

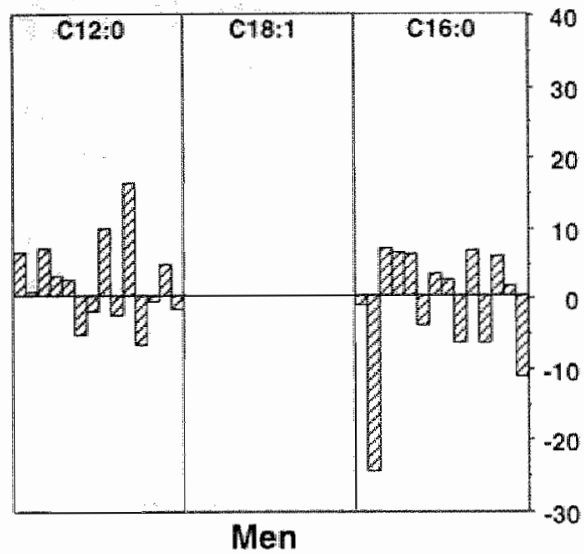

Figure 1. Individual changes in factor Vllam activity on diets high in lauric acid (C12:0) or palmitic acid $(\mathrm{C} 16: 0)$, relative to a diet high in oleic acid (C18:1). Subjects are sorted, from the left to right, according to factor Vllam activity on the oleic acid diet.
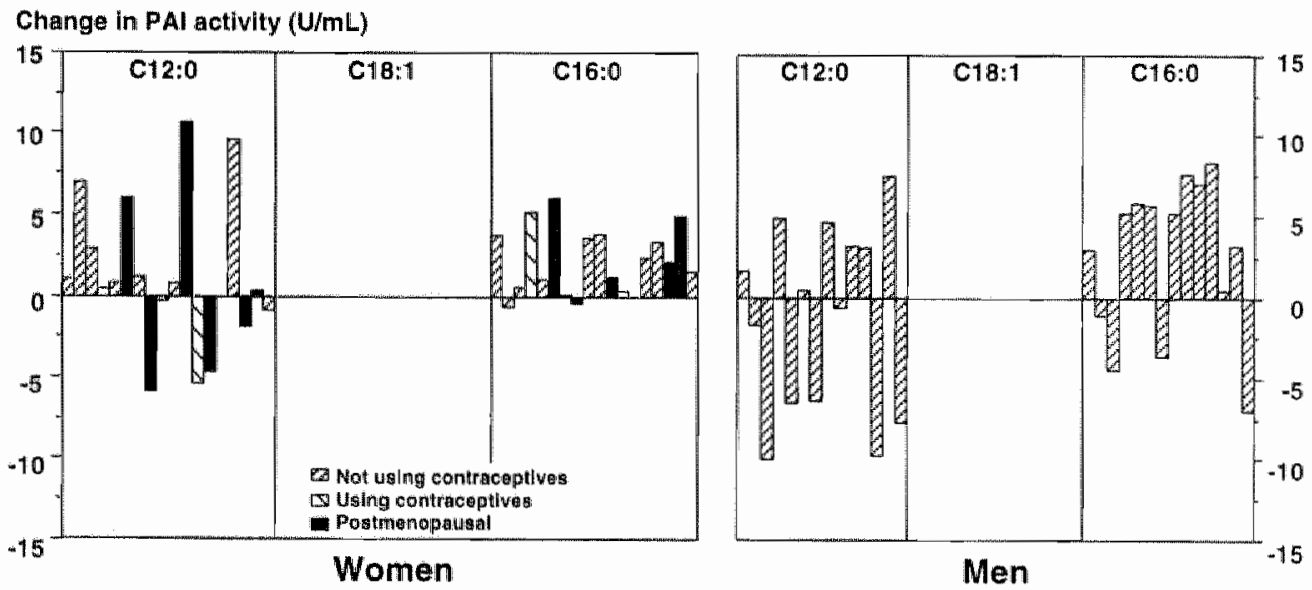

Figure 2. Individual changes in plasminogen activator inhibitor (PAl) activity on diets high in lauric acid (C12:0) or palmitic acid (C16:0), relative to a diet high in oleic acid (C18:1). Subjects are sorted, from the left to right, according to PAl activity on the oleic acid diet. 
The effects of the three diets on serum lipids and lipoprotein concentrations have been reported earlier (9). When all subjects together were taken into consideration, no strong associations were found between changes in coagulation or fibrinolytic parameters with changes in lipoproteins on the diets. In addition, no consistent correlations were demonstrated when separate correlation analyses were conducted according to gender. Intercorrellations of changes in coagulations and fibrinolytic factors demonstrated no significant associations when data of all subjects were combined, and no consistent correlations when data were analyzed according to gender.

\section{DISCUSSION}

In this study we investiglated the effects on plasma activities of coagulation and fibrinalytic factors of diets enriched in lauric and palmitic acids compared with a diet enriched in oleic acid.

Marked differences were noted in factor VIlam responses between our female and male subjects. Increased factor VIlam activity after the diets rich in saturated fatty acids was only apparent in women, which suggested an interaction between diet and hormonal or genetic backgrounds. Endogenous estrogen levels have been linked to factor VII activity before as, in agreement with our results, factor VIllam activity was higher in postmenopausal women $(16,17)$ and in contraceptive users (18) than in premenopausal women not using contraceptives. Differences in estrogen concentrations in these three groups of women, however, were not likely to explain different factor VIlam responses to the saturated fat diets as changes in factor VIlam were not more pronounced in one of the groups (figure 1). However, this might also be related to the relative small numbers of women in the different groups. A recent study (19) showed that contraceptive use affects factor VIlc responses to changes in dietary fatty acid composition. Factor Vllc activity increased after a diet rich in trans fatty acid compared with a stearic acid diet in females using contraceptives, while no change was found among the non-users (19).

Another major determinant of factor $\mathrm{V} / \mathrm{I}$ activity is a polymorphism of the gene coding for factor VIII $(20,21)$. Since similar frequencies of the different factor VII gienotypes are found in women and men $(20,21)$, we speculate on the basis of our findings that a similar genotype does not preclude factor VIl responses in a gender. specific way. An example of gender-specific influences on factor VIll activity between women and men with similar genotypes was recently reported for the association between non-fasting plasma triacylglycerols and factor VIIc activity (22), but not for factor VII responses after changes in dietary fat or fatty acids. Clearly, more research is needed to define the possible gender-dependent responses of dietary fatty acids on coagulation factors and their underlying mechanisms.

Tholstrup et al $(6,7)$ demonstrated, in young and lean men, that diets rich in lauric plus myristic acids or palmitic acid increase factor VIlc activity compared with a stearic 
acid diet (6). In a second experiment, myristic acid alone increased factor Vllc slightly (2\%) stronger than palimitic acid (7). Since different reference diets were consumed in both studies $(6,7)$, compared with the oleic acid diet in the present study, a valid comparison of the results of both studies is difficult. Relative to oleic acid, the absence of effects of lauric and palmitic acid on factors Vllam activity in our male subjects seems to contrast their results $(6,7)$. However, in line with our results, except for stearic acid, no (6) or only small (7) differences in factor VIlc were observed between saturated fatty acids, in men.

In both women and men, the combined effects of the saturated fat diets on coagulation factor activities and the slightly increased fibrinogen concentrations, indicate that these diets increase the coagulant capacity of plasma relative to oleic acid. The unchanged fragment $1+2$ concentrations, however, suggest that the saturated fat diets did not alter the in vivo activation of the coagulation system. Increased fragment $1+2$ concentrations have been reported in male subjects after diets rich in lauric plus myristic acid compared with stearic acid. (8). Whether diets with higher levels of dietary myristic acid induces a more potent fragment $1+2$ response is not known.

Compared with both the oleic and the lauric acid diet, palmitic acid increased PAI activity. Previous studies did not support this potentially unfavorable effect of palmitic acid on PAI. Tholstrup et al $(6,7)$ reported unchanged PAl antigen content and ouglobulin fibrinolytic capacity after diets rich in saturated fatty acids with 12 to 18 carbon atoms. A diet rich in butterfat decreased PAl activity compared with a diet with partially hydrogenated soybean oil (5). The butterfat diet was rich in a mixture of saturated fatty acids, mainly palmitic acid, but the lowering effects could also be attributed to the lower $18: 1$ trans fatty acid content of this diet.

To summarize, both saturated fatty acids increased factor VIlam activity, only in women. The lauric acid diet tended to decrease antithrombin activity, only in men. Fibrinogen concentrations were slightly, though not significantly, elevated in both women and men. The PAl activity of plasma was negatively affected with the palmitic acid diet. From this study we, therefore, conclude that the lauric and the palmitic acid diets, compared with the oleic acid diet, had a unfavorable effect on the coagulant capacity of the blood, in a gender specific manner. 


\section{REFERENCES}

1. Heinrich $J$, Balleisen $L$, Schulte $H_{3}$ Assmann $G_{3}$ van de $L 00 \mathrm{~J}$. Fibrinogen and factor vill in the prediction of coronary risk. Arterioscier Thromb 1994;14:54-59.

2. Meade TW, Brozovic M, Chakrabarti RR, Haines AP, Imeson JD, Mellows S, Miller Gu, North WRS, Stirling $Y$. Thompson SG. Haemostatic function and Ischaemic heart disease: principal results of the northwick park heart study. Lancet 1986;2:533-537.

3. Hamsten A, Walldius G, Szamosi A, Blombäck M, Faire Ud, Dahlén G, Landou C, Wiman B Plasminogen activator inhibitor in plasma: risk factor for recurrent myocardial infarction. Lancel $1987 ; 2: 3-8$

4. Mitropoulos KA, Miller GJ, Martin JC, Reeves BEA, Cooper J. Dietary fat induces changes in factor VII coagulant activity through effects on plasma free stearic acid concentration. Arterioscler thromb 1994:14:214-222.

5. Almendingen $\mathrm{K}$, Seljeflot I, Sandstad B, Pedersen Jl. Effects of partially hydrogenated fish oil. partially hydrogenated soybean oil, and butter on hemostatic variables in men. Arterioscler Thromb Vasc Biol 1996;16:375-380.

6. Tholstrup T, Marckmann $P$, Jespersen J, Sandström B. Fat high in stearic acid favorably affects blood lipids and factor Vil coagulant activity in comparison with fats high in paimilic acid or high in myristic and lauric acids. Am J Clin Nutr 1994;59:371-377.

7. Tholstrup T, Marckmann P, Jespersen J, Vessby B, Jart A, Sandström B. Effect on blood lipids, coagulation, and fibrinalysis of a fat high in myristic acid and a fat high in palmitic acid. Am J Clin Nutr $1994: 60: 919-925$.

8. Bladbjerg EM, Tholstrup T, Marckmann P, Jespersen J, Sandström B. Dietary changes in fasting levells of factor VII coagulant activity (FVII:C) are accompanied by changes in factor VII protein and other vitamin K-dependent proteins. Thromb Haemost 1995;73:239-242.

9. Temme EHM, Mensink RP, Hornstra G. Comparison of the effects of diets enriched in lauric, palmitic, or oleic acids on serum lipids and lipoproteins in healthy women and men. Am I Clin Nutr $1996 ; 63: 897-903$.

10. SAS Institute Inc. SAS: user's Guide Statistics, Version 5 Edition. Cary, NC: SAS Institute Inc, 1985.

11. Snedecor GW, Cochram WG. Statistical methods. 7 th ed. Ames, lowa: The lowa State Uniwersity Press, 1980.

12. van Haaster CMCJ, Engels W. Lemmens P.JMR. Hornstra G, van der Vusse Gu. Formation of prostanoids and hydroxy fatty acids by stimulated rat peritoneal mast cells: role of the dietary fitl iype. Biochim Biaphys Acta 1993;1167:147-154.

13. Clauss. A. Gerinnungsphysiologische schnillmethode zur bestimmung des fibrinogens. Acte Haematol 1957;17:237-246.

14. Folch J, Lees M. Sloane Stanley GH. A simple method for the isolation and purification of total lipides from animal tissues. J Biol Chem 1957;226:497-509.

15. Morrison WR, Smith LM. Preparation of fatty acid methylesters and dimethylacetals from lipidis with boron fluoride methanol. J Lipia Res 1964;5:600-608.

16. Kario K, Miyata T, Sakata T, Matsuo T, Kato H. Fluorogenic assay of activated factor VII. Arterioscler Thromb 1994;14:265-274.

17. Scarabin P-Y, Vissac A-M, Kirzin J-M, Bourgeal P, Amiral J, Agher R, Guize L. Population correlates of coagulation factor VII. Arterioscler Thromb Vase Biol 1996;16:1170-1176. 
18. Balleisen L, Bailley J, Epping P.H, Schulte H, van de Loo J. Epidemiological study on factor VI, factor VIII and fibrinogen in an industrial population: I. Baseline data on the relation to age, gender. bodyweight, smoking, alcohol, pill-using, and menopause. Thromb Haemost 1985;54:475-479.

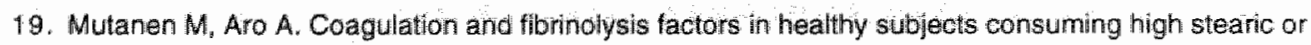
trans fatty acid diet: Thromb Haemost 1997;77:99-104.

20. Green $F$, Kelleher $C$, Wikes $H$, Temple A, Meade $T$, Humphries $S$. A common genetic polymorphism associated with lower coagulation factor WII levels in healthy individuals. Arterioscler Thromb $1991 ; 11: 540-546$.

21. Meilahn E, Ferrell R, Kiss J, Temple A, Green F. Humphries S, Kuller L. Genetic determinants of coagulation factor Vlic levells among healthy middle-aged women. Thromb Haemost 1995;73:623625.

22. Mennen $L_{i}$ de Maat MPM, Schouten EG, Kluft $C$, de Jong PTVM. Hofman A, Grobee DE. Coagulation factor VII, serum-triglyceride and the R/Q 353 polymorphism: differences between older men and women. Thromb Haemost 1997;78:984-986. 


\title{
Effects of diets rich in medium chain fatty acids (MCFA), myristic acid or oleic acid on coagulation and fibrinolysis
}

Elisabeth HM Temme, Ronald P Mensink, Gerard Hornstra

\begin{abstract}
In this study we investigated the effects on coagulation and fibrinolytic parameters of diets rich in medium chain fatty acids (MCFA) or myristic acid relative to those of oleic acid. Thirty-seven women and 23 men first consumed a 3 wk run-in diet enriched in oleic acid. For the next 6 weeks, 19 subjects continued with the oleic acid diet, 21 subjects with an MCFA enriched diet, while 20 subjects received a diet high in myristic acid. Experimental fats were incorporated into solid foods. The MCFA and the myristic acid fat were synthetic fats. Total diets contained $40 \mathrm{En} \%$ fats and the nutrient composition was the same in each diet except for $10 \mathrm{En} \%$, which was provided by MCFA, myristic or oleic acids. In the females, but not in the males, overall plasma coagulability as reflected by the tissue factor (TF)-induced thrombin potential increased with the myristic acid diet compared with the oleic acild diet (difference in changes: $7 \%, P=0.0022$ ). For all subjects combined, analysis of separate factors indicated increased factor VII amidolytic (factor VIlam) activity (difference in changes: $7 \%, \mathrm{P}=0.0106$ ) and decreased tissue factor pathway inhibitor (TFPI) activity (difference in changes: $-3 \%, P=0.0162$ ) an the myristic acid diet, whereas the MCFA diet did not significantly change factor VIlam activity and slightly decreased TFPI activity (difference in changes: $-3 \%, P=0.0384$ ) compared with the oleic acid diet. Changes in factor Vllam were more pronounced in women than in men. The diets did not affect fibrinogen concentrations, antithrombin activity and the fibrinolytic capacity of plasma as determined by plasminogen activator inhibitor type 1 (PAI) activity. In conclusion the present investigation showed that the plasma coagulant capacity is unfavorably affected by a myristic acid diet compared with an oleic acid, especially in wornen.
\end{abstract}




\section{INTAODUCTION}

Previous studies have shown that mixtures of saturated fatty acids not only unfavorably affect serum lipoprotein concentrations (1), but also have a negative impact on certain coagulation or fibrinolytic factors $(2,3)$, which may differ for the various saturated fatty acids (4-7). Diets enriched in lauric $(C 12: 0)(4)$, myristic (C14:0) (6) or palmitic acids $(C 16: 0)(4-6)$ have been reported to increase factor $\mathrm{VII}$ compared with diets rich in oleic acid $(C 18: 1(n-9))(4)$, habitual diets $(6)$, or stearic acid $(C 18: 0)$ (5). Myristic acid, on its turn, increased factor VII coagulant (factor VIIC) activity slightly stronger than palmitic acid (6) did, and might therefore be a more potent pro-thrombotic saturated fatty acid. However, the effects of myristic acid diets have only been studied once in young male subjects (6).

Fats rich in myristic acid (e.g. coconut fat, palm kernel fat, or dairy fat) also contain medium chain fatty acids (MCFA $(C \leq 10: 0)$ ). Diets rich in MCFA induced lower $L D L$ and HDL cholesterol levels compared with a diet rich in myristic acid (8) and also slightly reduced low density lipoprotein (LDL) cholesterol compared with palmitic acid (9). Whether effects of MCFA on coagulation and fibrinolytic parameters are also less strong than those of myristic acid is not known. In this study we, therefore, examined the effects of diets enriched in MCFA or myristic acid compared with oleic acid on blood coagulation and fibrinolysis.

\section{METHODS}

\section{Design and statistical analysis}

In this parallel designed study, the effects on serum lipids and lipoproteins were also investigated $(8)$. The protocol had been approved by the local medical ethics committee and all volunteers had given their written informed consent. After a run-in period of three weeks in which the volunteers consumed an olleic acid diet, 19 subjects continued with the oleic acid, 21 subjects consumed a diet enriched in MCFA and 20 subjects received a diet rich in myristic acid, each for six weeks.

Differences between the experimental diets were analyzed using the General Linear Models (GLM) procedure of the Statistical Analyses System (10). The values at the end of the experimental periods were used as dependent variables, diet as independent variable and values after the run-in period as covariate. When the analysis indicated a significant effect of diet $(P<0.05)$, the diets were compared pairwise. Because of the three-group comparison, statistical significance was set at a $P$ value $<0.05 / 3$ (or, 0.0167 ).

To determine whether the responses of the hemostatic variables were more pronounced in persons with higher run-in values, an interaction term between diet and run-in value was included in the model. Pearson correlation coefficients were calculated between those changes in coagulation or fibrinolytic factors and changes in lipoproteins that were significant. Correlation analyses were also carried out according to gender. 


\section{Subjects}

Volunteers were recruited vila advertisements in local newspaper and posters in public buildings. After they had been thoroughly informed about the purpose and protociol of the study, the subjects underwent the selection procedure. Subjects selected for the study were aged between 20 and 60 years, did not take a prescribed or reducing diet, had a blood pressure below $140 / 80 \mathrm{mmHg}$, serum total cholesterol concentrations below $6.7 \mathrm{mmol} / \mathrm{L}$ and did not use medications known to affect lipoproteins, hemostatic variables or platelet aggregation. The study included 60 subjects, 37 women and 23 men. Women were $22-60$ y of age (mean $40 \mathrm{y}$ ), weighed $48-101 \mathrm{~kg}$ (mean $67 \mathrm{~kg}$ ), measured between 155 and $183 \mathrm{~cm}$ in height (mean 167 $\mathrm{cm}$ ), while body mass indexes ranged between $20-30 \mathrm{~kg} / \mathrm{m}^{2}$ (mean $24 \mathrm{~kg} / \mathrm{m}^{2}$ ). The men were aged between $23-59$ y (mean $43 \mathrm{y}$ ), weighed $56-88 \mathrm{~kg}$ (mean $78 \mathrm{~kg}$ ), measured between 163 and $190 \mathrm{~cm}$ in height (mean $178 \mathrm{~cm}$ ), and had body mass indexes from 17 to $29 \mathrm{~kg} / \mathrm{m}^{2}$ (mean $25 \mathrm{~kg} / \mathrm{m}^{2}$ ). Nine women were postmenopausal and 10 women used oral contraceptives. Six women and 5 men smoked.

During the study period 7 subjects withdrew. One subject because of job commitments, two subjects because of illness and four subjects because of reasons specifically related to the strict study protocol. Results of an additional 3 subjects were excluded from analyses: 2 subjects started prescribed medication known to affect blood lipids during the experiment and one subject experienced very stressful personal circumstances, which may have influenced her response to the diets.

\section{Diets}

Before the study started, the subjects recorded their habitual food intake for two working days and one weekend day. From these food records, each subjects' actual energy intake was calculated by using the Dutch food-composition table (11) The study diets were formulated at 13 levels of energy ranging from $5 \mathrm{MJ}$ to $22 \mathrm{MJ}$, so that each subject received a diet that met his or her energy needs. Diets used in the study consisted of products in which the normal fat was replaced by the experimental fats. The products included margarines and bakery products (bread, cookies, pies and cakes). According to the subjects' energy level, lists were computed which stated the amount of experimental products the subject had to eat each day (margarine, bread, and cookies) and each week (cake and pie). These solid foods supplied $63 \%$ (25 En\%) of the total fat energy. The remaining $37 \%(15 \mathrm{En} \%)$ of the total fat intake had to be chosen from a list of "free-choice" fat-containing products. These products were given points according to their fat contents. One point was equal to one gram of fat. Each subject was required to eat a certain number of points daily, again corresponding with his or her energy intake, and to list the products chosen daily on a special form. The fat composition of the calculated diets was similar except for approximately $10 \%$ of total energy intake, which was provided by MCFA, myristic acid or oleic acid, respectively. The composition of the experimental fats has been described elsewhere (8)

Subjects came at least once a week to the university to receive a new supply of products, to be weighed, and to receive new forms to list the free-choice items. They 
were also asked to maintain the same activity level, and smoking and drinking habits throughout the study. They recorded in diaries any signs of illness, medication used, alcohol consumption, menstrual cycle and any deviations from the study protocol.

\section{Blood sampling and measurements}

Blood for coagulation and fibrinolytic parameters was sampled at the end of the run-in (week 2 and week 3 ) and at the end of the experimental period (week 8 and week 9). The two samples at the end of each period were pooled and analyzed as such. Samples for fibrinogen were analyzed separately, but the results are given as the mean of the two samples. Blood was sampled after an overnight fast and after abstinence from alcohol the preceding day and smoking on the morning before blood sampling. Sampling was performed with a minimum of stasis and using a $1.2 \mathrm{~mm}$ needle (Strauß Kanule, Luer, Wächtersbach, Germany) with the subject in recumbent position. All venipunctures were performed by the same person, at the same location, and for each subject generally at the same time of the same day of the week.

The first $5 \mathrm{~mL}$ blood was collected for measurement of hematologic parameters and platelet aggregation "to be reported elsewhere. Then, two $5 \mathrm{~mL}$ blood were collected in tubes containing citrate theophylline, adenosine and dipyridamole (CTAD). One tube was immediately placed on ice and centrifuged at $2000 \mathrm{~g}\left(4^{\circ} \mathrm{C}, 10\right.$ minutes), and used for measurement of plasminogen activator inhibitor type 1 (PAl) activity. The second CTAD tube was centrifuged at $2000 \mathrm{~g}\left(4{ }^{\circ} \mathrm{C}, 10\right.$ minutes $)$ followed by centrifugation at $11,500 \mathrm{~g}\left(4^{\circ} \mathrm{C}, 30\right.$ minutes $)$ and used for measurement of coagulation factors. Finally, a $10 \mathrm{~mL}$ tube was filled for serum preparation for lipid and lipoprotein analysis. samples were stored at $-80^{\circ} \mathrm{C}$ before analyses. A standard pool plasma was obtained from healthy donors, and prepared by the same methods as described. Activities of tissue factor (TF)- and actin-induced thrombin potential (see below), factor VII, tissue factor pathway inhibitor (TFPI) and antithrombin activities were expressed as percentage of these standard plasmas. All samples from one subject were analyzed within one run.

A novel global coagulation assay (the endogenous thrombin potential) was used to assess the overall coagulability of plasma. Plasma thrombin potential was measured with a centrifugal analyzer as described (12). Briefly, plasma samples were first defibrinated by mixing plasma with a reptilase solution (Boehringer Mannheim, Mannheim, Germany) and the fibrin formed removed with a small spatula. Coagulation was triggered by either recombinant tissue factor (Dade ${ }^{\circledR}$ Innovin, Baxter Diagnostics Inc., Deerfield, IL, USA) for the extrinsic process (TF-induced thrombin potential) or by actin $F S^{\circledR}$, a suspension of ellagic acid and soy bean phosphatides (Baxter Deutschland $\mathrm{GmbH}$, Unterschleissheim, Germany) for the intrinsic process (actin-induced thrombin potential). After 30 seconds of incubation, thrombin generation was started by adding a pre-warmed solution containing $\mathrm{CaCl}_{2}$ and the chromogenic thrombin substrate S68 (Kordia, Leiden, The Netherlands). The final reaction mixture consisted of four parts of defibrinated plasma, one part of TF- or actin-solution and one part of $\mathrm{CaCl}_{2} / \mathrm{S} 68$ solution. After the start of the reaction, the 
optical density was recorded at $405 \mathrm{~nm}$ at intervals of 30 seconds for 15 minutes. The thrombin potential values were calculated by a computerized system from the thrombin generation curves. The coefficient of variation within runs was $2.5 \%$ for TF. induced thrombin potential and $3.6 \%$ for actin-induced thrombin potential.

Factor VII amidolytic (factor VIlam) and antithrombin activities, were assessed with chromogenic assays (Coaset FVII, Coamatic antithrombin, Chromogenix, Mölndal, Sweden). The coefficients of variation within runs were $3.6 \%$ for factor VIlam and $2.3 \%$ for antithrombin. Functional TFPI activity was determined according to the method of Sandset et al (13). This assay measures total (free plus lipoprotein bound) TFPI activity. The coefficient of variation within runs was $2.4 \%$. Plasma fibrinogen concentration (mg/dL) was assessed by the method of Clauss (14), and the coefficients of variation within runs was $2.8 \%$. Plasminogen Activator Inhibitor-1 (PAI) activity was measured with a chromogenic assay (Spectrolyse@(pL)PAI, Biopool, Umea, Sweden). Coefficient of variation within runs was $3.6 \%$.

\section{RESULTS}

\section{Dietary composition}

The composition of the diets has been described previously (8). The average intake of fat was $38.9 \mathrm{En} \%$ during the run-in period and $40.0 \mathrm{En} \%$ during the test period. The average intake of oleic acid was $15.1 \mathrm{En} \%$ during the run-in period and decreased in the test period to 6.6 En\% with the MCFA and to $6.3 \mathrm{En} \%$ with the myristic acid diet. It was exchanged for MCFA or myristic acid. Oleic acid intake during the oleic acid diet did not change from the run-in to the test period. Changes in other nutrients, except for En\% saturated and monounsaturated fatty acids, did not significantly differ between the diets.

\section{Thrombin potential}

Table 1 shows that, in the female subjects, the plasma thrombin potential induced by tissue factor (TF-induced thrombin potential) increased with the myristic acid diet compared with the oleic acid (difference in changes: $7 \%, P=0.0022$ ), but not significantly with the MCFA diet (difference in changes: $5 \%, P=0.0471$ ). The thrombin potential response induced by actin did not differ between the three diets. Changes in TF-induced thrombin potential correlated strongly with changes in actin-induced thrombin potential $(r=0.60 ; P<0.0001)$ and with changes in factor Vllam activity $(r=0.28 ; P=0.0294)$. The latter correlation was significant in women $(r=0.55$; $P=0.0004)$, but not in men $(r=-0.19 ; P=0.4090)$. 
Table 1. Plasma thrombin potential after diets enriched in MCFA ( $n=21)$, myristic acid $(n=20)$ or oleic acid $(n=18)$."

\begin{tabular}{|c|c|c|c|c|c|c|}
\hline & \multicolumn{2}{|c|}{ MCFA Diet } & \multicolumn{2}{|c|}{ Myristic Acid Diet } & \multicolumn{2}{|c|}{ Oleic Acid Diet } \\
\hline & Run-in & Change & Run-in & Change & Run-in & Change \\
\hline \multicolumn{7}{|c|}{ TF-induced thrombin potentiall ( $\%$ standard) } \\
\hline All & $93 \pm 13$ & $3 \pm 7$ & $104 \pm 13$ & $3 \pm 6$ & $100 \pm 13$ & $-1 \pm 7$ \\
\hline Women & $92 \pm 10$ & $3+5$ & $101 \pm 12$ & $5 \pm 5 \dagger$ & $98 \pm 15$ & $-2+7$ \\
\hline Men & $94 \pm 17$ & $2+10$ & $109 \pm 13$ & $0 \pm 6$ & $105 \pm 9$ & $1 \pm 6$ \\
\hline \multicolumn{7}{|c|}{ Actin-induced thrombin potential ( $\%$ standard) } \\
\hline All & $96 \pm 11$ & $1 \pm 5$ & $109 \pm 14$ & $-1 \pm 11$ & $106 \pm 14$ & $-1 \pm 9$ \\
\hline Women & $94 \pm 10$ & $2+4$ & $108 \pm 12$ & $1 \pm 10$ & $104 \pm 14$ & $-4 \pm 8$ \\
\hline Men & $98 \pm 14$ & $1 \pm 7$ & $110 \pm 17$ & $-5 \pm 11$ & $110 \pm 15$ & $2+10$ \\
\hline
\end{tabular}

* Values are given as means \pm standard deviations. Values of one subject on the oleic acid diet were omitted from the analysis because of a clotted blood sample.

$\dagger P<0.01$, Significantly different lrom the oleic acid diet.

TF; tissue factor.

\section{Activities of coagulation and fibrinolytic factors in plasma}

Plasma activities of coagulation and fibrinolytic factors are given in table 2. Factor Vllam activity increased by $6 \%$ when the subjects switched to the myristic acid diet. This change, which was more pronounced in women than in men, was significantly different from the change in the volunteers who continued on the oleic acid diet (difference in changes: $7 \%, \mathrm{P}=0.0106)$. For women this effect (10\%; $\mathrm{P}=0.0069$ ) was more pronounced than in men $(3 \% ; P=0.2456)$. Factor Vllam activity responses within the MCFA diet group did not differ significantly from those within the myristic acid diet or the oleic acid diet groups.

Compared with the oleic acid diet, TFPI activity decreased with both the myristic acid diet (difference in changes: $-3 \%, P=0.0162$ ) and the MCFA diet (difference in changes: $-3 \%, P=0.0384$ ). Changes in TFPl activities did not correlate with changes in lipoproteins. Responses of antithrombin activity, fibrinogen, and PAl activity did not significantly differ between the three diets.

For women, significant interaction terms were observed between run-in values of TF-induced thrombin potential-and-diet ( $P=0.05$ for interaction) and between run-in values of factor Vllam activity-and-diet ( $P=0.05$ for interaction). This indicates that women with higher TF-induced thrombin potential values or factor Vllam activities after the oleic acid run-in diet responded stronger to the different experimental diets, than women with lower values. Premenopausal subjects using contraceptives demonstrated a significantly higher TF-induced thrombin potential than the premenopausal women not using contraceptives $(P<0.0001)$ and slightly, though not 
significantly, higher values than the postmenopausal women (P=0.0307) (table 3). Factor Vllam activity showed a trend to be higher in the premenopausal women using contraceptives compared with the premenopausal women not using contraceptives $(P=0.0267)$.

Table 2. Coagulation and fibrinolytic factors after diets enriched in MCFA $(n=21)$, myristic acid $(n=20)$ or oleic acid $(n=19)$.

\begin{tabular}{|c|c|c|c|c|c|c|}
\hline & \multicolumn{2}{|c|}{ MCFA Diet } & \multicolumn{2}{|c|}{ Myristic Acid Diet } & \multicolumn{2}{|c|}{ Oleic Acid Diet } \\
\hline & Run-in & Change & Runimin & Change & Run-in & Change \\
\hline \multicolumn{7}{|c|}{ Factor VIlam activity ( $\%$ of standard) } \\
\hline All & $75 \pm 19$ & $2+6$ & $80 \pm 27$ & $6 \pm 9+$ & $83+26$ & $.1 \pm 10$ \\
\hline Women & $81 \pm 20$ & $1 \pm 6$ & $87 \pm 32$ & $7 \pm 10 \dagger$ & $84 \pm 32$ & $-3 \pm 9$ \\
\hline Men & $65 \pm 11$ & $3 \pm 5$ & $71 \pm 15$ & $4 \pm 6$ & $82 \pm 10$ & $1 \pm 12$ \\
\hline \multicolumn{7}{|c|}{ Tissue Factor Pathway Inhibitor activity ( $\%$ of standard) } \\
\hline All & $95 \pm 5$ & $-1 \pm 6$ & $93 \pm 5$ & $-1 \pm 6+$ & $96 \pm 8$ & $2+12$ \\
\hline Women & $94 \pm 5$ & $-2 \pm 5$ & $94 \pm 5$ & $-2 \pm 6$ & $96 \pm 8$ & $1 \pm 11$ \\
\hline Men & $96 \pm 6$ & $-1 \pm 6$ & $92+5$ & $1 \pm 8$ & $96 \pm 10$ & $3+13$ \\
\hline \multicolumn{7}{|c|}{ Antithrombin activity ( $\%$ of standard) $\$$} \\
\hline All & $96 \pm 5$ & $1 \pm 5$ & $98 \pm 8$ & $0 \pm 6$ & $99 \pm 8$ & $2+4$ \\
\hline Women & $95 \pm 5$ & $-0 \pm 4$ & $99 \pm 8$ & $-2 \pm 7$ & $97 \pm 9$ & $3 \pm 5$ \\
\hline Men & $98+6$ & $3 \pm 6$ & $98 \pm 8$ & $4 \pm 5$ & $102+5$ & \pm 2 \\
\hline \multicolumn{7}{|c|}{ Fibrinogen $(\mathrm{mg} / \mathrm{dL})^{\$}$} \\
\hline All & $365 \pm 26$ & $-10 \pm 20$ & $358 \pm 31$ & $-6 \pm 33$ & $362+27$ & $2+27$ \\
\hline Women & $363+24$ & $-5 \pm 19$ & $355 \pm 34$ & $-2 \pm 30$ & $364 \pm 30$ & $0+27$ \\
\hline Men & $369 \pm 31$ & $-18 \pm 21$ & $363+29$ & $-11 \pm 37$ & $358+22$ & $6 \pm 29$ \\
\hline \multicolumn{7}{|c|}{ PAl activity $(\mathrm{U} / \mathrm{mL})$} \\
\hline All & $7.4 \pm 3.3$ & $1.9 \pm 3.9$ & $8.7 \pm 4.6$ & $-0.5+3.1$ & $9.1 \pm 5.0$ & $0.4 \pm 3.8$ \\
\hline Women & $7.3 \pm 3.4$ & $1.2 \pm 3.7$ & $7.2 \pm 3.1$ & $-0.4 \pm 3.4$ & $7.6 \pm 5.4$ & 0.814 .2 \\
\hline Men & $7.4 \pm 3.2$ & $3.0 \pm 4.1$ & 10.915 .8 & $-0.6 \pm 2.6$ & $11.7 \pm 2.8$ & $-0.2 \pm 3.2$ \\
\hline
\end{tabular}

* Values are given as meanststandard deviations.

$\$$ Values of one subject on the oleic acid diet were omitted from the analysis because of a clotied blood sample.

† P<0.02, Significantly different from the oleic acid diet.

PAl: plasminogen activator inhibitor, $\mathrm{U}$ : arbitrary units. 
Table 3. Hemostatic variables in premenopausal women not using oral contraceptives $(n=18)$, premenapausal women using comtraceptives $(n=10)$, and postmenopausal women $(n=9)$."

\begin{tabular}{lccc}
\hline & $\begin{array}{c}\text { Premenopausal } \\
\text { not on contraceptives }\end{array}$ & $\begin{array}{c}\text { Premenopausal } \\
\text { on contraceptives }\end{array}$ & Postmenopausal \\
& & $\%$ of standard & \\
TF-induced thrombin potential & $90 \pm 11$ & $108 \pm 9+$ & $98 \pm 8$ \\
Actin-induced & $96 \pm 12$ & $110 \pm 14 t$ & $105 \pm 8$ \\
thrombin potential & & & \\
& & $101 \pm 42$ & $78 \pm 12$ \\
Factor Vllam & $97 \pm 6$ & $94 \pm 8$ & $100 \pm 9$ \\
Antithrombin & $94 \pm 7$ & $95 \pm 5$ & $96 \pm 3$ \\
TFPI & $363 \pm 29$ & $357 \pm 18$ & $358 \pm 39$ \\
Fibrinogen (mg/dL) & & & $8.1 \pm 4.1$ \\
PAl (U/mL) & $7.7 \pm 4.5$ & $6.1 \pm 2.7$ & \\
\hline
\end{tabular}

\footnotetext{
* Values are given as meanststandard deviations after the oleic acid run-in period.

+ Significantly different from the premenopausail women not on contraceptives: $P<0,01$.

TF: tissue factor, TFPI: tissue factor pathway inhibitor, PAl: plasminogen activator inhibitor, $U$ : arbitrary units.
}

\section{DISCUSSION}

Prospective studies in middle aged men have stressed that the coagulant capacity of plasma, which can be affected by the fatty acid composition of the diet $(2$, $3)$, is an important imarker for the development of coronary heart disease $(15,16)$. The present study, therefore, examined the effects of diets enriched in MCFA or myristic acid compared with oleic acid on separate coagulation factors (factor Vilam activity and fibrinogen) and inhibitors of coagulation (antithrombin and TFPI activities). However, changes in these separate clotting activities do not necessarily implicate an effect on the full clotting mechanism that is eventually important for the coagulant capacity of the blood. We, therefore, also, studied the effects of the diets on the plasma thrombin potential. This coagulation assay measures the total amount of thrombin formed, when all plasma factors that influence the coagulation process are taken into account, and is a sensitive assay to detect small changes in coagulability (12).

Compared with the oleic acid diet, the TF-induced thrombin potential increased with the myristic acid, but only in the female subjects. We are, to our knowledge, the first to report in human subjects changes in plasma coagulability as measured by 
thrombin potential, after dietary fatty acid alterations. Plasma hypercoagulability, as determined by increased thrombin potential has been reported before in patients with an active thrombotic process (12), and also in women using contraceptives but not suffering from thrombosis (17). The latter observation was confirmed in the present study (table 3). Decreased thrombin potential, on the other hand has been demonstrated after heparin injection (18) or in orally anticoagulated patients (19).

Of the separate coagulation factors, factor Vllam activity significantly increased with the myristic compared with the oleic acid diet. Diets enriched in MCFA, however, did not change factor Vllam activity. Recent studies on the effects of specific saturated fatty acids on factor Vil activity also demonstrated that those saturated fatty acids that increased LDL cholesterol concentrations (lauric, myristic and palmitic acids) also increased factor VII activity (4-6). The magnitude of the factor VIlam response with the myristic acid compared with the oleic acid diet was comparable to increases reported for diets enriched in lauric or palmitic acids (4) and does not suggest a more potent factor VIII response, as was observed in a myristic acid versus palmitic acid comparison (6).

The more pronounced coagulant activity response in women after saturated fat diets confirmed our earlier observations with diets enriched in lauric or paimitic compared with oleic acid (4). A stronger association between dietary saturated fat content and factor $V I I$ in women compared to men was also observed in a large prospective study (20). To explain factor VII differences between women and men, we earlier suggested a role for differences in hormonal backgrounds. In agreement with the earlier study and other reports $(21,22)$, the present results show that factor VIlam was especially high in premenopausal women using contraceptives, although their factor VII values vary widely. Both dietary responses of factor VIllam and TF-induced thrombin potential in women were stronger with higher run-in values, indicating that especially contraceptive users and to a lesser degree postmenopausal women are more prone to coagulation responses following dietary fatty acid alterations. The interactions, however, could not be demonstrated in our previous study, which might be related to the small numbers of contraceptive users in that study. Also, Mutanen et a) (23) showed that in women using contraceptives factor Vllc increased after a trans fatty acid diet whereas in women not using contraceptives this effect was not observed.

Both the myristic acid and the MCFA diet decreased TFPl activity compared with the oleic acid diet indicating a lower capacity of the plasma to inhibit TF-induced coagulation (24). Since changes in TFPI activity are opposite to, and not associated with changes in LDL cholesterol or other lipoproteins, this suggested that these changes reside in the carrier free pool rather than the lipoprotein bound pool of TFPI. A recent study (25) also indicated that both pools, are probably regulated independently as cholesterol-lowering by Lovastatin ${ }^{(B)}$ did not affect the pool of free TFPI "but only lowered the LDL-TFPI complexes (25). However, no other conditions are known that cause increased LDL cholesterol levels and decreased TFPI activity as is presently reported for the saturated fat diets. It has been proposed (25) that free 
TFPI has a stronger anticoagulant activity than lipoprotein bound-TFPl, which may emphasize the importance of our findings. Future research on the effects of dietary fatty acid compostion on TFPI should therefore also aim to differentiate between the two forms.

To summarize, the present investigation shows that in females, but not in males, the overall plasma clotting capacity as determined by TF-induced thrombin potential is unfavorably affected by a myristic acid and to a lesser extent by an MCFA compared with an oleic acid diet. For all subjects combined, analysis of separate factors indicate increased factor VIlam activity and decreased TFPI activity on the myristic acid diet; whereas the MCFA diet did not change factor VIlam activity and slightly decreased TFPI activity compared with the oleic acid diet. The diets did not affect the fibrinolytic capacity of plasma as measured by PAll activity. Diets low in myristic acid not only have beneficial effects on LDL \|ipoprotein concentrations, but also on the coagulation capacity of blood, the latter especially in women.

\section{ACKNOWLEDGMENTS}

We thank Prof Dr HC Hemker and Dr S Béguin (Department of Biochemistry, Maastricht University) for providing us the facilities to measure the thrombin potential. 


\section{REFERENCES}

1. Mensink RP, Katan MB. Effect of dietany tatty acids on serum lipids and lipoproteins: meta-analysis of 27 trials. Arterioscler Thromb 1992;12:911-919.

2. Mitropoulos KA, Miller GJ, Martin JC, Reeves BEA, Cooper J. Dietary fat induces changes in factor VIl coagulant activity through effects on plasma free stearic acid concentration. Arterioscler Thromb $1994 ; 14: 214-222$.

3. Almendingen $K$, Seljeflot $\|$, Sandstad $B$, Pedersen $U$. Effects of partially hydrogenated fish oil, partially hydrogenated soybean oll, and butter on hemostatic variables in men. Arterioscler Thromb Vasc Biol 1996:16:375-3:80.

4. Temme EHM, Mensink RP. Homstra G. Effects of diets entiched in lauric, palmitic or oleic acids on blood coagulation and fibrinalysis. Hoofdstuk 6 .

5. Tholstrup $T$, Marckmann P. Jespersen $J$, Sandström B. Fat high in stearic acid favorably affects blood lipids and factor VII coagulant activity in comparison with fats high in pallmitic acid or high in myristic and lauric acids, Am J Clin Nutr 1994;59:371-377.

6. Tholstrup T, Marckmann $P_{n}$ Jespersen J, Vessby B, Jart A, Sandström B. Effect on blood lipids, coagulation, and tibrinolysis of a fat high in myristic acid and a fat high in palmitic acid. Am J Clin Nutr $1994 ; 60: 9119-925$.

7. Bladbjerg EM, Tholstrup T, Marckmann P. Jespersen J, Sandström B. Dietary changes in fasting levels of factor VII coagulant activity (FVII:C) are accompanied by changes in factor VII protein and other vitamin K-dependent proteins. Thromb Haemost 1995;73:239-242.

8. Temme EHM, Mensink RP, Hornstra G. Effects of medium chain latty acids, myristic acid, and oleic acid on serum lipoproteins in healthy subjects. J Lipid Res 1997;38:1746-1754.

9. Cater NB. Heller HJ. Denke MA. Comparison of the effects of medium-chain triacylglycerols, palm oil, and high oleic acid sunflower oil on plasma triacylglycerol fatty acids and lipid and lipoprotein concentrations in humans. Am J Clin Nutr 1997;65:41-45.

10. SAS Institute Inc. SAS: user's Guide Statistics, Version 5 Edition.Cary, NC: SAS Institute Inc, 1985.

11. Stichting NEVO. NEVO tabel, Nederlands voedingstoffenbestand (Dutch food composition table). Den Haag: Voorlichtingsbureau voor de Voeding, 1989.

12. Wielders $S$, Mukherjee M, Michels $\downarrow$, Rijkers DTS, Cambus J P. Knobel RWC, Kakkar V, Hemker HC, Beguin $S$. The routine determimation of the endogenous thrombin potential, first results in different forms of hyper- and hypocoagulability. Thromb Haemost 1997;77:629-636.

13. Sandset $P$, Abildgaard $U$, Petersen $M$. Sensitive assay of extrinsic pathway inhibitor (EPI). Thromb Res 1987;47:389-400.

14. Clauss A. Gerinnungsphysiologische schnellmethode zur bestimmung des fibrinogens. Acta Haematol 1957:17:237-246.

15. Meade TW, Brozovic M, Chakrabarti RR, Haines AP, Imeson JD, Mellows S, Miller GJ, North WRS, Stirling $Y_{1}$, Thompson SG. Haemostatic function and ischaemic heart disease: principal results of the Northwick Park Heart Study. Lancet 1986;2:533-537.

16. Heinrich J, Balleisen L. Schulte $H_{4}$ Assmann $G$, van de Loo J. Fibrinogen and factor VII in the prediction of coronary risk. Arterioscler Thromb 1994:14:54-59.

17. Rotteveel RC. Roozendaal KJ, Eijsman L, Hemker HC. The influence of oral contraceptives on the time-integral of thrombin generation (thrombin potential). Thromb Haemost 1993;70:959-962. 
18. Bendetowicz AV, Kaf $H$, Knebel R, Caplain $H$, Hemker $H C$, Lindhout $T$, Béguin $S$. The effect of subcutaneous injection of untractionaled and low molecular weight heparin on thrombin generation in platelet rich plasma, a study in human volunteers. Thromb Haemost 1994:71:305-313.

19. Xi M, Beguin $S$, Hemker HC. The relative importance of the factors II, VII, $I X$ and $X$ for the prothrombinase activity in plasma of orally anticoagulated patients. Thromb Haemost 1989;62:788791.

20. Mennen LI, Witteman JCM, den Breejen $J H$, Schouten EG, de Jong PTVM, Hofman A, Grobbee DE. The association of dietary fat and fiber with coagulation factor VII in the elderly: the Rotterdam study. Am J Clin Nutr 1997;65:732-736.

21. Meade TW, Chakrabarti A, Haines A., North WRS, Stirling Y. Haemostatic, lipid and blood-pressure profiles of women on oral contraceptives containing $50 \mu \mathrm{g}$ or $30 \mu \mathrm{g}$ oestrogen. Lancet 1977:2:948. 951.

22. Scarabin P-Y, Vissac A-M, Kirzin J-M, Bourgeat $P$, Amiral J, Agher $A_{\text {, }}$ Guize L. Population correlates of coagulation tactor Vil. Arterioscler Thromb Vasc Biol 1996;16:1170-1176.

23. Mutanen $\mathrm{M}_{\mathrm{x}}$ Aro A. Coagulation and fibrinolysis factors in healthy subjects consuming high stearic or trans fatty acid diet. Thromb Haemost 1997;77:99-104.

24. Sandset PM, Abildgaard U. Extrinsic pathway inhibitor: the key to feedback control of blood coagulation initiated by tissue thromboplastin. Haemostasis 1991;21:216-239.

25. Hansen J-B. Raanaas Huseby $K_{n}$ Huseby N-E, Sandset $P$, Hanssen T-A, Nordøy A. Effects of cholesterol lowering on intravascular pools of TFPI and its anticoagulant potential in lype II hyperlipoproteinemia. Arterioscler Thromb Vasc Biol 1995;15:879-885. 


\section{Dietary fatty acid composition and feelings of appetite}

Elisabeth HM Temme, Ronald P Mensink, L Arthur Campfield, Gerard Hornstra

Submitted for publication

\section{ABSTRACT}

Little is known on the effects of dietary fatty acid composition on satiety mechanisms. This study compared the effects of diets enriched in medium chain fatty acids (MCFA), myristic acid or oleic acid on feelings of appetite and concentrations of some proposed regulators of food intake: apolipoprotein A-IV (apoA-IV) and leptin. Thirty-seven women and 23 men first consumed a 3 wk run-in diet enriched in oleic acid. For the next 6 weeks, 19 subjects continued with the oleic acid diet, 21 subjects with the MCFA enriched diet, while 20 subjects received a diet high in myristic acid. Total diets contained 40 percent of energy from fat and the nutrient composition was the same in each diet except for $10 \mathrm{En} \%$, which was provided by MCFA, myristic or oleic acids. Feelings of hunger were determined with $100 \mathrm{~mm}$ visual analog scales and were higher with the myristic acid diet compared with the oleic acid diet (difference in changes of $7.3 \mathrm{~mm} ; \mathrm{P}=0.0036$ ). The MCFA acid diet did not change feelings of hunger compared with the oleic acid diet and a trend for lower hungerfeelings was demonstrated compared with the myristic acid diet (difference in changes of $-3.3 \mathrm{~mm} ; P=0.0546$ ). Of the proposed post-absorptive regulators of food intake apoA-IV concentrations did not significantly differ between the diets and were not associated with feelings of hunger. The diet high in MCFA showed a trend for higher leptin concentrations compared with the diet rich in myristic (difference in changes of $1.1 \mathrm{ng} / \mathrm{mL} ; P=0.0293$ ) and in oleic acid (difference in changes of 1.1 $\mathrm{ng} / \mathrm{mL} ; 0.0904)$. We conclude that a diet enriched in myristic acid increases feelings of hunger compared with a diet enriched in oleic acid. The mechanism of regulation remains obscure since changes in fasting apoA-IV or leptin concentrations were not observed for this comparison. 


\section{INTRODUCTION}

Maintaining a healthy body weight is important for the prevention of health problems like coronary heart disease, diabetes mellitus and hypertension (1-3). A high intake of dietary fat is thought to be a key factor in the etiology of obesity (4). Dietary guidelines, therefore, stress the importance to reduce fat intake and to replace fats with (complex) carbohydrates. One of the arguments for this advise is that carbohydrates have a more satiating effect than iso-energetic amounts of fat in lean (5) and obese subjects $(5,6)$.

Iso-energetic replacement of fats for carbohydrates, however, unfavorably lowers the anti-atherogenic HDL cholesterol concentrations (7). Another suggested approach (8), therefore, is to repiace dietary saturated by unsaturated fatty acids. Effects of the type of dietary fatty acids on feelings of hunger and satiety, however, are largely unknown. Results of Rolls et al (9) suggest that differences on satiety mechanisms between different fatty acid classes exist, because preloads of medium chain triglycerides (MCT with C8:0 and C10:0) reduced food intake shortly after the preload had been given, compared with preloads of corn oil, rich in linoleic acid (9). Whether these effects are also valid on the longer term (i.e. for intakes later on the day) and whether they are specific for MCT or also count for other saturated fatty acids than MCT is not known. MCT, namely, is composed of medium chain fatty acids (MCFA; $\mathrm{C} \leq 10: 0$ ) with a unique metabolism. Compared with longer chain fatty acids their absorption, transportation via the portal vein, to the liver and oxidation in the tissues is very rapid (10). Fats rich in MCFA (coconut oil, palm kernel oil or dairy fat) also contain other saturated fatty acids, like myristic acid ( $14: 0)$, which are transported to the liver via the, more common and slower, lymphatic system and the uptake of which involves chylomicron formation. A similar transport route applies to oleic acid (cisC 18:1(n-9)), the major unsaturated tatty acid in these fats.

So far, little is known as to why different fatty acids should modulate feelings of satiety or hunger. It has been suggested that apolipoprotein A-IV (apoA-IV), which is synthesized in the small intestines, acts as a fat-amount $(11,12)$ and fat-source $(13)$ dependent post-absorptive signal for satiety. Fujimoto and colleagues (11) observed that intravenous infusions of mesenteric lymph with apoA-IV suppressed food intake in rat. This effect was mimicked by the infusion of purified apoA-IV and prevented by feeding an inhibitor of the chylomicron formation and by immunoprecipitation of apoA-IV by a monospecific antibody. Further experiments showed that apoA-IV acts directly on the central nervous system (12).

Another potent regulator of food intake might be leptin, excreted from adipose tissue cells (14). Campfield et al $(15,16)$ showed that mice treated with leptin decreased food intake. So far, only the mass effects of the adipose tissue have been described as an important regulator of the production of leptin (14). First reports on the effects of dietary energy source do not indicate that leptin concentrations are modulated by the replacement of fat for carbohydrates $(17,18)$ or vise versa $(19)$. However, effects of dietary fatty acid composition on serum leptin concentrations have not been reported, yet. 
We, therefore, have now studied the effects of saturated fat diets either rich in medium chain fatty acids (MCFA; C6:0, C8:0 and C10:0) or in myristic acid (C14:0) and a diet rich in the major unsaturated fatty acid, oleic acid (C18:1), on feelings of hunger and on fasting apoA-IV and leptin concentrations.

\section{SUBJECTS AND METHODS}

\section{Subjects}

Sixty subjects ( 37 women and 23 men) completed this controlled dietary experiment. Women were aged $22-60$ y (mean $40 \mathrm{y}$ ), weighed $48-101 \mathrm{~kg}$ (mean 67 $\mathrm{kg}$ ), were between 155 and $183 \mathrm{~cm}$ in height (mean $167 \mathrm{~cm}$ ), and had body mass indexes from 20-30 kg/m2 (mean $24 \mathrm{~kg} / \mathrm{m}^{2}$ ). The men were aged between $23-59 \mathrm{y}$ (mean $43 \mathrm{y}$ ), weighed $56-88 \mathrm{~kg}$ (mean $78 \mathrm{~kg}$ ), were between 163 and $190 \mathrm{~cm}$ in height (mean $178 \mathrm{~cm}$ ), and had body mass indexes from 17 to $29 \mathrm{~kg} / \mathrm{m}^{2}$ (mean 25 $\mathrm{kg} / \mathrm{m}^{2}$ ). Nine women were postmenopausal and 10 women used oral contraceptives. Six women and 5 men smoked.

\section{Design and diets}

The main purposes of this experiment was to test the effects of diets enriched in MCFA, myristic or oleic acid on lipoproteins and hemostatic parameters. Details of the study have been published elsewhere (20). The triall had a parallel design and was approved by the medical ethics committee of Maastricht University. During a 3 wk runin period all subjects consumed a diet high in oleic acid. They were then divided into three groups. One group consumed the MCFA diet $(n=21)$, a second group the myristic acid diet $(n=20)$ and a third group continued on the oleic acid diet $(n=19)$ each for six weeks. The groups were stratified for initial serum cholesterol concentrations and sex.

Before the study started, the subjects recorded their habitual food intake for two working days and one weekend day. From these food records, each subjects' actual energy intake was calculated by using the Dutch food-composition table (21). The study diets were formulated at 13 levels of energy ranging from $5 \mathrm{MJ}$ to $22 \mathrm{MJ}$ per day, so that each subject received a diet that met his or her energy needs. Diets used in the study consisted of products in which the normal fat was replaced by the experimental fats. The products included margarines and bakery products (bread, cookies, pies and cakes). Based on the subjects' energy intake, the amount of experimental products the subject had to eat each day (margarine, bread, and cookies) and each week (cake and pie) were calculated and used. These solid foods supplied $63 \%(25 \mathrm{En} \%)$ of the total fat energy. The remaining $37 \%(15 \mathrm{En} \%)$ of the total fat intake had to be chosen from a list of "free-choice" fat-containing products. These products were given points according to their fat contents. One point was equal to one gram of fat. Each subject was required to eat a certain number of points dally, again corresponding with his or her energy intake, and to list the products chosen 
daily on a special form: The fat composition of the calculated diets was similar except for approximately $10 \%$ of total energy intake, which was provided by MCFA, myristic

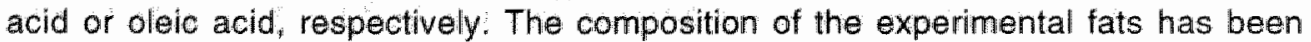
described elsewhere $(20)$.

Subjects were asked to record food intakes in a diary on one weekend and two weekdays in both the run-in and the test period. They were also asked to maintain the same activity level, smoking and drinking habits throughout the study. They recorded in diaries any signs of illness, medication used, alcohol consumption, menstrual cycle and any deviations from the study protocol. The effectiveness of blinding and the palatability of the diets was measured using a questionnaire at the end of the experiment.

\section{Hunger rating}

The subjects rated feelings of hunger at the end of the run-in period (week 3 ) and at the end of the test period (week 9) daily for one week on $100 \mathrm{~mm}$ visual analog scales (VAS) of hunger. The hunger rating was part of a more extensive series of VAS on mood. The sentence "Today I was at all not hungry" was anchored on the right and "Today I was extremely hungry" on the right side of the $100 \mathrm{~mm}$ scale. Subjects were asked to rate the feeling of hunger of that day just before retiring for the night. Hunger ratings were averaged per week and the response to the experimental diet was calculated per subject as the change from the end of the run-in period to the end of the MCFA, myristic acid or oleic acid diet period.

\section{Apolipoprotein A-IV and leptin analyses}

Serum apoA-IV concentrations were measured according to the "sandwich"-type enzyme-linked immunosorbent assay as described by Rosseneu et al (22). The coefficient of variation within runs was $3.6 \%$.

Serum leptin concentrations were measured using a double-antibody "sandwich" ELISA assay using a monoclonal antibody specific for human leptin. This assay measures total (free and bound) leptin concentrations. The lowest concentration of detection was $0.5 \mathrm{ng} / \mathrm{mL}$ and the upper limit was $50 \mathrm{ng} / \mathrm{mL}$. The coefficient of variation within runs was $9 \%$. Leptin concentrations of normal weight subjects range from 1 to $12 \mathrm{ng} / \mathrm{mL}$.

\section{Statistical analysis}

Differences between the experimental diets were analyzed with the General Linear Models (GLM) procedure of the SAS Program (23) with diet as independent variable and values after the oleic acid run-in period as covariate. When the analysis indicated a significant effect of diet $(P<0.05)$, the diets were compared pair-wise. Because of the three-group comparison the Bonferonni correction was applied and statistical significance was reached at a $P$ value $<0.05 / 3$ (or, 0.0167). Because leptin values and changes in leptin values were not normally distributed, the changes were analyzed with the non-parametric Kruskal-Wallis test (24). 


\section{RESULTS}

Table 1 shows the composition of the diets during the run-in and the test period as calculated from the three day food records. Mean macronutrients composition (fat, carbohydrates and proteins) of the three diets, which included the consumed fat-free products, did not change from run-in to test period.

As expected, the energy percentages of total and specific saturated fatty acids (MCFA and myristic acid) increased at the expense of those from the monounsaturated fatty acids. The reported intakes of MCFA, myristic acid or oleic acid include only the contribution of the experimental fats used during the study. Fiber intake increased slightly, though not significantly, in the myristic acid diet group compared with both the MCFA and the oleic acid groups.

Table 1. Composition of the diets as calculated from 3 days food records."

\begin{tabular}{|c|c|c|c|c|c|c|}
\hline & \multicolumn{2}{|c|}{ MCFA Diet } & \multicolumn{2}{|c|}{ Myristic Acid Diet } & \multicolumn{2}{|c|}{ Oleic Acid Diet } \\
\hline & Rum-in & Change & Rurn-in & Change & Run-in & Change \\
\hline \multirow[t]{2}{*}{ Energy (MJ/day) } & $9.2+3.0$ & $-0.1 \pm 1.1$ & $11.0 \pm 3.6$ & $-0.2 \pm 1.6$ & $9.8+2.2$ & $-0.4 \pm 1.4$ \\
\hline & \multicolumn{6}{|c|}{ Percentage of energy } \\
\hline Fat & $38.7 \pm 6.5$ & $1.7 \pm 5.1$ & $38.4 \pm 4.6$ & $1.3 \pm 4.3$ & $39.7 \pm 3.2$ & $0.3 \pm 4.1$ \\
\hline SAFA & $11.3+2.0$ & $10.0+2.2$ & $11.3 \pm 1.4$ & $9.6 \pm 2.1$ & $11.7 \pm 1.4$ & $-0.1 \pm 2.0$ \\
\hline MCFAt & $0.0 \pm 0.0$ & $9.9 \pm 1.9$ & $0.0 \pm 0.0$ & $0.0 \pm 0.0$ & $0.0 \pm 0.0$ & $0.0 \pm 0.1$ \\
\hline Myristic acidt & $0.1 \pm 0.2$ & $-0.1 \pm 0.2$ & $0.1 \pm 0.1$ & $9.6 \pm 1.6$ & $0.1 \pm 0.0$ & $0.0 \pm 0.0$ \\
\hline MUFA & $20.3+4.1$ & $-8.2 \pm 3.5$ & $20.4 \pm 2.7$ & $-8.6 \pm 2.2$ & $21.2+1.9$ & $0.3 \pm 2.7$ \\
\hline Oleic acidt & $15.0 \pm 4.2$ & $-8.5 \pm 4.0$ & $14.8 \pm 2.3$ & $-8.5 \pm 2.1$ & $15.7 \pm 1.6$ & $0.9 \pm 2.3$ \\
\hline PUFA & $4.9 \pm 1.0$ & $-0.1 \pm 1.0$ & $4.6 \pm 1.1$ & $0.2 \pm 1.0$ & $4.5 \pm 0.6$ & $0.1 \pm 0.7$ \\
\hline Linoleic acid & $4.0 \pm 0.8$ & $0.0+0.7$ & $4.0 \pm 0.9$ & $0.0 \pm 0.8$ & $3.7 \pm 0.5$ & $0.3 \pm 0.8$ \\
\hline Carbohydrates & $47.4 \pm 5.5$ & $-3.4 \pm 4.9$ & $46.4 \pm 5.2$ & $-1.0+5.5$ & $46.3 \pm 4.0$ & $-1.7 \pm 4.3$ \\
\hline Protein & $11.8 \pm 2.8$ & $1.5 \pm 2.2$ & $11.9 \pm 1.3$ & $0.3 \pm 1.3$ & $12.4 \pm 1.9$ & 0.242 .1 \\
\hline Alcohol & $2.0+2.2$ & $0.2+2.5$ & $3.1 \pm 3.6$ & $-0.5 \pm 2.5$ & $1.6 \pm 2.6$ & $1.2 \pm 3.9$ \\
\hline \multicolumn{7}{|l|}{ Chollesterol } \\
\hline$(\mathrm{mg} / \mathrm{MJ})$ & $16.3 \pm 4.1$ & $0.7 \pm 5.5$ & $14.4 \pm 3.1$ & $0.4 \pm 5.3$ & $15.8 \pm 5.0$ & $-1.5 \pm 4.4$ \\
\hline Fiber (g/MJ) & $2.4 \pm 0.3$ & $-0.1 \pm 0.3$ & 2.240 .4 & $0.3 \pm 0.5$ & $2.4 \pm 0.4$ & $-0.1 \pm 0.7$ \\
\hline
\end{tabular}

\footnotetext{
* Values are means \pm standard deviations.

+ As provided by the experimental fats only.

SAFA: saturated fatty acids, MUFA: monounsaturated fatty acids, PUFA: polyunsaturated fatly acids.
} 
The effectiveness of blinding was good. Twenty-three subjects $(38 \%)$ recognized the run-in diet as the oleic acid diet. Six subjects (29\%) recognized the MCFA diet, 9 subjects $(45 \%)$ the myristic acid diet and 7 subjects $(37 \%)$ the oleic acid diet. These numbers could be expected by chance. Palatability as measured with an anonymous questionnaire at the end of the study revealed that margarines, bread, cookies and pie from the MCFA and the myristic acid diet were less palatable than those from the oleic acid diet.

Mean body weight (meanststandard deviations) of the MCFA, myristic acid and the oleic acid group were after the run-in period $70 \pm 10 \mathrm{~kg}, 72 \pm 9 \mathrm{~kg}, 71 \pm 12 \mathrm{~kg}$, respectively and did not change over the test period.

Hunger ratings with the three diets are given in table 2 and individual changes of hunger ratings from the run-in to the test period are illustrated in figure 1. Feelings of hunger were higher with the myristic acid diet compared with the oleic acid diet (difference in changes of $7.3 \mathrm{~mm} ; \mathrm{P}=0.0036$ ). With the MCFA acid diet a trend for lower hunger-feelings was demonstrated compared with the myristic acid diet (difference in changes of $-3.3 \mathrm{~mm} ; \mathrm{P}=0.0546$ ). The MCFA diet did not change feelings of hunger compared with the oleic acid diet (difference in changes $4.0 \mathrm{~mm}$; $\mathrm{P}=0.2960)$.

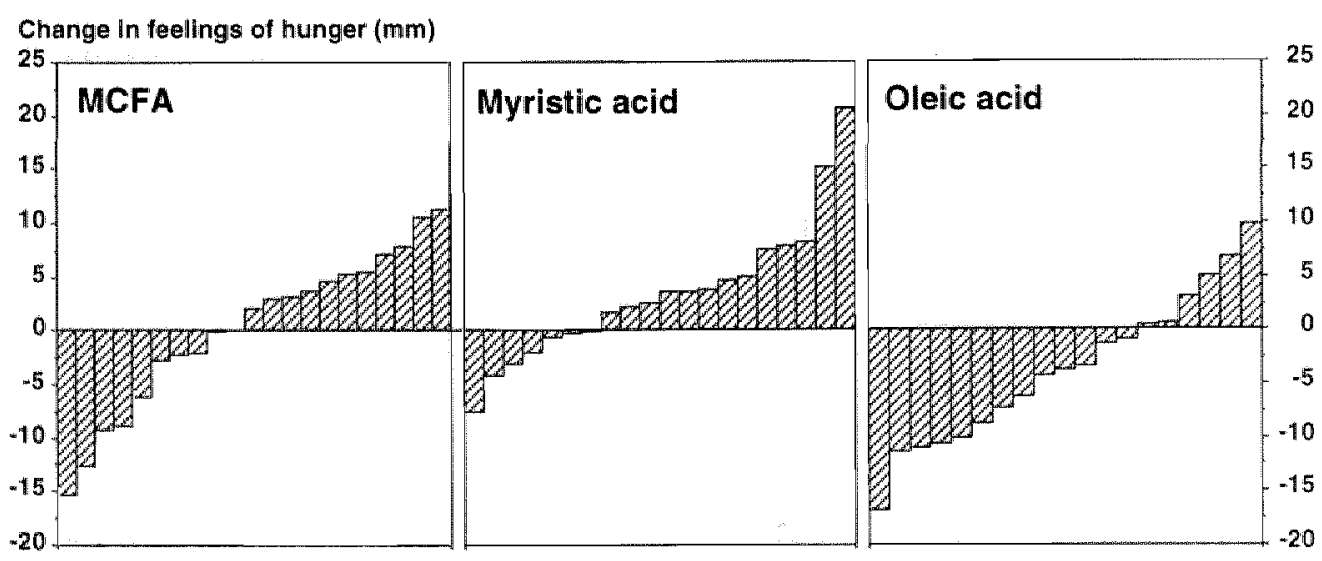

Figure 1. Individual changes in feelings of hunger ( $\mathrm{mm}$ of $100 \mathrm{~mm}$ visual analog scale) on diets rich in MCFA ( $n=21)$, myristic acid $(n=20)$ or oleic acid diet $(n=19)$ compared with a run-in diet rich in oleic acid. 
Table 2. Hunger ratings ( $\mathrm{mm}$ of $100 \mathrm{~mm}$ visual analog scale) in 60 healthy subjects consuming a MCFA $(n=21)$, myristic acid $(n=20)$ or oleic acid diet $(n=19)$.

\begin{tabular}{|c|c|c|c|c|c|c|}
\hline & \multicolumn{2}{|c|}{ MCFA Diet } & \multicolumn{2}{|c|}{ Myristic Acid Diet } & \multicolumn{2}{|c|}{ Oleic Acid Diet } \\
\hline & Run-in & Change & Run-in & Change & Run-in & Change \\
\hline \multicolumn{7}{|l|}{ Hunger (mm) } \\
\hline All & $35 \pm 16$ & $0 \pm 7$ & $43 \pm 16$ & $3 \pm 7+$ & $48 \pm 14$ & $-4 \pm 7$ \\
\hline Wamen & $35 \pm 18$ & $-1 \pm 7$ & $42 \pm 17$ & $4 \pm 8$ & $48 \pm 11$ & $-4 \pm 7$ \\
\hline Men & $34 \pm 13$ & $2+8$ & $45 \pm 16$ & $2+4$ & $47 \pm 17$ & $-4 \pm 7$ \\
\hline
\end{tabular}

* Values are meanststandard deviations.

t $P<0.01$, significantly different from the oleic acid diet.

Serum apoA-IV concentrations are shown in table 3. ApoA-IV concentrations were $1.4 \mathrm{mg} / \mathrm{dL}$ lower with the myristic acid diet compared with the oleic and the MCFA diet. The differences in changes between the diets did not reach statistical significance ( $P=0.1482$ and $P=0.2125$, respectively for differences in changes).

Table 3. Apolipoprotein A-IV concentrations in 60 healthy subjects consuming diets enriched in MCFA $(n=21)$, myristic acid $(n=20)$ or oleic acid diet $(n=19)$.

\begin{tabular}{|c|c|c|c|c|c|c|}
\hline & \multicolumn{2}{|c|}{ MCFA Diet } & \multicolumn{2}{|c|}{ Myristic Acid Dilet } & \multicolumn{2}{|c|}{ Oleic Acid Diet } \\
\hline & Run-in & Change & Run-in & Change & Run-in & Change \\
\hline \multicolumn{7}{|c|}{ Apolipoprotein A-IV (mg/dL) } \\
\hline All & $12.1 \pm 2.8$ & $0.2+2.4$ & $13.7 \pm 4.0$ & $-1.2 \pm 2.5$ & $12.9 * 4.9$ & $0.2 \pm 3.2$ \\
\hline Women & $11.3 \pm 2.8$ & $0.6 \pm 2.7$ & $12.0 \pm 3.8$ & $-0.5 \pm 2.1$ & $12.2 \pm 3.7$ & $0.4+2.8$ \\
\hline Men & $13.4+2.4$ & $-0.3+2.1$ & $16.2 \pm 3.0$ & $-2.3 \pm 2.7$ & $14.1 \pm 6.6$ & $-0.2 \pm 3.9$ \\
\hline
\end{tabular}

- Values are meanststandard deviations.

Serum leptin concentrations are given in table 4 . In subjects consuming the myristic acid or the oleic acid diet no changes in serum leptin concentrations were demonstrated. The MCFA diet induced higher leptin concentrations compared with both the myristic (difference in change of $1.1 \mathrm{ng} / \mathrm{mL} ; P=0.0293$ ) and the oleic acid diet (difference in change of $1.1 \mathrm{ng} / \mathrm{mL} ; P=0.0904$ ). The overall $P$-value for diet, however, did not reach significance $(P=0.0752)$.

A negative Spearman correlation coefficient between changes in hunger-feelings and changes in leptin concentrations was demonstrated in subjects consuming the 
MCFA diet $(r=-0.54 ; P=0.0115)$, whereas a positive association was observed in subjects consuming the myristic acid diet $(r=0.54 ; P=0.0133)$. No significant correlations were found between changes in apoA-IV and changes in hungerfeellings. A correlation was demonstrated between leptin concentrations and $B M \|(r=$ 0.27 ; $P=0.0402$, all subjects combined after oleic acid run-in period). 


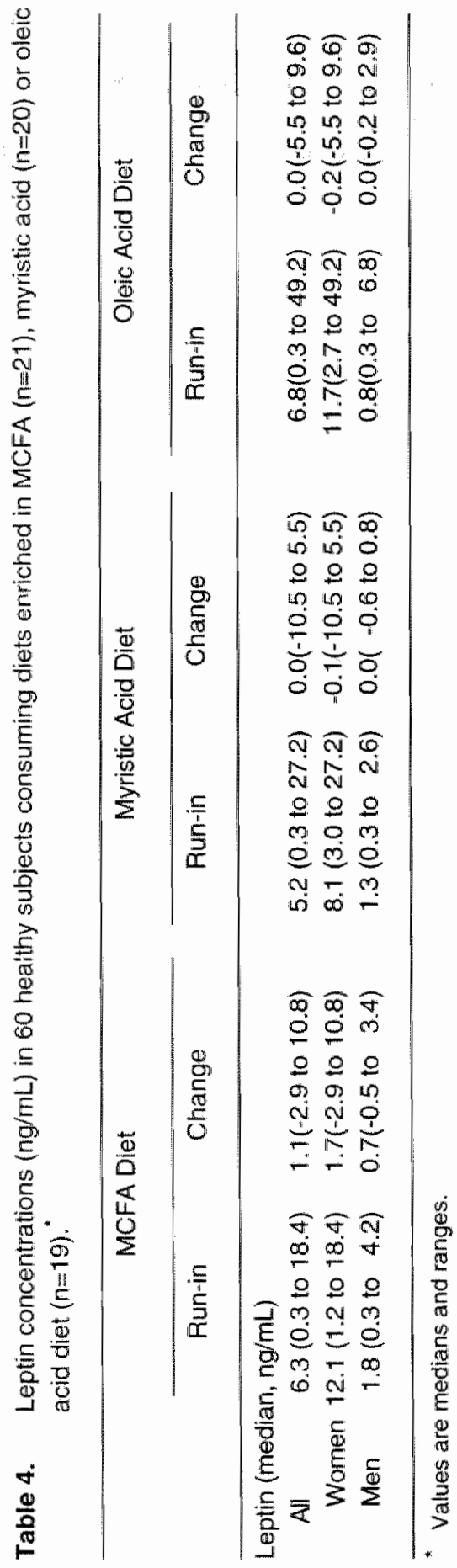




\section{DISCUSSION}

The present results indicated that a diet rich in myristic acid increased feelings of hunger compared with an oleic acid diet. The increased feelings of hunger on the myristic acid compared with those on the MCFA diet were less pronounced and did not reach statistical significance.

In this study it was important that the diets did not differ in other aspects (for example, palatability) than fatty acid composition as we were interested post absorptive regulators of satiety mechanisms. If the observed differences in palatability would have affected feelings of hunger, the changes with the MCFA and the myristic acid diet would have been expected to occur in a similar direction relative to the oleic acid diet. The present results, however, rather indicate opposite effects of both saturated-fat diets.

Of the possible regulating mechanisms for satiety, differences in gastric emptying of the various diets are not very likely to explain the changed hunger feelings. Longer chain unsaturated fatty acids, like oleic acid, leave the stomach at a slower rate than shorter chain fatty acids as myristic acid (25). Gastric emptying of MCFA has been reported to be even faster than glucose (26). However, compared with the oleic acid diet feelings of hunger did not change with the MCFA diet and were increased with the myristic acid diet.

The unchanged fasting concentrations of some proposed regulators of food intake -apoA-IV and leptin- with the myristic compared with the oleic acid diet may indicate that their concentrations change in a different time span (for example shortly after a meal) or that other regulatory components are involved. Cholecystokinin (CCK), which concentrations change shortly after a meal, might be one of these regulators. The intestinal release of CCK is stimulated by long chain fatty acids (27) and administration of CCK reduces short-term food intake (28). A recent study (29) showed that CCK release is fatty acid chain length dependent as MCFA did not, and lauric acid (C12:0) increased CCK release. Also oleic acid increased CCK release compared with saline (30). However, whether the oleic acid-induced release of CCK is higher than for myristic acid or other saturated fatty acids remains to be investigated in further postprandial experiments.

From our results, it is tempting to speculate that exchanging dietary saturated rich fats for fats rich in oleic acid decreases feelings of appetite. This may, on the longer term, help to maintain a proper weight. It is therefore interesting that an inverse association between the intake of vegetable fat, in which major fatty acids are oleic and linoleic acid, and body mass index has been observed (31). Stamler and Dolecek (32), in addition, demonstrated a greater weight loss at lower intakes of fats and oils rich in saturated fatty acids and with higher intakes of polyunsaturated fatty acids. It should, therefore, be also investigated whether exchanges of saturated fatty acids (especially the major fatty acid palmitic acid (C16:0) or mixtures of saturated fats) for polyunsaturated fatty acids reduces feelings of hunger and food intake. 
Whereas MCFA did not change feelings of hunger compared with oleic acid and only slightly increased those compared with the myristic acid diet, a trend for increased leptin concentrations was demonstrated. So far, body mass is considered to be the most important regulator of leptin levels $(16,33)$. Also, in the present study a positive association between BMII and leptin levels was observed. In addition, leptin concentrations were higher in women than in men, as has been reported before (33). However, the fact that leptin concentrations tended to increase with the MCFA diet, without concomitant changes of body weight, indicates that leptin concentrations may also be finely tuned independent of changes in BMI. Recently this was also demonstrated in subjects, in whom fasting was associated with a decline of leptin concentrations $(18,34)$. This and the rise in leptin concentrations after a prolonged exposure to hyperglycemia and resultant hyperinsulinemia indicated that the leptin release is sensitive to changes in insulin and glucose levels (35-37). Since the time of fasting was on average similar for our subjects within the different diet groups, the hyperinsulinic effect of MCFA (10) compared with longer chain fatty acids, might be related to the elevated leptin levels with this diet.

To summarize, this study indicates that the diet rich in myristic acid increased feelings of hunger compared with the diet rich in oleic acid. The mechanism of regulation remains obscure. No changes in fasting apoA-IV or changes in leptin concentrations were observed for this comparison.

\section{ACKNOWLEDGMENTS}

We thank Prof Dr M Rosseneu (Lipoprotein Laboratory, Gent University, Belgium) for the measurement of the apolipoprotein A-IV concentrations and R Tenenbaum (Department of Metabolic Diseases, Hoffman La Roche, Nutley, USA) for the measurement of leptin concentrations. 


\section{REFERENCES}

1. Burton BT, Foster WR. Health implications of obesity: an NHH concensus development conference. J Am Diet Assoc 1985;85:1117-1121.

2. Borkan $G A_{s}$ sparrow D, Wishewski $C$, Vokonas PS. Body weight and coronary heart disease risk: patterns of risk factor change associated with long-term weight change. Am J Eprideniol $1986 ; 124: 410-419$.

3. Van ltalle TB. Health implications of overweight and obesity in the United States. Ann intern Med $1985 ; 103: 983-988$.

4. National Pesearch Council Diel and health: implications for reducing chronic disease risk. Washington, DC: National Academy Press, 1989

5. Blundell JE, Burley VJ, Cotton JR, Lawtori CL. Dietary tat and the control of energy intake: evaluating the effects of fat on meal size and post-meal satiety. Am J Clin Nutr 1993;57:7725-778S.

6. Rolls BJ, Hammer VA. Fat, carbohydrate and the regulations of energy intake. Am $J$ Chin Nutr 4995;62(suppl): 10865-1095S.

7. Mensink RP, Katan MB. Effect of monounsaturated fatty acids versus complex carbohydrates on high-density lipoproteins in healthy men and women. Lancet 1987:1:122-125.

8. Katan MB, Grundy SM, Willet WC. Beyond low-fat diets. N Engl I Med 1997;336:563-566.

9. Rolls Bl, Gnizak N, Summerfelt A, Jacobs Laster L. Food intake in dieters and non-dieters after a liquild meal containing medium-chain triglycerides. Am J Chin Nutr 1988;48:66-71.

10. Bach AC, Ingenbleek $Y$, Frey A. The usefulness of dietary medium-chain fatty triglycerides in body weight control: fact of fancy? J Lipid Res 1996;37:708-726.

11. Fujimoto $K_{a}$ Cardelli JA. Tso P. Increased apolipoprotein A.IV in rat mesenteric lymph after lipid meal acts as a physiological signal for satiation. Am J'Physiol 1992;262:G1002-G1006.

12. Okumura T, Fukagawa K, Tso P. Taylor IL, Pappas TN. Apolipoprotein A-IV acts in the brain to inhibit gastic emptying in the rat. Am J Physiology 1996;33:G49-G53.

13. Satoh $M$, Nagao K. Hayama T, Sugano M, Imaizumi K. Repression of fat-dependent intestinal ApoA. IV mRNA abundance by Medium Chain Triacylglycerols and proteins, and elevation by carbohydrates of fat-dependent Apo A-IV transport in suckling rat pups. I Nutr Sci Vitaminol 1995:41:293-306.

14. Spiegelman BM. Flier J5. Adipogenesis and obesity: rounding out the big picture. Cell 1996;87:377-389.

15. Campfield LA, Smith FJ, Guisez Y, Devos R, Bum P. Recombinant mouse ob protein: Evidence for a peripheral signal linking adiposity and central neural networks. Science 1995:269:546-549.

16. Campfield LA, Smith FJ, Burn P. The OB protein (leptin) pathway- a link between adipose tissue mass and central ineural networks. Horm Metab Res 1996;28:619.632.

17. Havel PJ, Kasim-Karakas $S_{n}$ Mualler W, Johnson PR, Gingerich RL, Stem JS. Relationship of plasma leptin to plasma insulin and adiposity in normal weight and overweight women: effects of dietary fat content and sustained weight loss, J Clin Endocrinol Metabol 1996;81:4406-4413.

18. Weigle DS, Duell B, Connor WE, Steiner RA, Soules MR, Kuliper dL. Effect of fasting, reteeding. and dietary fat restriction on plasma leptin levels. J Clin Endocrinol Metabol 1997:82:561-565.

19. Schrauwern $P$, van Marken Lichtenbelt WD, Westerterp KR, Saris WHM. Effect of diet composition on leptin concentrations in lean subjects. Metabolism 1997;46:1-6. 
20. Temme EHM, Mensink RP. Hornstra G. Effects of medium chain fatty acids, myristic acid, and oleic acid on serum lipoproteins in healthy subjects. J Lipid Res 1997;38:1746-1754.

21. Stichting NEVO. NEVO tabel, Nederland's voedingstoffenbestand (Dutch food composition table). Den Haag: Voorlichtingsbureau voor de Voeding, 1989.

22. Rosseneu M, Michels $G$, De Keersgieter W, Bury $J$, De Slypere JP, Dieplinger H. Uteman $G$. Quantification of human apolipoprotein A-IV by "sandwich"-type enzyme-linked immunosorbent assay. Clin Chem 1988;34:739-743.

23. SAS Institute Inc. SAS: user's Guide Statistics, Version 5 Edition.Cary, NC: SAS Institute linc, 1985.

24. Siegel $S$, Castellan Nu. Nonparametric statistics for the behavioral sciences.Singapore: McGraw-Hill Book Co, 1988.

25. Hunt JN, Knox MT. Regulation of gastric emptying. In: Handbook of physiology. American Physiology Society, 1968;4:1917-1935.

26. Beckers EJ, Jeukendrup AE, Brouns F, Wagenmakers A.JM, Saris WHM. Gastric emptying of carbohydrate medium chain triglyceride at rest. Int I Sport Med 1992;13:581-584.

27. Meyer $\mathrm{JH}$, Jones RS. Canine pancreatic responses to intestinally perfused fat and products of fat digestion. Am J Physiol 1974;226:1178-1187.

28. Gibbs $J$, Smith GP. Effects of brain gut peptides on satiety. In: Björntorp. P. Brodoff BN, ed. Obesity. Philadelphia: Lipincolt, 1992: 399-410.

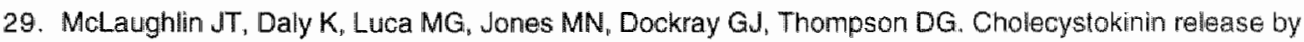
fatty acid: evidence for a threshold acyl chain length and a concentration effect. Gut 1996;38 (suppl 1):A5 (abstract).

30. McLaughlin JT, Luca MG, Jones A, Mamtara H, Dockray GJ, Thompson DG. Fat induced CCK release and effect on antral and gallbladder motility are dependent on meal composition. Gut 1995;73 (Suppl 2):A51 (abstract).

31. Colditz GA, Willet WC, Stampfer MJ, London S $\downarrow$, Segal MR, Speizer FE. Patterns of weight change and their relation to diet in a cohort of healthy women. Am I Cirn Nutr 1990,51:1100-1105.

32. Stamler $\mathrm{J}$, Dolecek TA. Relation of food and nutrient intakes to body mass in the special intervention and usual care groups in the Multiple Risk Factor Intervention Trial. Am J Clin Nutr 1997;65 (supp):366S-373S.

33. Considine RV, Sinha MK, Heiman ML, Kriauciunas A Stephens TW. Nyce MFi, Ohannessian J, Marco $C C$, McKee LJ, Bauer TL. Serum immunoreactive.leptin concentrations in normal-weight and abese huimans. N Engl J Med 1996:334:292-295.

34. Sonnenberg GE, Krakower GA, Hoftmann RG, Maas DL, Hennes MMI, Kissebah AH. Plasma leptin concentrations: effects of extended fasting and stepwise increases in glucose infusions. Obesity Res 1996;4 (suppl 1):13S (abstract).

35. Kolaczynski JW, M.R. N "Considini RV, Baden G, Nolan JJ, Henry R, Mudaliar SR, Oletsky J, Caro JF. Acute and chronic effect of insulin on leptin production in humans. Diabetes 1996;45:699-701.

36. Dagoge-Jack S, Fanelii C, Paramore $D$, Brothers J, Landt $M$. Plasma leptin and insulin relationships in obese and nonobese humans. Diabetes 1996;45:695-698.

37. Ryan AS, Elahi D. The effects of acute hyperglycemia and hyperinsulinemia on plasma leptin levels: its relationship with body fat, visceral adiposity, and age in women. I Clin Endocrinol Metabol $1996 ; 81: 4433-4438$. 

General discussion 
This thesis describes the effects of medium chain fatty acids (MCFA), lauric acid. myristic acid and palmitic acid on the cardiowascular risk profile in healthy women and men. So far, specific effects of these saturated fatty acids on serum lipid and lipoprotein concentrations have hardly been studied (MCFA and lauric acid) or results were conflicting (lauric, myristic and palmitic acids). In addition, the effects of individual saturated fatty acid on hemostatic factors have not been examined in sufficient detail, while mainly young and lean men were studied, whereas we now studied both women and men aged between 20 and 60 years.

\section{Design of the studies}

The first study (lauric and palmitic acid study) followed a cross-over and the second (MCFA and myristic acid study) a parallel desigin. The advantage of a crossover design is that subjects receive each diet and, therefore, to achieve the same statistical power, less subjects are needed than in a parallel designed study. The disadvantage is that carry-over effects may occur, which, however, was not the case in our study. Also the long duration of a cross-over designed experiment together with the controlled nature of the study could have been one of the reasons that 11 of the 43 subjects that started the trial dropped out during the first study.

In the second study (MCFA and myristic acid study) a parallel design was applied. The test period was preceded by a run-in period of controlled diets. In this way between subject variation in the variables of interest was excluded as each subject was used as its own control. In addition, the variation in the results due to the different habitual diets was eliminated.

The diets contained $40 \mathrm{En} \%$ from fat, of which the major amount of fatty acids (70\% in the first study and $63 \%$ in the second study) was supplied to the subjects with experimental margarines and products that were made of these margarines. The remaining fat-intake was left at the subjects' own decision, although controlled with a point system of "free-choice" items. To exclude some potential confounders, body weights were kept constant during the study by adjusting the level of energy intake when the weekly recorded body weight indicated changes. Subjects were asked to maintain the same activity level, the same smoking and drinking habits and not to changle intakes of medicines such as oral contraceptives throughout the study.

The compliance to the protocols was checked in different ways. Subjects visited the university every week to receive a new supply of experimental products and were then interviewed by a registered dietitian to check their adherence to the study protocol and discuss possible difficulties with it. The self reported food intake records in each experimental period, records of the products chosen as "free-choice" items, body weight, and fatty acid anallysis of pooled serum samples provided further evidence for good compliance to the protocol. The subjects did not receive any payment for their contributions, to avoid unmotivated subjects participating only for their filnancial benefit. 
In both studies, values on a diet rich in oleic acid were used as references, in the parallel designed study, for the coagullation and fibrinolytic parameters it was noted that changes were still observed after three weeks of the run-in period in the oleic acid group. Whether this effect was caused by a drift in time, or because the run-in period was too short to achieve stable measurements of the different factors is not known from the present experiment.

\section{Experimentall fats}

The lauric, palmitic and oleic acid rich experimental fats were composed of blends of natural fats. Edible consumption fats that are rich only in MCFA or myristic acid do not exist. Therefore, special MCFA and myristic acid rich synthetic fats were manufactured. To evaluate the extent to which the positional distribution of the fatty acids in these synthetic fats corresponded to that from natural fats (chapter 3), we determined the fatty acids at the sn-2 position. From these results, and the total fatty acid composition, the fatty acid distribution over the $s n-1$ or $5 n-3$ position was calculated. As in dairy fat, MCFA from the MCFA experimental fat was attached mainly to the $s n-1$ and $s n-3$ position. In the myristic acid fat, myristic acid and the other saturates were equally distributed among the $s n-2$ and $s n-1,3$ positions. Myristic acid rich fat sources as palm kernel or coconut fat have myristic acid mainly at the $5 n-1,3$ positions (1), whereas dairy fat carries half of the total proportion of myristic acid at the sn-2 position (2). So far, dietary experiments comparing fats rich in palmitic acid $(3,4)$ and stearic acid (5) suggest that the positional distribution of these saturates do not affect lipid and lipoprotein concentrations. Whether a different positional distribution of MCFA and myristic acid could have influenced their cholesterolemic effects or effects on hemostatic parameters is, however, not known.

When comparing the two studies carried out, it should be taken into account that the amounts of fatty acids exchanged, as confirmed by the food records, were lower in the first study ( $\approx 8$ En\% from lauric acid or from palmitic acid for oleic acid) than in the second study (10 En\% from MCFA or from myristic acid for oleic acid). Because naturall fats were consumed in the first study, the lauric acid diet contained somewhat more myristic acid $(\approx 2 \mathrm{En} \%$ ) than the other two experimental diets, which might have influenced the results. For proper comparisons, the values in the figures and in the tables presented in this chapter are therefore recalculated to effects that are expected when $10 \mathrm{En} \%$ of a particullar saturated fatty acid would have been exchanged for oleic acid. In addition, the lipid and lipoprotein values on the lauric acid diet are corrected for the higher percent of energy myristic acid, using data of the study comparing the effects of myristic acid with those of oleic acid (Chapter 3 ). 


\section{INDIVIDUAL SATURATED FATTY ACIDS AND CARDIOVASCULAR RISK}

The effects of MCFA and lauric, myristic and palmitic acids on lipid and hemostatic tactors are summarized in table 1.

Table 1. Summary of the effects on fasting lipid and hemostatic factors of diets enriched in MCFA, lauric, myristic or palmitic acid compared with those of oleic acid."

\begin{tabular}{|c|c|c|c|c|c|}
\hline & MCFA & $\begin{array}{l}\text { Lauric } \\
\text { acid }\end{array}$ & $\begin{array}{l}\text { Myristic } \\
\text { acid }\end{array}$ & $\begin{array}{l}\text { Palmilic } \\
\text { acid }\end{array}$ & $\begin{array}{l}\text { CVD } \\
\text { risk }\end{array}$ \\
\hline \multicolumn{6}{|l|}{ Lipid factors } \\
\hline LDL cholesterol & $+=$ & + & + & + & + \\
\hline HDL cholesterol & $=$ & + & + & $=$ & - \\
\hline Triacylglycerols & $+=$ & $=$ & $=$ & $=$ & $+?$ \\
\hline Lipoprotein(a) & $=$ & $=$ & - & $=$ & + \\
\hline Apolipoprotein B & $=$ & + & $t=$ & + & + \\
\hline Apolipoprotein A-I & $=$ & + & $+=$ & $=$ & - \\
\hline \multicolumn{6}{|l|}{ Hemostatic factors } \\
\hline $\begin{array}{l}\text { Whole blood } \\
\text { aggregation }\end{array}$ & $=$ & $=$ & $=$ & $=$ & $+?$ \\
\hline \multicolumn{6}{|l|}{ Coagulation } \\
\hline Factor VIlam activity & $=$ & + & + & + & + \\
\hline Fibrinogen & $=$ & $t=$ & $=$ & $t=$ & + \\
\hline Antithrombin activity & $=$ & $\cdot$ & $=$ & $=$ & $-o r+?$ \\
\hline \multicolumn{6}{|l|}{ Fibrinolysis } \\
\hline PAl activily & $=$ & $=$ & $=$ & + & $+?$ \\
\hline
\end{tabular}

* See also table 2 in the general introduction for remarks on the relationships of these wariables with CVD-risik. PAl: plasminogen activator inhibitor.

\section{Lipid factors}

Changes in LDL and HDL cholesterol concentrations and total to HDL cholesterol ratios, when $10 \mathrm{En} \%$ from oleic acid is exchanged for either MCFA or lauric, myristic or palmitic acids, are shown in figure 1. 


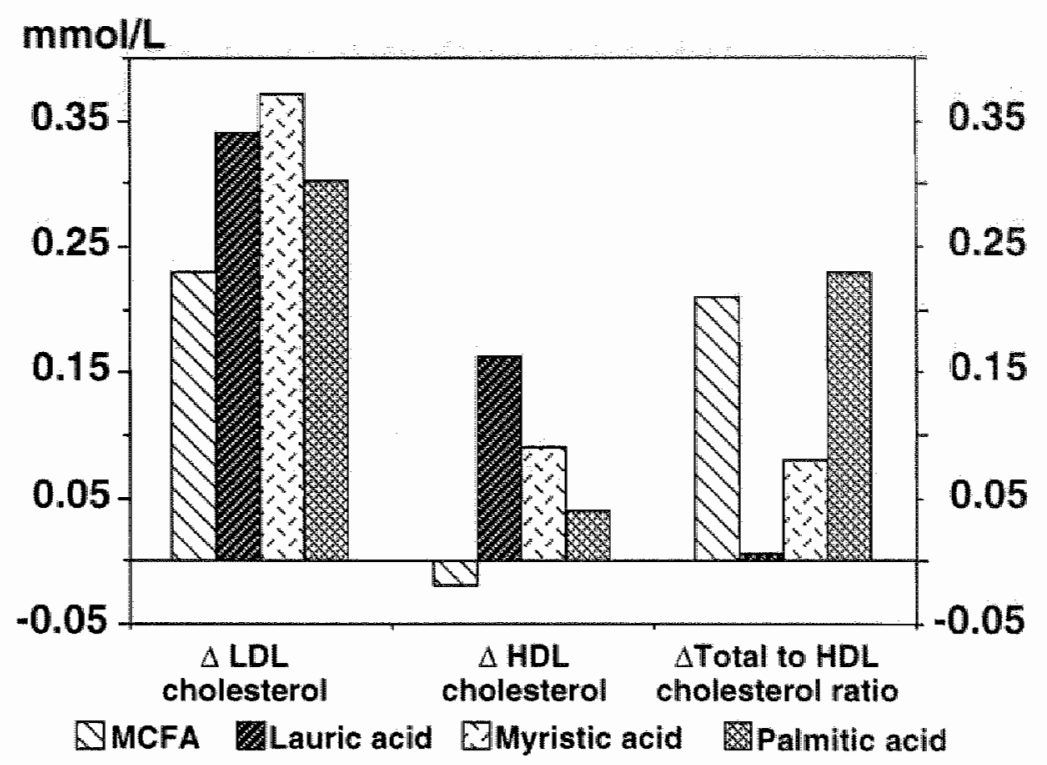

Figure 1. Mean changes in LDL and HDL cholesterol concentrations and tolal to HDL cholesterol ratios when 10 percent of energy from oleic acid is exchanged for either MCFA or lauric acid or myristic acid or palmitic acid.

MCFA did not significantly change HDL and LDL cholesterol concentrations compared with the oleic acid or the myristic acid diet. MCFA, however, tended to increase LDL cholesterol concentrations compared with oleic acid. A recent controlled study (6), in which extremely high concentrations of MCFA ( 43 En\%) were given, reported a more pronounced increase in LDL cholesterol compared with oleic acid. Recalcullated to a 10 En\% exchange from oleic acid, however, the LDL cholesterol-raising effect of MCFA was $0.13 \mathrm{mmol} / \mathrm{L}(6)$, which is smaller than the 0.23 mmol/L raise of $L D L$ cholesterol concentrations found in the present study. The HDL cholesteral concentrations, in agreement with our results, did not change compared with the oleic acid diet (6). Therefore, referring to the effects of MCFA as neutral compared with carbohydrates $(7,8)$ does not seem justified, because carbohydrates do decrease HDL chollesterol levels compared with oleic acid (9). The effects on HDL cholesterol concentrations of MCFA compared with iso-energetic amounts of carbohydrates, of course, meeds further investigation in a side-by-side comparison. In contrast to the other saturates, MCFA tended to raise triacylglycerol concentrations. Triacylglycerol-raising effects have been found in several other studies also $(6,10$, 11). The less pronounced effects of the MCFA diets on the triacylglycerol concentrations in the present study was probably also related to the smaller doses of MCFA given in our diets.

Lauric and myristic acids demonstrated the stronglest total cholesterol-raising effect compared with oleic acid. Lauric acid significantly raised total, LDL and HDL 
cholesterol levels compared with oleic acid. The total cholesterol-raising effects of lauric acid compared with oleic acid were also found in an earlier experiment (12), but the total cholesterol-raising potency compared with other individual saturated fatty acids like paimitic acid is still not clear. Because of the presumed strong effects of myristic acid on lipids and lipoproteins concentrations, the values for lauric acid (see figure 1) were corrected for the $2 \mathrm{Er} \%$ higher myristic acid in the lauric acid diet. Then, the expected rise in LDL and HDL cholesterol would be $0.34 \mathrm{mmol} / \mathrm{L}$ instead of $0.43 \mathrm{mmol} / \mathrm{L}$ for $\mathrm{LDL}$ cholesterol when $10 \mathrm{En} \%$ of oleic acid is exchanged for lauric acid, as $0.09 \mathrm{mmol} / \mathrm{L}$ was due to the higher myristic acid content of this diet relative to oleic acid. The expected change for HDL cholesterol is $0.16 \mathrm{mmol} / \mathrm{L}$ instead of 0.19 $\mathrm{mmol} / \mathrm{L}$, as $0.03 \mathrm{mmol} / \mathrm{L}$ is due to the higher myristic acid content. Combined results, therefore, suggest (figure 1), that the LDL cholesterol-raising effect of lauric acid is between that of palmitic acid and myristic acid. The major difference between lauric and palmitic acids is the more pronounced increasing effect of lauric acid on HDL cholesterol concentrations, which explains the stronger total cholesterol-raising effects of this saturated fatty acid compared with palmitic acid.

The myristic acid diet raised total, LDL and HDL cholesterol concentrations compared with the oleic acid diet. The presumed very potent effects of myristic acid on total (8) and LDL cholesterol levels (13), however, needs to be attenuated. Total cholesterol concentrations raised with $0.40 \mathrm{mmol} / \mathrm{L}$ relative to the oleic acid diet which was less than expected from regression equations (8). Using Hegsteds regression equation, which includes myristic and palmitic acids, polyunsaturates and dietary cholesterol, total cholesterol concentrations are estimated to increase with $2.19 \mathrm{mmol} / \mathrm{L}$ when 10 energy percent of oleic acid is exchanged for myristic acid. Using the equation including all variables (MCFA, lauric, myristic and palmitic acids, monounsaturates, polyunsaturates and dietary cholesterol), the estimated change is $1.35 \mathrm{mmol} / \mathrm{L}$ (8). In agreement with our results, other controlled experiments found, smaller changes in total cholesterol when myristic acid was compared with oleic acid (14) or no change when it was compared with pallmitic acid (15). Myristic acid does paise HDL cholesterol concentrations, which has been found earlier $(14,15)$. As for lauric acid, the unfavorable LDL cholesterol-raising effects of myristic acid "go with the postulated favorable effects on HDL cholesterol concentrations. Thus, the LDL and HDL cholesterol raising effects of palm kernel (16) or coconut fat (17-19), rich in both lauric and myristic acids, compared with for example palm or olive oils, are most likely due to the cholesterol-raising action of both lauric and myristic acid.

Relative to oleic acid, palmitic acid elevated total and LDL cholesterol and apoB concentrations, but not HDL cholesterol concentrations. This study, therefore, confirmed previous studies $(12,14,20,21)$ that palmitic acid is a cholesterol-raising fatty acid although the effects on LDL cholesterol concentrations were less than those of myristic acids (see figure 1). Hayes and colleagues have hypothesized that, under certain conditions, palmitic and oleic acids can be exchanged without affecting LDL cholesterol concentrations (13). Conditions, in which palmitic acid does not raise LDL cholesterol levels include those in which diets contain adequate linoleic acid and are low in cholesterol $(17,22)$. It has been postulated that, under these conditions, 
linoleic acid increases LDL-receptor activity, and thereby counteracts the stimulating effects of palmitic acid on apoB production (13). As the linoleic acid content of the diets used was adequate and cholesterol intake was low, cholesterol-raising effects of palmitic acid presented in chapter 2 only fit in the proposed model (13) when a high total fat intake also moderates the LDL metabolism and consequently the cholesterolemic effects of palmitic acid. In the present study dietary fal intake was around $40 \mathrm{En} \%$, whereas in the few studies, which found that palmitic acid did not raise $L D L$ cholesterol compared with oleic acid, total fat intake was around $30-34$ En\% $(17,22)$. With Western diets, containing on average 37 En\% of fat $(23)$, the major saturated fatty acid of this diet (palmitic acid) must be classified as a fatty acid that raises $\mathrm{LDL}$ cholesterol concentrations. HDL cholesterol levels remain stable after palmitic acid rich diets, relative to oleic acid rich diets. Whether this is not true at lower fat intakes needs more study.

\section{Lipoprotein(a)}

The myristic acid diet decreased $L p(a)$ concentrations compared with the oleic acid diet. Other studies indicate that mixtures of saturated fatty acids lower Lp(a) concentrations compared with oleic acid (cisc18:1(n-9)) (24), elaidic acid (transC18:1(n-9)) (21, 24, 25) and stearic acid (C18:0) (26). Lp(a) concentrations on diets rich in linoleic acid did not differ from those on diets rich in oleic acid (24). Combining these results suggests that mixtures of saturated fatty acids lower Lp(a) concentrations compared with fatty acids containing 18 carbon atoms, irrespective of the number of double bonds. In the first study we did not observe LP(a) lowering effects of the lauric or palmitic acid compared with oleic acid. The suggestion, however, that myristic acid in particular decreases $L P(a)$ is not supported by a recent study that reported similar $L p(a)$ concentrations after diets rich in myristic or palmitic acids (27). Since reduced $L p(a)$ concentrations on the myristic acid diet and mixtures of saturated fatty acids are accompanied by increased LDL cholesterol concentrations, both lipoprotein fractions are likely to be changed through mechanism that do not follow a similar pathway.

To summarize the effects on lipid factors: lauric, myristic and palimitic acids unfavorably raise LDL cholesterol concentrations relative to oleic acid, whereas the LDL cholesterol-raising effects of MCFA diets are less strong. The saturated fatty acids studied, sorted according to their LDL cholesterol-raising potency, are in ascending order: MCFA, palmitic acid, lauric acid and myristic acid. HDL cholesterol concentrations are favorably elevated by diets rich in lauric or myristic acids, but not by diets rich in MCFA or palmitic acid. Combined results on total to HDL cholesterol ratio (see figure 1), which has been proposed as a strong predictor of CVD-risk (28, 29), therefore, suggests higher ratios with the palmitic acid and the MCFA diets. The responses to the diets of lipid factors did not differ between women and men. 


\section{Hemostatic factors}

\section{Platelet aggregation}

The saturated fatty acids studied did not induce changes in wholle blood aggregation induced by elther collagen (MCFA, lauric, myristic and palmitic acids): ADP (MCFA and myristic acid). Diets rich in lauric or palmitic acids did not change thromboxane $\mathrm{B}_{2}$ production in collagen activated blood samples compared with the oleic acid diet (chapter 5). With the used method for measuring aggregation, we tried to mimic the in vivo aggregation situation as closely as possiblle. Hirudin was used as anticoagulant, because it binds directly to thrombin and does not lower the calcium concentrations as is the case in citrate-anticoagulated blood samples.

Partly due to the broad scala of platellet aggregation methods used by different laboratoria, the literature on the aggregatory effects of fatty acids is difficult to compare with each other and very confusing. In addition, saturated fatty acids have hardly been studied in detail and no studies have been carried out on whole blood aggregation with hirudinized anticoagulated blood samples. Using other methods, saturated fatty acids have been reported to increase PRP aggregation induced with thrombin (30), whereas others indicated lower PRP aggregation induced with ADP or collagen of a milkfat diet compared with diets enriched in sunflower or rapeseed oil (31). In this area of research, a validation and standardisation program for the methods to be used is needed, in addition to new approaches to assess the in wivo platelet activity.

\section{Coagulation factors}

Our studies demonstrated that diets enriched in lauric myristic or palmitic acids signifficantly increased factor VIlam activity. Marked differences were noted in factor VIlam responses between women and men (figure 2). Changes in factor Vllam only reached statistical significance in women. Whether changes in factor Vllam were more pronounced in women using contraceptives or in postmenopausal women. could not be examined in the first study on lauric and palmitic acids because groups were to small to draw conclusions. The second study on MCFA and myristic acid, however, demonstrated an interaction effect between diet and factor VIlam activity after the run-in period, suggesting that dietary responses were more pronounced in women with higher factor VIlam activities. Because contraceptive users and postmenopausal women have higher factor VIlam activity or coagulant activity than non-users ((32) and results given in chapter 6 and 7$)$, data from parallel designed studies must be corrected for the womens" baseline values, or study groups need to be balanced according to menopausal status and contraceptive use.

As the gender differences were observed in both studies, this finding certainly deserves follow-up and the proposed explanations (in chapters 6 and 7), such as hormonal differences or differences in interactions between diet and genetic backgrounds need more research.

A recent population-based study sustains that the association between saturated fat intake and factor VIlc activity is stronger in elderly women than in elderly men (33). 
Implications of a higher factor VII activity in women for CVD-risk are not known from prospective studies because these only included men $(34,35)$. Cross-sectional studies, however, do demonstrate, like in men, higher factor VIlc and factor V\|lantigen in women with CVD compared with women without CVD (36).

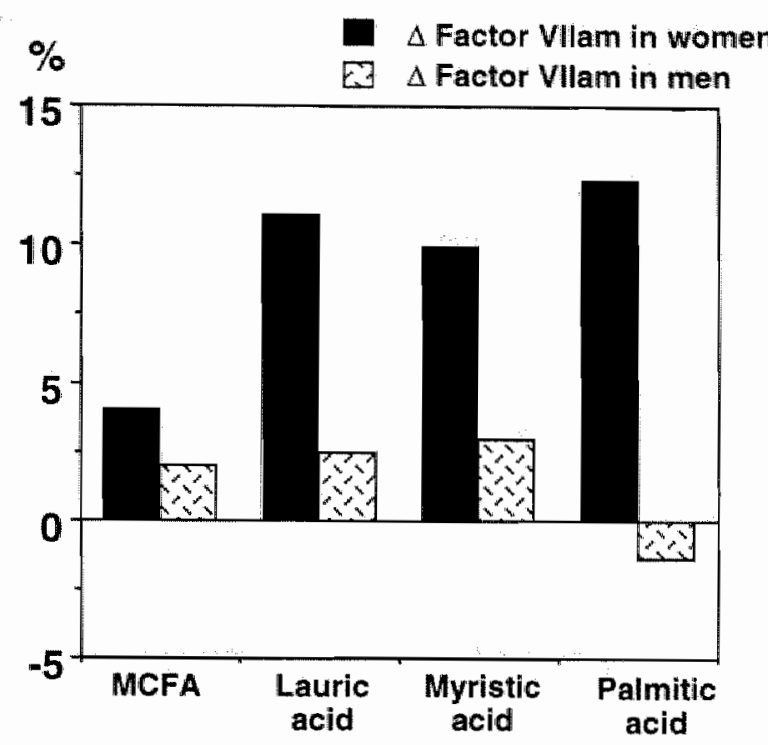

Figure 2. Changes in factor Vllam activity for women and men when 10 percent of energy from oleic acid is exchanged for either MCFA or lauric acid or myristic acid or palmitic acid.

The factor VII elevating effects of myristic or palmitic acid rich fats were also demonstrated by Tholstrup et all $(15,16)$. It is, however, difficult to compare their $(15$, 16) and our studies. Firstly, we have compared the individual saturates with oleic acid, whereas Tholstrup et al $(15,16)$ compared diets rich in lauric plus myristic acid or palmitic acid with diets rich in stearic acid (16) or a diet enriched in myristic acid with a palmitic acid enriched diet (15). Secondly, the study populations differed. We investigated the effects of saturates in healthy women and men with a broad age distribution (20-60 years), while they included only young and lean male subjects (15. 16). The use of different factor VII assays (Tholstrup et al used a one-staged coagulant assay with human thromboplastin) was probably of less importance for the comparison of results, because in our and their assay a human thromboplastin was used and the correlation between factor VIlam activity measured with a chromogenic assay and factor VIlc activity is high (37). Tholstrup et al found, except for stearic acid, no differences in factor VIlc activity between the individual saturated fatty acids (for the lauric plus myristic acid diet compared with the palmitic acid diet (16)) or small differences (for the myristic relative to the palmitic acid diet (15)). Stearic acid 
decreased factor Vllc activity compared with lauric plus myristic acids or palmitic acid (16).

Inhibitors of coagulation were affected differently by the individual saturated fatty acids. Antithrombin activity tended to be lower on the lauric acid diet and did not change on the MCFA, myristic or palmitic acid diets compared with the oleic acid diet. The myristic acid diet decreased the activity of TFPI, and the MCFA tended to decrease TFPl compared with oleic acid. TFPl activity on diets rich in lauric or palmitic acids, however, was not measured. The significance for CVD-risk of these findings is not clear. Higher activities of the coagulant inhibitors would expected to be beneficial for CVD-risk. However, also elevated levels of antithrombin (38) and TFPI (39) have been found in CVD patients.

For a valid conclusion on the effects of saturated fatty acids on the overall thrombotic capacity of the plasma, it might be important to evaluate how much thrombin can be formed.

In the second study (MCFA and myristic acid) we measured overall thrombin generation capacity of plasma with a global coagulation assay. the thrombin potential assay. Our study showed that the tissue factor-induced thrombin potential increased on the myristic compared with the oleic acid diet, in women but not in men. This finding again underlined the gender-specific effects of dietary saturated fatty acid on the coagulant capacity of the blood.

Concentrations of the prothrombin fragment $1+2$ (chapter 6), which is released when prothrombin is converted into thrombin and, therefore, is used as a marker for thrombin formation in vivo, did not change between the diets rich in lauric or palmitic acid compared with the oleic acid rich diet. This suggests an unaltered in wivo coagulant state of the blood after these diets. Why fragment $1+2$ concentrations increased in another dietary experiment on the effects of diets rich in lauric plus myristic acids compared with a stearic acid rich diet $(40)$ is not known.

The increased factor VIlam activity after lauric, myristic or palmitic acid rich diets relative to the oleic acid diet is of particular significance because results of epidemiological studies suggest that fatal coronary episodes are frequently preceded for months or years by increased plasma activity of this coagulation factor $(34,35)$. This then constitutes a hypercoagulable capacity of the blood implying an augmented risk on the longer term.

Prospective studies, in addition, suggest that both a high factor VIlc activity and high $L D L$ cholesterol concentrations implicate the strongest risk for the development of CVD $(34,35,41)$. When the effects of the individuall saturated fatty acids on changes in LDL cholesterol concentrations and changes in factor Vllam activity are combined and compared with those of oleic acid (figure 3), they indicate that MCFA is lless potent to increase these risk markers compared with the other saturated fatty acids. The action of myristic acid seems slightly less favorable than the action of lauric or palmitic acid, through the more potent LDL cholesterol-raising effects. 


\section{Fibrinolytic factors}

Palmitic acid significantly increased PAl activity compared with oleic acid which suggested a less favorable fibrinolytic state of the plasma. Differences in fibrinolytic capacity have not been reported before after diets enriched in specific saturated fatty acids $(15,16,26)$, but a diet rich in butterfat decreased PAl activity compared with hydrogenated soybean oil (25). Besides differences in MCFA, lauric, myristic and especially palmitic acids contents, the diets compared in that study (25) also differed with respect to trans fatty acids, which prevent a valid comparison with our results.

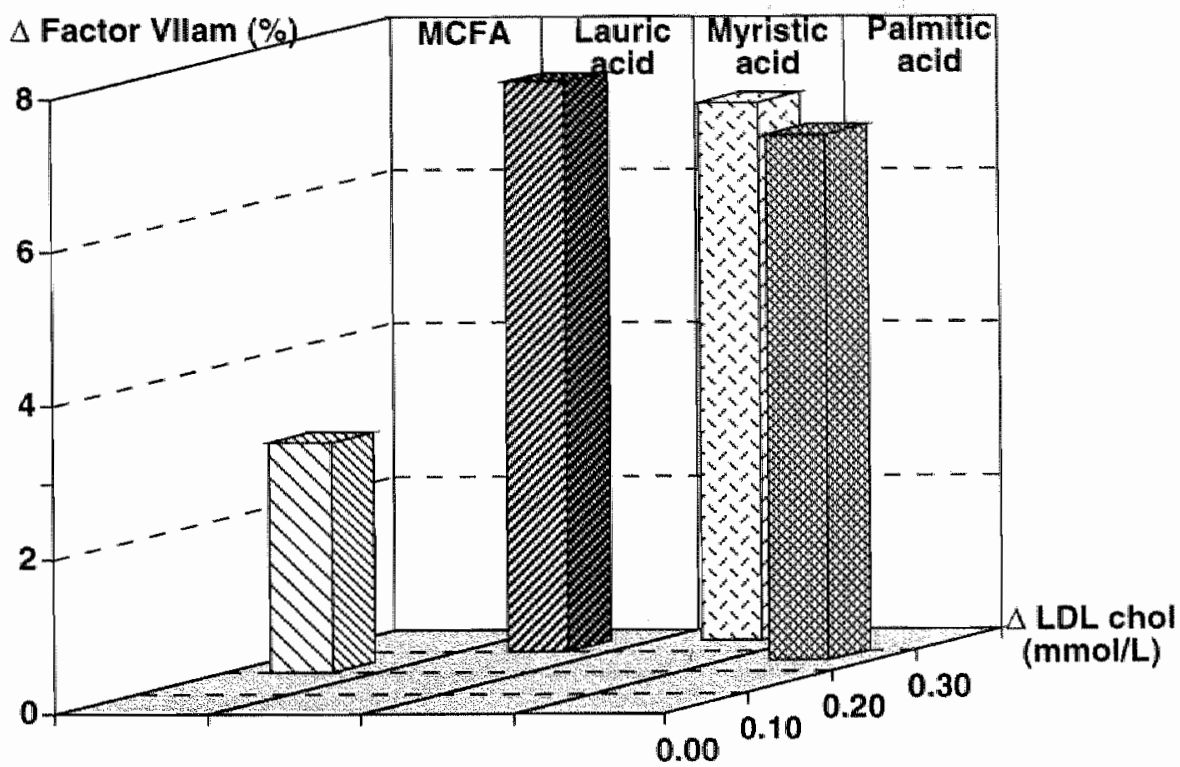

Figure 3. Changes in factor VIltam and LDL cholesterol concentrations when 10 percent of energy from oleic acid is exchanged for either MCFA or lauric acid or myristic acid or palmitic acid.

\section{Feelings of appetite and mood}

In the second study we found significantly increased feelings of hunger with the myristic compared with the oleic acid diet (chapter 8), whereas mood and anxiety scores did not differ between the diets (chapter 4 ). The findings on feelings of hunger indicate that dietary fatty acid composition might be a determinant of food intake regulation. Further research, however is needed to confirm these new findings. 


\section{Conclusions and recommendations}

The present investigations show dissimilar effects on serum lipid and lipoprotein levels of the saturated fatty acids studied. Diets rich in myristic acid raise LDL cholesterol concentrations most pronounced, followed by lauric and then palmitic acid rich diets. High LDL cholesterol concentrations increase CVD-risk. The effects of MCFA are different from the other saturated fatty acids studied, because they increase LDL cholesterol concentrations only slightly. The raise of HDL cholesterol by lauric and myristic acid rich diets has potentially beneficial effects on CVD-risk, but the effects of diet-induced elevations of HDL cholesterol concentrations remain to be established.

Lauric, myristic and palmitic acid rich diets, to the same extent, unfavorably raise plasma coagulant activity, as measured with factor Vllam activity. Therefore, there appears little need to differentiate, with respect to this parameter, between individual saturated fatty acids, except for MCFA and probably stearic acid $(16,26)$. However, the differences in responses between women and men are evident and deserve further mechanistic study and CVD-risk assessment.

The increase of CVD-risk is most pronounced when elevated levels of LDL cholesterol go together with increased coagulant capacity (41). Therefore, it will be advisable to decrease the intake of fats rich in lauric, myristic acids and palmitic acids in favor of a higher intake of unsaturated fatty acids for example from oils rich in monounsaturated fatty acids (oleic acids) such as olive oil, high oleic sunflower oil or rapeseed oil. Additional positive effects on feelings of appetite might be expected with the exchange of saturated fatty acids for monounsaturated fatty acids, but need confirmation in future research. 


\section{REFERENCES}

1. Small DM. The effects of glyceride structure on absorption and metabolism. Annu Rev Nutr $1991 ; 11: 413-434$.

2. Jensen JG, Ferris AM, Lammi-Keefe CJ. The composition of milk fat. J Dairy Soi 1991;74:3228. 3243.

3. Nestel PJ, Noakes M, Belling GB, MCArthur $R$, Clifton PM. Effect on plasma lipids of interesterifying a mix of edible oils. Am J Clin Nutr 1995;62:950-955.

4. Zock PL, de Vries JHM, de Fouw NH, Katan MB. Postional distribution of fatty acids in dietary triglycerides: effects on fasting bload lipoprotein levels in humans. Am J Clin Nutr 1995;61:48-55.

5. Grande F, Anderson JT, Keys A. Comparison of effects of palmitic and stearic acids in the diet on serum cholesterol in man. Am J Clin Nutr 1970;23:1184-1193.

6. Cater NB, Heller HJ "Denke MA. Comparison of the effects of medium-chain triacylglycerols, palm oil, and high oleic acid sunflower of on plasma triacylglycerol fatty acids and lipid and lipoprotein concentrations in humans. Am J Clin Nutr 1997;65:41-45.

7. Keys A, Anderson JT, Grande F. Serum cholesterol response to changes in the diet. IV. Particular saturated fatty acids in the diet. Metabolism 1965;14:776-786.

8. Hegsted DM, McGandy RB, Myers ML, Stare FJ. Quiantitative effects of dietary fat on serum cholesteral in man. Am J Clin Nutr 1965;17:281-295.

9. Mensink RP "Katan MB. Effect of monounsaturated fatty acids versus complex carbohydrates on high-density lipoproteins in healthy men and women. Lancet 1987:1:122-125.

10. Swift LL, Hill JO, Peters JC, Greene HL. Plasma lipids and lipoproteins during 6 d of maintenance feeding with long-chain, medium-chain, and mixed-chain triglycerides. Am J Clin Nutr 1992;56:881886.

11. McGandy RB, Hegsted $D M_{n}$ Myers ML. Use of semisynthetic fats in determining effects of specific dietary fatty acids on serum lipids in man. Am J Clin Nutr 1970;23:1288-1298.

12. Denke MA, Grundy SM. Comparison of effects of lauric acid and palmitic acid on plasma lipids and lipoproteins. Am J Clin Nutr 1992;56:895-898.

13. Hayes KC, Khosla P. Dietary fatty acid thresholds and cholesterolemia. FASEB I 1992;6:2600\% 2607.

14. Zock PL, de Vries JHM, Katan MB, Impact of myristic acid versus palmitic acid on serum lipid and lipoprotein levels in healthy women and men. Arteriosider Thromb 1994;14:567-575.

15. Tholstrup T, Marckmann $P_{n}$ Jespersen J, Vessby B. Jart A, Sandsitröm B. Effect on blood lipids, coagulation, and fibrinolysis of a fat high in myristic acid and a fat high in palmitic acid. Am $J$ Clin Nutr 1994;60:919-925.

16. Tholstrup T, Marckmann P. Jespersen J, Sandström B. Fat high in stearic acid tavorably affects blood lipids and factor VII coagulant activity in comparison with fats high in palmitic acid or high in myristic and lauric acids. Am J Clin Nutr 1994;59:371-377.

17. Ng TKW, Hayes KC, DeWitt GF, Jegathesan $M$, Satgunasingam $N$, Ong ASH, Tan D. Dietary palmitic and oleic acids exert similar effects on serum cholesterol and lipoprotein profiles in normocholesterolemic men and women. I Am Coll Nutr 1992;11:383-390.

18. Ng TKW, Hassan K, Lim JB, Lye MS, Ishak . Nonhypercholesterolemic effects of a palm-oil diet in Malaysian volunteers. Am U Clin Nutr 1991;53:1015S-1020\$. 
19. Sundram $\mathrm{K}$, Hayes $\mathrm{KC}$, Siru $\mathrm{OH}$. Dietary palmitic acid results in lower serum cholesterol than does a lauric-myristic acid combination in nomolipemic humans. Am J Clin Nutr 1994;59:841-846.

20. Bonanome $A_{4}$ Grundy SM. Etfect of dietary stearic acid on plasma cholesterol and lipoprotein levels. N Engl I Med 1988;318:1244-1248.

21. Neistel P, Noakes M, Belling B, McArthur R, Clifton P, Janus E, Abbey M. Plasma lipoprotein lipid and LP[a] changes with substitution of elaidic acid for oleic acid in the diet. I Lipid Res 1992;33:1029 1036;

22. Choudhury N, Tan L, Truswell AS. Comparison of palmolein and olive oill: effects on plasma lipids and vitamin $E$ in young adults. Am J Clin Nutr 1995;61:1043-1051.

23. Ministeries van Welzijn, Volksgezondheid en Cultuur en van Landbouw, Natuurbeheer en Visserii. Zo eet Nederland, 1992. Voorlichtingsbureau voor de woeding, 1993.

24. Mensink RP, Zock PL, Katan MB, Hornstra G. Effect of dietary cis and trans fatty acids on serum lipoprotein[a] levels in humans. J Lipid Res 1992,33:1493-1501.

25. Almendingen $\mathrm{K}$, Seljeflot $\mathrm{I}$, Sandstad $\mathrm{B}$, Pedersen Jl. Effects of partially hydrogenated fish oil, partially hydrogenated soybean oil, and butter on hemostatic variables in men. Arterioscler Thromb Vase Biol 1996;16:375-380.

26. Mutanen $M$, Aro A. Coagulation and fibrinolysis factors in healthy subjects consuming high stearic or trans fatty acid diet. Thromb Haemost 1997;77:99-104.

27. Tholstrup T, Marckmann P, Vessby B, Sandström B. Effects of fats high in individual saturated fatty acids on plasma lipoprotein(a) levels in young healthy men. J Lipid Res 1995:36:1447-1452.

28. Gardner CD, Fortmann SP, Krauss AM. Association of small low-density lipoprotein particles with the incidence of coronary artery disease in men and women. JAMA 1996;276:875-881.

29. Castelli WP, Anderson K, Wilson PWF, Lewy D. Lipids and risk of coronary heart disease: The Framingham Study. Ann Epidemiol 1992;2:23-28:

30. Renaud $S$, Godsey $F$, Dumont $E$, Thevenon $C$, Ortichanian $E$, Martin JL. Influence of long-term diet modification on platelet function and composition in Moselle tarmers. Am J Clin Nutr 1986;43:136150.

31. Mutanen M, Freese $R$, Valsta $L$, Ahola I, Ahlström A. Rapeseed oil and sunflower oil diets in vitro aggregation and thromboxane production in healthy men when compared with milk fat or habitual diets. Thromb Haemost 1992;67:352-356.

32. Balleisen L, Bailey J. Epping P-H, Schulte $H_{0}$ van de Loo J. Epidemiological study on factor Vil, factor VIII and fibrinogen in an industrial population: I. Baseline data on the relation to age, gender. bodyweight, smoking, alcohol, pill-using, and menopause. Thromb Haemost 1985:54:475-479.

33. Mernen $\mathrm{LI}$, Witteman JCM, den Breeljen alH, Schouten EG, de Jong PTVM, Holman A Grobbee DE. The association of dietary fat and fiber with coagulation factor VIl in the elderly: the Rotterdam study. Am J Clin Nutr 1997;65:732-736.

34. Meade TW, Brozovic M, Chakrabarti RR, Haines AP, Imeson JD, Mellows S, Miller GJ, North WRS, Stirling $Y$ "Thompson SG. Haemostatic function and ischaemic heart disease: principal results of the Northwick Park Heart Study. Lancet 1986;2:533-537.

35. Heinrich $J_{4}$ Balleisen $L_{0}$ Schulte $H_{4}$ Assmann $G$, van de $L o o$ J. Fibrinogen and factor $V 1 l$ in the prediction of coronary risk. Arterioscler Thromb 1994:14:54-59.

36. Kario K, Matsuo T, Nakao K. Factor VII hyperactivity in the elderly. Thromb Haemost 1991;65:25-27. 
37. Kario K, Matsuo T, Asada R, Sakata T, Kato H, Miyate T. The strong positive correlation between factor VIl clotting activity using bovine thromboplastin and the activated factor VIl lewel. Thromb Haemost 1995;73:429-434.

38. Meade TW, Cooper $J_{3}$ Miller GJ, Howarth DJ, Stirling Y. Antithrombin Ill and arterial disease. Lancet $1991 ; 337: 850-851$.

39. Sandset PM, Simes PA, Abildgaard U. Factor VII and extrinsic pathway inhibitor in acute coronary disease. Br J Haematol 1989;72:391-396.

40. Bladbjerg EM, Tholstrup T, Marckmann P, Sandström B, Jespersen J. Dietary changes in fasting levels of factor VII coagulant activity (factor VII:c) are accompanied by changes in tactor VII protein and other vitamin K-dependent proteins. Thromb Haemost 1995;73:239-242.

41. Junker $R$, Heinrich $J$ Schulte $H$, van de Loo J, Assmann $G$. Coagulation factor VIl and the risk of coronary heart disease in healthy men. Arterioscler Thromb Vaso Biol 1997:17:1539-1544. 
Samenvatting 


\section{INLEIDING}

Door de gemiddelde Nederlander wordt per dag 37 procent van de totale op een dag opgenomen energie als vet geconsumeerd. Dit komt neer op gemiddeld 92 gram vet per dag. Deze hoeveelheid wordt niet alleen geconsumeerd in de vorm van zichtbare vetten zoals bijvoorbeeld margarines of bak-en braadvetten, maar ook via "onzichtbare" vetten in koekjes, brood, kaas, melk en dergelijke.

Vetten bestaan voor het grootste gedeelte uit vetzuren. Uitgaande van de chemische structuur bestaan er verschillende klassen van deze vetzuren: de verzadigde vetzuren, de enkelvoudig onverzadigde vetzuren en de meervoudig onverzadigde vetzuren. Elk vet bestaat steeds uit een combinatie van de vetzuren uit de verschillende groepen, waarbij één of twee vetzuren in meerderheid aanwezig zijn. De consumptie van verzadigde vetten bedraagt ongeveer $14 \%$ van de dagelijkse energiebehoefte van de mens en komt neer op ongeveer 35 gram per dag. In tabel 1 (hoofdstuk 1) worden de vetten met veel verzadigde vetten genoemd. De belangrijkste vetzuren in boter zijn bijvoorbeeld palmitinezuur (C16:0) en het enkelvoudige onverzadigde vetzuur oliezuur (C18:1), met daarnaast kleinere hoeveelheden myristinezuur ( $\mathrm{C} 14: 0)$, korte- en middenlange keten vetzuren $(\leq \mathrm{C} 10: 0)$ en stearinezuur (C18:0). Vetten met veel verzadigde vetzuren kan men herkennen doordat deze hard zijn in gekoelde staat, terwijl vetten met veel onverzadigde vetzuren vloeibaar zijn.

Binnen de groep verzadigde vetzuren zijn de volgende vetzuren met hun bijbehorende chemische structuur te onderscheiden: de korte- en de middenlange keten vetzuren $(\leq C 10: 0)$, laurinezuur $(C 12: 0)$, myristinezuur (C14:0), palmitinezuur (C16:0) en stearinezuur (C18:0). In de westerse landen bestaat ongeveer de helft van de totale hoeveelheid geconsumeerde verzadigde vetzuren uit palmitinezuur. De andere helft bestaat uit een combinatie van stearinezuur, myristinezuur, laurinezuur en de korte- en middenlange keten vetzuren.

Mensen die veel vet rijk aan verzadigde vetzuren eten hebben een groter risico om hart- en vaatziekten te onwikkelen. Al in de jaren zestig werd door Amerikaanse onderzoekers waargenomen, dat vetten met eenzelfde gehalte aan verzadigde vetzuren, maar met verzadigde vetzuren van een verschillende ketenlengte, een verschillend effect op het cholesterolgehalte van het bloed -én van de risicofactoren voor hart- en vaatziekten- hebben. Boter bijvoorbeeld verhoogt het totaal cholesterolgehalte ten opzichte van eenzelfde hoeveelheid cacaovet. Omdat resultaten van uitgevoerde studies voor sommige van de verzadigde vetzuren schaars of tegenstrijdig zijn, werden in onze studies de effecten van voedingen rijk aan middenlange keten vetzuren (MCFA), laurinezuur, myristinezuur of palmitinezuur onderzocht op het vetgehalte van het bloed (bloedlipiden, zoals onder andere cholesterol en triglyceriden) en op dat van de deeltjes die deze bloedvetten vervoeren (de lipoproteïnen). Processen betrokken bij de bloedstolling spelen waarschijnlijk ook een belangrijke rol bij het ontstaan van hart- en vaatziekten. De effecten van verschillende verzadigde vetzuren op de bloedstolling zijn tot nu toe nauwelijks onderzocht. Daarom werden in onze studies ook factoren gemeten die 
betrokken zijn bij de bloedstolling, zoals de mate van samenklontering van de bloedplaatjes (bloedplaatjesaggregatie), en de activiteit van verschillende eiwitten betrokken bij de bloedstolling of de afbraak van stolsels (de fibrinolyse). Tevens hebben we de effecten van de voedingen onderzocht op de gemoedstoestand en de eethust.

\section{ONDERZOEKSMETHODEN}

Er werden twee onderzoeken uitgevoerd. De effecten van de verschillende verzadigde vetzuren werden bestudeerd ten opzichte van een voeding rijk aan oliezuur.

Het eerste onderzoek bestudeerde de effecten van voedingen rijk aan laurinezuur of palmitineżuur ten opzichte van een voeding rijk aan oliezuur. Elke vrijwilliger in dit onderzoek consumeerde ledere voeding zes weken lang. Aan het einde van die periode werd tweemaal een nuchter bloedmonster afgenomen.

Het tweede onderzoek bestudeerde de effecten van voedingen rijk aan MCFA of myristinezuur vergeleken met een voeding rijk aan oliezuur. De groep vrijwilligers in deze studie consumeerde eerst gedurende drie weken de voeding rijk aan oliezuur (inloopperiode) en vervolgens werd de groep in drieën opgedeeld voor de zesweekse experimentele periode; één groep kreeg de voeding rijk aan MCFA, één groep de voeding rijk aan myristinezuur en één groep bleef de oliezuurverrijkte voeding gebruiken. Aan het einde van de drieweekse inloopperiode werd tweemaal een nuchter bloedmonster afgenomen evenals aan het einde van de experimentele periode.

\section{Voedingen}

Voor het bereiken van de juiste vetzuursamenstelling van de voedingen werden speciale vetten samengesteld. Voor het eerste onderzoek werden deze samengesteld uit bestaande vetten rijk aan verzadigde of enkelvoudig onverzadigde vetzuren (zie tabel 1, hoofdsluk 1). Het vet rijk aan laurinezuur bestond bijvoorbeeld uit een mengsel van palmpitvet en een zonnebloemolie met veel oliezuur; het palmitinevet uit een mengsel van palmstearine (dit wordt gemaakt uit palmolie), botervet en een deel zonnebloemolie.

Voor het tweede onderzoek was het minder gemakkelijk de juiste vetzuursamenstelling te bereiken door het gebruik van "natuurlijke" vetten en daarom werden er speciale vetten met een bepaalde vetzuursamenstelling gemaakt met behulp van een chemisch proces genaamd interesterificeren.

De experimentele vetten werden in beide onderzoeken in producten verwerkt zoals margarines, brood, koekjes, vlaai, cake, kaas en desserts.

Alle deelnemers schreven voorafgaande aan de studies gedurende drie dagen op wat ze aten en dronken. Aan de hand van deze gegevens werd berekend hoeveel energie zij per dag gebruikten en vervolgens hoeveel van onze experimentele producten zij dan zouden moeten gebruiken. De berekende voedingen bevatten in 
totaal 40 energie-procenten vet, waarvan 25 (studie 1) of 28 energieprocent (studie 2) geleverd werd door de experimentele vetten. Het overige deel van de vetconsumptie kon worden ingevuld met behulp van een systeem van vrije punten voor de verschillende vet bevattende levensmiddelen. De voedingen rijk aan de verschillende verzadigde vetzuren werden zo samengesteld dat ze 8,5 (studie 1) of 10 (studie 2) energieprocenten meer van het te onderzoeken vetzuur bevatten vergeleken met de voeding rijk aan oliezuur.

\section{Vrijwilligers}

De vrijwilligers voor de eerste studie waren 18 vrouwen en 14 mannen. In de eerste studie was de leettijd gemiddeld 41 jaar. De vrouwen wogen gemiddeld $69 \mathrm{~kg}$ en hadden een lengte van $166 \mathrm{~cm}$. De mannen wogen gemiddeld $81 \mathrm{~kg}$ en waren $179 \mathrm{~cm}$ lang. Aan de tweede studie namen 37 vrouwen en 23 mannen deel. De leeftijd van de vrijwilligers was gemiddeld 40 jaar. De vrouwen wogen gemiddeld 67 $\mathrm{kg}$ en waren $167 \mathrm{~cm}$ lang terwijl de mannen $78 \mathrm{~kg}$ wogen en $178 \mathrm{~cm}$ lang waren. De karakteristieken van de vrijwilligers wat betreft leeftijd, lengte en gewicht in beide studies waren dus vergelijkbaar.

\section{Compliantie}

Op verschillende manieren werd getracht na te gaan of de deelnemers zich aan de voorgeschreven voedingen hielden en de producten in de juiste hoeveelheden en volgens de richtlijnen consumeerden (compliantie). De vrijwilligers kwamen elke week naar de Universiteit en kregen daar een nieuwe portie van de producten voor de komende week. Tevens werden dan met een diëtist de eventuele problemen met het studie-protocol besproken. Tijdens dit wekelijkse bezoek werd verder het gewicht gemeten. Als bleek dat de deelnemer in gewicht toenam of juist afviel werden de richtlijnen aangepast. In de praktijk kwam het er op neer dat er soms in het begin van het experiment inschattingsfouten waren gemaakt, maar dat daarna nauwelijks meer aanpassingen van de richtlijnen voor consumptie van de producten nodig waren.

Tijdens de studie schreef de vrijwilliger gedurende vier (studie 1) of drie (studie 2) dàgen op wat er gegeten en gedronken was en ook dit werd doorgesproken met de diëtist. De gegevens gaven aan dat de voedingen gemiddeld als voorgeschreven gebruikt werden. Tevens verzamelden de vrijwilligers in de eerste studie gedurende twee dagen een duplicaat portie van het eten en drinken. Deze porties werden gemengd, het vet eruit gehaald en de vetzuursamenstelling van dit vet bepaald. De verkregen gegevens kwamen overeen met de getallen berekend uit de gegevens van de opschrijfdagen.

Tenslotte hebben we de vetzuursamenstelling van het bloed gemeten. Als er veel van een bepaald vetzuur gegeten wordt, zouden verhoogde nivo's van dat vetzuur in het bloed aangetroffen kunnen worden. Dit was ook het geval. 


\section{METINGEN EN RESULTATEN}

\section{Bloedlipiden en lipoproteïnen (hoofdstukken 2 en 3)}

Cholesterol wordt in het bloed getransporteerd door kleine vetbolletjes, lipoproteïnen genaamd. In het bloed komen diverse lipoproteïnen voor. De lipoproteïnen verschillen van elkaar in samenstelling en in dichtheid. Ongeveer $30 \%$ van het cholesterol wordt getransporteerd door Hoge Dichtheids Lipoproteinen (HDL) en ongeveer $65 \%$ in de vorm van Lage Dichtheids Lipoproteinen (LDL). Te hoge concentraties van de cholesterolrijke LDL-deeltjes kunnen indirect hart- en vaatziekten veroorzaken. HDL-deeltjes hebben dit effect niet en lijken juist gunstig om het risico voor thart- en vaatziekten te verminderen.

Zoals verwacht zijn er duidelijke verschillen tussen de verzadigde vetzuren op lipiden en lipoproteinengehalten. Myristinezuur verhoogt het ongunstige LDL cholesterolgehalte het meest, gevolgd door laurine- en daarna palmitinezuur (zie ook figuur 1, hoofdstuk 9). Het mogelijk gunstige HDL cholesterolgehalte wordt alleen verhoogd door laurine- en myristinezuurrijke voedingen, maar niet door palmitinezuurrijkevoedingen. Het is echter nog de vraag of deze door de voeding veroorzaakte verhoging van het HDL cholesterolgehalte ook het risico op hart- en vaatziekten daadwerkelijk verlaagt. De effecten van MCFA zijn verschillend van de overige bestudeerde verzadigde vetzuren. MCFA verhogen het totaal en LDL cholesterolgehalte nauwelijks en het HDL cholesterolgehalte niet ten opzichte van oliezuur.

Vanwege de effecten op het LDL cholesterolgehalte zal een vervanging van vetten rijk aan laurine- en myristinezuuir (zoals bijvoorbeeld cocosvet of boter) of palmitinezuur (zoals palmolie, boter, runder- of varkensvet) door oliezuurrijke vetten (zoals olijf-, zonnebloem- of raapzaadolie) gunstige effecten opleveren voor het risico op hart- en vaatziekten.

\section{Gemoedstoestand (hoofdstuk 4)}

Uit de langdurige epidemiologische onderzoeken blijkt in de categorie mensen met een laag totaal cholesterolgehalte, (gunstig voor het risico op hart-en vaatziekten), de sterfte door oorzaken die niet ziekte gerelateerd zijn hoger te zijn dan bij mensen met een hoger cholesterolgehalte. Niet ziekte gerelateerde sterfte zijn sterften als gevolg van ongevallen, zeltdoding of geweld. Uit onderzoeken blijkt daarnaast dat verlaging van het totaal cholesterolgehalte door medicijnen of dieet, ook stijgingen van de niet-ziekte gerelateerde sterfte teweeg brengt. Een lager cholesterolgehalte zou mogelijk samengaan met meer gevoelens van depressiviteit. Omdat wij in onze studies veranderingen van het cholesterolgehalte verwachtten, hebben we ook verschillende items, met betrekking tot gemoedstoestand, door de deelnemers laten scoren. Wij zagen evenwel geen effect van de verschillende voedingen -en de daarbij horende veranderingen in cholesterolgehalten- op de gemoedstoestand. Dus een richtlijn voor mensen met een normaal cholesterolgehalte om verzadigde vetzuren te vervangen door enkelvoudig onverzadigde vetzuren zal geen negatieve gevolgen hebben voor het gemoed. 


\section{Bloedplaatjesaggregatie (hoofdstuk 5)}

Bloedplaatjes spelen een grote rol bij de ontwikkeling van een bloedstolsel. Wij hebben geprobeerd mel behulp van speciale apparatuur de samenklontering van bloedplaatjes na te bootsen, vlak na de bloedafname. De snelheid van samenklontering van de bloedplaatjes (bloedplaatjesaggregatie) werd daarbij gemeten. Ten opzichte van oliezuur, had geen van de bestudeerde verzadigde vetzuren effect op de snelheid van de bloedplaatjesaggregatie in een bloedmonster.

\section{Factoren betrokken bij de bloedstolling en afbraak van stolsels (hoofdstukken 6 en 7 )}

In het bloed zijn verschillende eiwitten aanwezig die betrokken zijn bij de bloedstolling. Deze eiwitten zijn in een normale situatie niet actief, en dat is maar goed ook want het bloed moet vloeibaar blijven. De stollingsfactoren komen pas in actie als eir bijvoorbeeld een beschadiging in de vaatwand onstaat. Een teveel aan actie kan echter problemen veroorzaken, een bloedstolsel kan bijvoorbeeld in kleine aderen vast blijven zitten en zo de bloedtoevoer van een gedeelte van het hart afsluiten, met een hartinfarct als gevolg. In het afgenomen bloed bepaalden we de activiteit van verschillende stollingsfactoren, bijvoorbeeld de factor VII activiteit, en hiermee de potentie van het bloed om te stollen. Een verhoogde activiteit van stollingsfactor VII is geassocieerd met een verhoogd risico op hart- en vaatziekten, en met name de ziekten met fatale afloop.

Voedingen rijk aan laurine, myristine en palmitinezuur verhoogden de factor VII activiteit van het bloed in ongeveer dezelfde mate ten opzichte van de oliezuurvoeding. Opmerkelijk daarbij was, dat de stollingsactiviteit van factor VII sterker werd beïnvloed bij de groep vrouwen dan bij de groep mannen (zie figuur 2 , hoofdstuk 9). Een verklaring daarvoor zou de verschillende hormonale of genetische achtergrond van vrouwen kunnen zijh of een verschillend samenspel van de verzadigde vetzuren en de genetische of hormonale achtergrond. Hierover is helaas nog weinig bekend. De voedingen rijk aan laurinezuur of myristinezuur hadden ook effect op verschillende remmers voor de bloedstolling. De myristinezuurvoeding verlaagde het TFPI ten opzichte van de oliezuurvoeding en de laurinezuurvoeding verlaagde het antithrombine. De betekenis van deze remming voor het risico op harten vaatzieken is ook nog onvoldoende bestudeerd.

De voeding rijk aan palmitinezuur verhoogde de activiteit van plasminogeen activator inhibitor (PAI). Dit is een remmer van het proces van bloedstolsel-afbraak. Een hogere PAl activiteit is geassocieerd met een toegenomen risico op hart- en vaatziekten. Misschien betekent onze bevinding dat de palmitinezuur voeding een verlaagde activiteit oplevert om stolsels weer te kunnen oplossen, maar dit zal nog moeten worden bevestigd met andere metingen van de fibrinolyse. De voeding rijk aan MCFA gaff nauwelijks effecten op de verschillende factoren betrokken bij de stolling en de fibrinolyse. 


\section{Eetlust (hoofdstuk 8)}

In de tweede studie, die MCFA en myristinezuur onderzocht, hebben we ook de effecten van de verschillende vetten op gevoelens van honger bestudeerd. De deelnemers gaven vlak voor het naar bed gaan op lijstjes aan of ze die dag heel veel of juist heel weinig honger hadden gehad. De hongerscores werden op hetzelfde moment gemeten als de scores voor de gemoedstoestand. Het bleek dat vrijwilligers, die de myristimezuurvoeding consumeerden, gemiddeld meer gevoelens van honger hadden dan de vrijwilligers die de ollezuurvoedingen consumeerden. Dit zou kunnen betekenen dat de mensen die een myristinezuurrijke voeding eten in "normale situatie zonder verdere richtlijnen" misschien meer hadden gegeten vergelleken met mensen die een ollezuurrijke voeding consumeren met wellicht gevolgen voor het gewicht.

\section{CONCLUSIE}

Vergeleken met ollezuur hebben de onderzochte individuele verzadigde vetzuren een verschillend effect op het lipidenprofiel van het bloed. Myristinezuur verhoogt het ongunstige LDL cholesterolgehalte het meest, gevolgd door laurinezuur en daama palmitinezuur. Het potentieel gunstige HDL cholesterolgehalte wordt alleen verhoogd door laurinezuur-en myristinezuurrijke voedingen, maar het is nog de vraag of deze door de voeding veroorzaakte verhoging ook daadwerkelijk het risico op hart- en vaatziekten verlaagt. Die effecten van MCFA zijn verschillend van de overige bestudeerde verzadigde vetzuren; ze verhogen het LDL cholesterolgehalte nauwelijks en het HDL cholesterolgehalte niet.

Laurine-, myristine- en palmitinezuur hebben vergelijkbare effecten op de stollingscapaciteit van het bloed (gemeten als factor VII activiteit), alhoewel er kleine nuances zijn in de effecten op andere stollingsfactoren of stollingsremmers. Het lijkt dus nauwelijks zin te hebben. wat de effecten op stollingsactiviteil betreft. onderscheid te maken tussen de verschillende verzadigde vetzuren, behalve voor MCFA en wellicht het niet onderzochte stearinezuur. Opmerkelijk is dat de effecten wan de voedingen op de stollingscapaciteit van het bloed sterker zijn bij vrouwen dan bij mannen. Deze bevinding zal verder ondersteund moeten worden met mechanistisch onderzoek en risicoschattingen voor hart- en vaatziekten in vrouwen.

Het risico op hart- en vaatziekten is het hoogst bij mensen met zowel een hoog LDL cholesterolgehalte als een hoge stollingsactiviteit van het bloed. Het verdient daarom aanbeveling vooral het eten van velten rijk aan laurine en myristinezuur (0.a. cocosvet en boter) en palmitinezuur (o.a. palmolie, boter, runder- of varkensvet) te verminderen. Deze vetten kunnen dan vervangen worden door olien rijk aan onverzadigde vetzuren, zoals bijvoorbeeld olien rijk aan oliezuur (o.a. olijf= of raapzaadolie of oliezuurrijke zannebloemolie). De vervanging zal mogelijk ook gunstige effecten hebben op de eetlust. 



\section{Met dank aan...}

Allereerst wil ik de proefpersonen bedanken voor hun grote inzet om de twee wetenschappelijke experimenten tot een succes te maken. Bedankt voor het in vastgestelde hoeveelheden eten van onze proefprodukten, het afstaan van vele buisjes bloed en het bijhouden van de onontbeerlike administratie bij het onderzoek.

Mijn persoonlijk begeleidingsteam tijdens het AlO-traject bestond uit Gerard Hornstra en Ronald Mensink. Promotor, Gerard Homstra, bedankt voor het initiëren van dit promotieonderzoek en voor het kritisch volgen van de grote linnen daarvan. Fonald Mensink bedank ik voor de goede wijze waarop hij mij de afgelopen jaren begeleid heeft. Ronald, bedankt voor het aanleten van de onderzoeksvaardigheden, noodzakelijk voor het opzetten, uitvoeren en analyseren van voedingsexperimenten. Ik heb veel geleerd van je kritische opmerkingen in de verschillende versies van de manuscripten. Tevens dank $i k j e$ voor de laatste inspectie van het proefschrift.

Voor de technische ondersteuning stonden de volgende personen paraat. Tanja Hermans bedank ik voor de uitstekende begeleiding van de proefpersonen, de hulp bij de opzet van de studies, hel meten van duizenden stemmingslijstjes en je opbeurende collegialiteit. Frank Cox, Jo Wients en Rob Kalafusz' bedankt voor het plezierige teamwork tijdens de bloedafnames, het verwerken van de buisjes bloed, het uitvoeren van de aggregatiemetingen en de metingen van stollingsfactoren. René Offermans bedank ik voor het uitvoeren van de thrombine potentiaal metingen en Puck Muller voor de fibrinogeen en TFPI bepalingen. Rian van Houwelingen bedankt voor de ondersteuning van de projecten op het medische vlak en Arnold Kester voor zijn adviezen van statistische aard.

Collega's van Humane Biologie bedankt voor de gezelligheid op de werkvloer. Mede door mijn vele verhuizingen binnen de vakgroep heb $k$ een aantal van jullie gelukkig wat beter leren kennem. Met name wil ik mijn ex-kamergenoten (hoezo zitkamerproblematiek ??): Gerard, Tanja, Susan, Jogchum, Esther, Suzie, Anita en Yvonne en de buurtjes van daarachter: Carin, Cecile en Riëtte van harte bedanken.

I am indebted to Prof. dr. W.H.M. Saris, Prof. dr. ir. P.A. van den Brandt, Dr. K. Hamulyak, Prof. dr. M.B. Katan and Dr. G.J. Miller for their time and effort to critically evaluate my thesis.

Dit onderzoek had niet uitgevoerd kunnen worden zonder de financiële ondersteuning van de Stichting Zuivel Voeding en Gezondheid (SZVG). Ik heb vooral de oprechte interesse gewaardeerd van Wiebe Visser, Gert-Jan Hiddink en Wendy van Koningsbruggen voor de voortgang en de uitkomsten van het onderzoek.

Lieve familieleden (vooral natuurlijk: Chris en Riet, Dirk en Addie, Kees en Bert) en vrienden (met name wil ik noemen: Evelien, Anita, Lourens, René, Ria, Aad , Tom, Margriet, Erik, Michael, Ingeborgt, Wilrike, Roel, Katinka en Robert) bedankt voor jullie belangstelling voor mijn werk en bezigheden, maar vooral voor de gezelligheid buiten werk-tijd. Roel, bedankt voor je steun de laatste tijd, ik vind het fijn dat je mijn maatje bent. 


\section{Curriculum vitae}

Elisabeth Helena Maria Temme, geboren 10 november 1966 te Heemskerk (Noord Holland), volgde de middelbare school opleiding aan het St. Michael College te Zaandam. Van 1985 tot en met 1991 studeerde zij aan de Landbouwuniversiteit te Wageningen, Voeding van de Mens. Zij verrichtte afstudeeronderzoeken op het gebied van Fysiologie (Vakgroep Fysiologie van Mens en Dier te Wageningen), Voeding (Afdeling Interne Geneeskunde van het Radboudziekenhuis te Nijmegen) en Toxicologie (Vakgroep Toxicologie te Wageningen). Als onderdeel van haar studie deed ze een stage binnen de "Commonwealth, Scientific and Industrial Research Organization" (CSIRO) divisie Humane Voeding. Vanaf april 1992 was zij werkzaam als assistent in opleiding (AIO) op de Vakgroep Humane Biologie van de Faculteit Gezondheidswetenschappen van de Universiteit Maastricht. Zij verrichtte onderzoek in de gezonde mens naar de effecten van vetzuren op risicoindicatoren voor hart- en vaatziekten. Ze presenteerde haar onderzoeksresultaten op internationale congressen te Lugano (Zwitserland), Adelaide (Australië) en Maastricht (Nederland). Zij heeft in 1995 enkele zomercursussen gevolgd van "The New England Epidemiology Institute" te Boston USA. Sinds oktober 1997 is zij tijdelijk medewerkster van het Instituut Voeding (afdeling Epidemiologie) van de Nederlandse Organisatie voor Toegepast Natuurwetenschappelijk Onderzoek (TNO) te Zeist.

Elisabeth Helena Maria Temme was born on November 10, 1966, in Heemskerk, the Netherlands. In 1985, she passed secondary school at the St. Michael College in Zaandam. In the same year, she started her training in Human Nutrition at the Agricultural University in Wageningen. Major subjects of study were human physiology, human nutrition and toxicology. As part of the training she spent 6 months of practical research at the Division of Internal Medicine, St. Radboud Hospital, University of Nijmegen and 5 months of practical research at the Commonwealth Scientific Industrial Research Organisation (CSIRO) in Adelaide, Australia. She graduated November 1991. From april 1992 on, she worked as a PhD-fellow at the Department of Human Biology. Maastricht University. She conducted dietary intervention studies with healthy subjects to investigate the effects of saturated fatty acids on risk indicators for cardiovascular diseases. The risk indicators studied included effects on lipoproteins, coagulation and fibrinolytic factors, and platelet aggregation. Parts of the research findings have been presented at international conferences in Lugano (Switzerland), Adelaide (Australia) and Maastricht (the Netherlands). In June 1995, she attended the New England Epidemiology Summer Program, a 3 wk course at Tufts University, Boston, USA. From Oktober 1997 on, she is appointed at the Nutrition and Food Institute of the Netherland Organisation for Applied Scientific Research (TNO) in Zeist. 
3 


\section{Publications}

\section{Research papers}

* van Dusseldorp M. Smits P, Lenders JWM, Temme L, Thien Th, Katan MB. Effect of coflee on cardiovascular responses to stress." a 14-week controlled trial. Psychosomatic Medicine 1992;54:344-353.

* Smits P. Temme L, Thien Th. The cardiovascular interaction between caffeine and nicotine in humans. Clinical Pharmacology \& Therapeutics 1993;54:194-204.

* Temme EHM, Mensink RP, Hornstra G. Effecten van laurinezLur en palmitinezuur op serumlipiden. Voeding 1994;55(4):32.

Mensink RP. Temme EHM, Hornstra G. Dietary saturated and trans fatty acid and lipoprotein metabolism. Annals of Medicine 1994:26:461-464.

* Temme EHM, Mensink RP, Hornstra G. De effecten van voedingen verrijkt met middenlange keten vetzuren en myristinezuur of oliezuur op lipiden en lipoproteinen. Voeding 1996;57(3);31.

* Temme EHM, Mensink RP. Hornstra G. Comparison of the effects of diets enriched in lauric, palmitic or oleic acids on serum lipids and lipoproteins in healthy women and men. American Journa of Cinical Nutrition 1996;63:897-903.

* Temme EHM, Mensink RP, Hornstra G. Effecten van verzadigde vetzuren op bloedstolling en fibrinolyse. Voeding 1997;58(6);29.

* Temme EHM Mensink RP, Hornstra G. Effects of medium chain fatty acids (MCFA), myristic acid, and oleic acid on serum lipoproteins in healthy subjects. Journal of Lipid Research 1997:38:17461754.

\section{Submitted papers or papers in preparation}

* Temme EHM, Mensink RP. Hornstra G. Effects of diets enriched in lauric, palmitic or oleic acids on blood coagulation and fibrinolysis.

* Temme EHM, Mensink RP, Hornstra G. Individual saturated fatty acids and effects on whole blood aggregation in vitro.

* Temme EHM, Mensink RP, Hornstra G. Effects of diets rich in medium chain tatty acids (MCFA), myristic acid or oleic acid on coagulation and fibrinolysis.

* Temme EHM, Mensink RP, Campfield LA, Honstra G. Dietary fatty acid composition and feelings of appetite.

* Temme EHM, Mensink RP, Hornstra G. Effects of diet-induced changes in lipoproteins and mood.

* Mensink RP, Temme EHM, Wagenmakers AJM, Simonis MMG, Hornstra G. Conversion and oxidation of medium chain triglycerides (MCT) in healthy subjects after 6 weeks consumption of diets enriched in medium chain fatty acids, myristic acid or oleic acid (in preparation).

* Lagrost Lx Mensink RP, Guyardwangremant $V$, Temme EHM, Desrumaux C, Athias A, Hornstra $G$, Gambert $P$. Variations in serum cholesteryl ester transfer and phospholipid transfer activities in healthy women and men consuming diets enriched in either lauric, palmitic or oleic acids. 


\section{Letters to the editor}

* Temme EHM, Mensirik RP. Hornstra G. Dietary paimitic and oleic acid effects on lipoprotein cholesterol. American Joumal of Clinical Nutrition 1997;65:171 (reply).

* Temme EHM. Mensink RP. Hornstra $G$. The linoleic acid content of test diets must be carefully monitored in cholesterol studies. American Jowmal of Clinical Nutrition 1997;65:1088 (reply).

* Temme EHM, Mensink RP. Homstra G. American Joumal of Clinical Nutrition 1997 (reply, in press).

\section{Book Chapters}

* Temme EHM, Mensink. AP. Fatty acids: Health effects of saturated fatty acids. Encyclopedia of Human Nutrition edited by M Sadler, B Caballero and S Strain. Academic Press Ltd: London.

* Mensink RP. Temme EHM, Plat J. Dietary fats and coronary heart disease. Chapter in: Lipid chemistry edited by DB Min and CC Ako. Marcel Dekker: New York. 